\title{
AVALIAÇÃo do POTENCIAL FISIOLÓGico DE SEMENTES DE TOMATE
}

MARISTELA PANOBLANCO

Engenheira Agrônoma

Orientador: Prof. Dr. JULIO MARCOS FILHO

Tese apresentada à Escola Superior de Agricultura "Luiz de Queiroz", Universidade de São Paulo, para obtenção do título de Doutor em Agronomia, Área de Concentração: Fitotecnia.

P I R A C I C A B A

Estado de São Paulo - Brasil

Agosto - 2000 


\section{Dados Internacionais de Catalogação na Publicação (CIP) DIVISÃO DE BIBLIOTECA E DOCUMENTAÇÃO - Campus "Luiz de Queiroz"/USP}

Panobianco, Maristela

Avaliaçāo do potencial fisiológico de sementes de tomate / Maristela Panobianco. - Piracicaba, 2000.

152 p. : il.

Tese (doutorado) - Escola Superior de Agricultura Luiz de Queiroz, 2000. Bibliografia.

1. Condutividade elétrica 2. Deterioração de semente 3. Estufa 4. Envelhecimento 5. Fisiologia vegetal 6. Genminaçăo 7. Semente hibrida 8. Teste de vigor 9. Tomate I. Título

CDD 635.642 


\section{DEDICO}

Aos meus pais, Celso e Ignez À minha irmã 


\section{AGRADECIMENTOS}

A Deus, pela presença constante em minha vida.

Ao Prof. Dr. Julio Marcos Filho, pela orientação dedicada, incentivo e apoio constantes.

Aos professores Walter Rodrigues da Silva e Silvio Moure Cícero, pela atenção e ensinamentos durante o curso.

Às Engenheiras Agrônomas Ana D.C.L. Novembre e Helena M.C.P. Chamma, pela colaboração e amizade.

Ao Prof. Dr. Roberval Daiton Vieira, pela contribuição e amizade.

Ao Conselho Nacional de Desenvolvimento Cientifico e Tecnológico (CNPq), pela concessão da bolsa de estudos.

À Fundação de Amparo à Pesquisa do Estado de São Paulo (FAPESP), pelo suporte financeiro para realização da pesquisa.

À Empresa AGROFLORA S/A, pelo fornecimento das sementes.

Ao Marcelo Melarato, pela compreensão e valioso estimulo nesses anos de convivência. 


\section{SUMÁRIO}

Página

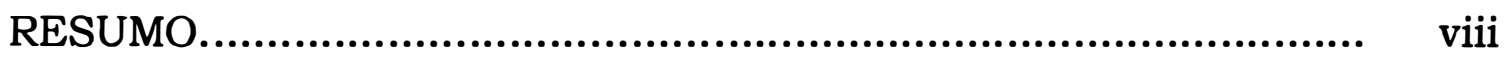

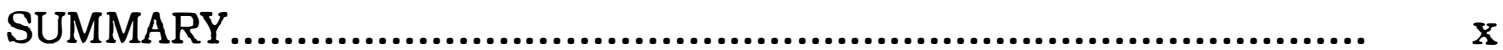

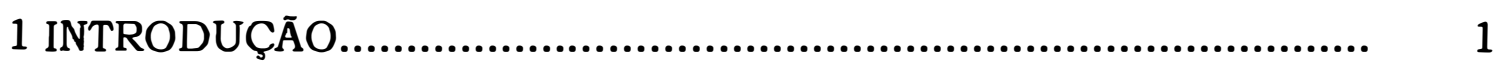

2 REVISÃO DE LITERATURA................................................. 4

2.1 Avaliação do vigor de sementes......................................... 6

2.1.1 Condutividade elétrica................................................ 6

2.1.2 Lixiviação de Potássio.............................................. 12

2.1.3 Envelhecimento acelerado....................................... 15

2.1.4 Deterioração controlada............................................ 19

3 MATERIAL E MÉTODOS................................................. 22

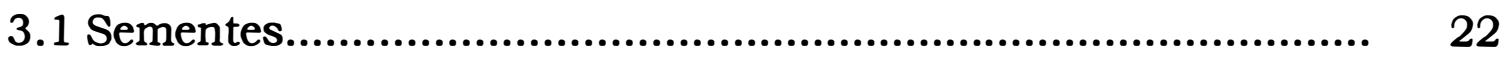

3.2 Estudo dos testes de condutividade elétrica, lixiviação de potássio, envelhecimento acelerado e deterioração controlada (Etapa 1).................................................................. 23

3.2.1 Determinação do grau de umidade............................. 23

3.2.2 Germinação........................................................ 24

3.2.3 Condutividade elétrica (CE) ................................... 24

3.2.3.1 CE I.......................................................... 24

3.2.3.2 CE II..................................................... 24

3.2.3.3 CE III........................................................... 25

3.2.4 Lixiviação de potássio.............................................. 25

3.2.5 Envelhecimento acelerado (procedimento tradicional)...... 27

3.2.6 Envelhecimento acelerado (solução saturada de sal)........ 28

3.2.7 Deterioração controlada............................................ 28 
3.2.8 Método Agroflora para avaliação do vigor em tomate........ 29

3.2.8.1 Critérios de avaliação das plântulas..................... 30

3.2.8.1.1 Plântula Normal................................ 30

3.2.8.1.2 Plântula Normal Fraca........................ 30

3.2.8.1.3 Plântula Anormal................................ 31

3.2.9 Emergência de plântulas em casa de vegetação............... 33

3.2.10 Procedimento estatístico (Etapa 1).............................. 33

3.3 Comparação entre testes para avaliação do potencial fisiológico das sementes (Etapa 2).................................................... 39

3.3.1 Determinação do grau de umidade............................... 39

3.3.2 Teste de germinação.................................................... 39

3.3.3 Condutividade elétrica............................................. 39

3.3.4 Lixiviação de potássio.................................................. 40

3.3.5 Envelhecimento acelerado (procedimento tradicional)....... 40

3.3.6 Envelhecimento acelerado (solução saturada de sal)........ 41

3.3.7 Deterioração controlada............................................ 41

3.3.8 Método Agroflora para avaliação do vigor em tomate........ 42

3.3.9 Emergência de plântulas em casa de vegetação................ 42

3.3.10 Determinações complementares.................................. 42

3.3.10.1 Lixiviação de sódio....................................... 42

3.3.10.2 Composição química das sementes................... 43

3.3.10.3 Composição química do exsudato das sementes. $\quad 44$

3.3.10.4 Morfologia da semente................................. 44

3.3.11 Procedimento estatístico (Etapa 2)............................... 44

4 RESULTADOS E DISCUSSĀO............................................ 46

4.1 Etapa 1 - Estudo preliminar de procedimentos alternativos para condução dos testes de condutividade elétrica, lixiviação de potássio, envelhecimento acelerado e deterioração controlada. 
4.1.1 Avaliação inicial da qualidade dos lotes........................... 46

4.1.1.1 Hibrido Debora Plus............................................ 46

4.1.1.2 Hibrido Bruna.................................................. 48

4.1.2 Condutividade elétrica - CE I.................................... 50

4.1.2.1 Hibrido Debora Plus......................................... $\quad 50$

4.1.2.2 Hibrido Bruna.............................................. 59

4.1.2.3 Consideraçōes gerais......................................... 68

4.1.3 Condutividade elétrica - CE II................................. 70

4.1.3.1 Hibrido Debora Plus......................................... $\quad 70$

4.1.3.2 Hibrido Bruna................................................... 72

4.1.3.3 Consideraçōes gerais......................................... 75

4.1.4 Condutividade elétrica - CE III.................................. 75

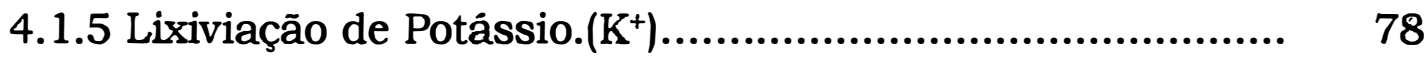

4.1.5.1 Hibrido Debora Plus.......................................... $\quad 78$

4.1.5.2 Hibrido Bruna................................................. 79

4.1.5.3 Consideraçōes gerais........................................ 81

4.1.6 Envelhecimento acelerado (procedimento tradicional)....... 81

4.1.6.1 Hibrido Debora Plus....................................... 81

4.1.6.2 Híbrido Bruna.................................................. 86

4.1.6.3 Consideraçōes gerais........................................ 89

4.1.7 Envelhecimento acelerado (solução saturada de sal)........ 90

4.1.7.1 Hibrido Debora Plus......................................... 90

4.1.7.2 Híbrido Bruna.................................................. 94

4.1.8 Deterioração controlada........................................... 98

4.1.8.1 Hibrido Debora Plus....................................... 98

4.1.8.2 Hibrido Bruna.............................................. 102

4.1.9 Considerações finais (Etapa 1).................................. 106 
4.2 Etapa 2 - Comparação entre os testes para avaliação de potencial fisiológico das sementes, utilizando-se os protocolos considerados mais eficientes para a condução de cada um deles, com base nas informações obtidas durante a primeira etapa

4.2.1 Hibrido Debora Plus............................................... 109

4.2.1.1 Análise comparativa entre os testes................... 109

4.2.2 Híbrido Bruna....................................................... 118

4.2.2.1 Análise comparativa entre os testes.................... 118

4.2.3 Considerações finais (Etapa 2)................................ 126

5 CONCLUSŌES......................................................... 131

REFERÊNCIAS BIBLIOGRÁFICAS........................................... 132 


\title{
AVALIAÇÃo DO POTENCIAL FISIOLÓGICO DE SEMENTES DE TOMATE
}

\author{
Autor: MARISTELA PANOBIANCO \\ Orientador: Prof. Dr. JULIO MARCOS FILHO
}

\section{RESUMO}

A pesquisa teve por objetivo o estudo da metodologia dos testes de condutividade elétrica, lixiviação de potássio, envelhecimento acelerado e deterioração controlada, procurando-se verificar sua eficiência para a identificação de diferentes niveis de vigor de lotes de sementes de tomate (Lycopersicon lycopersicum L.).

Para tanto, foram conduzidas duas etapas de testes, utilizando-se cinco lotes de sementes dos hibridos Debora Plus e Bruna. Na primeira etapa, foram realizados, além dos testes de germinação, emergência de plântulas em casa de vegetação e Método Agroflora, estudos especificos sobre a metodologia dos testes de condutividade elétrica (avaliando-se os efeitos das temperaturas de $25^{\circ} \mathrm{C}$ e $30^{\circ} \mathrm{C}$, dos volumes de 25, 50 e $75 \mathrm{ml}$ de água, dos números de 25 e 50 sementes e dos períodos de 30, 60 e 90 minutos, $2,3,4,6,8,10,16,20$ e 24 horas), de lixiviação de potássio (utilizando-se 100 sementes, embebidas em $25 \mathrm{ml}$ de água, a $30^{\circ} \mathrm{C}$, durante 3 horas), de envelhecimento acelerado, com e sem solução salina (empregando-se os periodos de 48, 72 e 96 horas a $38^{\circ} \mathrm{C}$ ou $41^{\circ} \mathrm{C}$ ) e de deterioração controlada (utilizandose os graus de umidade de $19 \%, 21 \%$ e $24 \%$, a temperatura de $45^{\circ} \mathrm{C}$ e os periodos de 24 e 48 horas). Os procedimentos que forneceram 
indicaçōes mais consistentes sobre o vigor das sementes foram, então, avaliados na segunda etapa, que também incluiu os seguintes testes: germinação, emergência de plântulas em casa de vegetação e Método Agroflora.

Dentre os testes estudados, o de envelhecimento acelerado $\left(41^{\circ} \mathrm{C} / 72 \mathrm{~h}\right)$ e o de deterioração controlada $\left(24 \% / 45^{\circ} \mathrm{C} / 24 \mathrm{~h}\right)$ foram considerados eficientes para avaliação do vigor de sementes de tomate, possibilitando a identificação de lotes com diferentes niveis de potencial fisiológico. $\mathrm{O}$ teste de lixiviação de potássio (100sementes/ $25 \mathrm{ml} / 30^{\circ} \mathrm{C} / 3 \mathrm{~h}$ ), por sua vez, constituiu opção promissora para avaliação do potencial fisiológico de sementes de tomate, identificando principalmente os lotes de pior desempenho, em periodo de tempo consideravelmente reduzido. Por outro lado, a avaliação do vigor de sementes de tomate através do teste de condutividade elétrica foi menos adequada, uma vez que seus resultados sofreram interferência tanto do parâmetro avaliado (conjunto de ions) quanto de caracteristicas do embrião, apresentando eficiência variável de acordo com o híbrido estudado. 


\title{
EVALUATION OF THE PHYSIOLOGICAL QUALITY \\ OF TOMATO SEEDS
}

\author{
Author: MARISTELA PANOBIANCO \\ Adviser: Prof. Dr. JULIO MARCOS FILHO
}

\section{SUMMARY}

This research was conducted with the main objective of studying the methodology of electrical conductivity, potassium leachate, accelerated aging and controlled deterioration tests to identify different vigor levels of tomato seed lots (Lycopersicon lycopersicum L.).

Those tests were conducted in two phases using five seed lots of Debora Plus and Bruna hybrids. On first phase, in addition to germination and seedling emergence tests, specific studies were performed on the methodology of the electrical conductivity (evaluation of the effects of temperatures of $25^{\circ} \mathrm{C}$ and $30^{\circ} \mathrm{C}$, water volumes of 25,50 and $75 \mathrm{ml}$, number of 25 and 50 seeds and periods of 30,60 and 90 minutes, $2,3,4,6,8,10,16,20$ and 24 hours); potassium leachate (100 seeds soaked in $25 \mathrm{ml}$ of water at $30^{\circ} \mathrm{C}$ for 3 hours); traditional accelerated aging and using saturated salt solution (periods of 48, 72 and 96 hours at $38^{\circ} \mathrm{C}$ or $\left.41^{\circ} \mathrm{C}\right)$ and controlled deterioration $(19 \%, 21 \%$ and $24 \%$ water content, $45^{\circ} \mathrm{C}$ and 24 - and 48 -hour periods). The procedures identified as more consistent to indicate seed vigor levels were then evaluated on the second phase that also included the tests of germination and seedling emergence. 
Among the tests studied accelerated aging $\left(41^{\circ} \mathrm{C} / 72 \mathrm{~h}\right)$ and controlled deterioration $\left(24 \% / 45^{\circ} \mathrm{C} / 24 \mathrm{~h}\right)$ were considered efficient to evaluate tomato seed vigor thus allowing for the identification of lots with different levels of physiological quality. Also, the potassium leachate test ( 100 seeds $/ 25 \mathrm{ml} / 30^{\circ} \mathrm{C} / 3 \mathrm{~h}$ ) can be a promising option for the evaluation of tomato seeds physiological quality mainly to identify seed lots of lower performance in a considerably reduced period. On the other hand, the use of the electrical conductivity test can be considered less suitable for the evaluation of tomato seed vigor since the results can showed interference both of the test evaluation procedure (set of ions) and of the embryo characteristics, with a variable efficiency according to the hybrid studied. 


\section{INTRODUÇĀO}

A avaliação do potencial fisiológico das sementes é realizada rotineiramente através do teste de germinação. Entretanto, em razão de suas limitações, principalmente quanto à menor sensibilidade para a diferenciação da qualidade e à freqũente discrepância dos resultados, em relação à emergência das plântulas em campo, têm sido desenvolvidos estudos sobre testes de vigor. Nestes, buscam-se respostas complementares às fornecidas pelo teste de germinação e a possibilidade da obtenção de informações consistentes, de preferência em prazo de tempo relativamente curto.

Em levantamento realizado nos EUA e Canadá, constatou-se que os testes de vigor de maior aceitação, no período de 1976-1990, eram o teste de frio, o de tetrazólio e o de envelhecimento acelerado (TeKrony, 1983; Ferguson, 1993). Por outro lado, em pesquisa semelhante desenvolvida junto a laboratórios membros da International Seed Testing Association - ISTA, em 1990, verificou-se que predominava o uso dos testes de condutividade elétrica e de frio (Hampton, 1992). No Brasil, levantamento semelhante (Krzyzanowski \& França Neto, 1991), indicou os testes de envelhecimento acelerado, de tetrazólio e de frio como os mais utilizados por empresas produtoras de sementes. É importante ressaltar que, em todos os levantamentos citados, não houve destaque para sementes de hortaliças, em razão do uso limitado de testes para avaliação do vigor de sementes dessas espécies. 
Para algumas culturas, testes especificos têm mostrado eficiência, como o de frio para sementes de milho, o de envelhecimento acelerado para as de soja e o de condutividade elétrica para as de ervilha. Porém, poucos estudos têm sido conduzidos sobre o uso de testes de vigor para avaliação do potencial fisiológico de sementes de hortaliças; nesse sentido, a literatura consultada indica que o teste de primeira contagem de germinação é o mais utilizado (Andrade \& Formoso, 1991). Esta situação não se modificou acentuadamente nos últimos dez anos, embora o teste de deterioração controlada, desenvolvido por Matthews (1980), venha assumindo importāncia crescente.

Segundo Marcos Filho (1999a), as informaçōes sobre o vigor são ainda mais importantes para sementes de maior valor comercial, como as hortaliças. Estas, em razão de apresentarem menores quantidades de reservas armazenadas, possuem maior propensão à deterioração após a maturidade fisiológica. Tanto assim, que são habitualmente armazenadas em embalagens herméticas ou em ambientes especiais, sob temperatura e/ou umidade relativa reduzidas.

Dentre as hortaliças, o tomate é produzido em volumes significativos. As sementes, por apresentarem alto valor comercial e, ainda, pela forma de comercialização, merecem atenção especial quanto ao potencial fisiológico; para tanto, estudos dirigidos à determinação do vigor devem ser intensificados (Nascimento et al., 1993). Todavia, também para esta espécie, a pesquisa não tem oferecido alternativas suficientes para a avaliação segura do vigor, especialmente quando se considera a importāncia da obtenção relativamente rápida das informaçōes.

Diante do exposto, o presente trabalho teve por objetivo o estudo da metodologia dos testes de condutividade elétrica, lixiviação de 
potássio, envelhecimento acelerado e deterioração controlada, procurando-se verificar sua eficiência para a identificação de diferentes niveis de vigor de lotes de sementes de tomate.

Esses testes foram escolhidos em função da sua rapidez e/ou objetividade, incluindo procedimentos baseados na integridade das membranas celulares (condutividade elétrica e lixiviação de potássio) e na tolerância a estresse (envelhecimento acelerado e deterioração controlada). Diante dos resultados obtidos para outras espécies, esses testes podem ser considerados promissores para a avaliação do potencial fisiológico de sementes de tomate. 


\section{REVISÃO DE LITERATURA}

O objetivo básico dos testes de vigor é a identificação de diferenças importantes no potencial fisiológico das sementes, principalmente das que compõem lotes com poder germinativo elevado e semelhante (Marcos Filho, 1999a). Freqüentemente, observa-se que lotes de sementes apresentando germinação semelhante exibem comportamentos distintos no campo e/ou armazenamento.

Essas diferenças podem ser explicadas pelo fato de que as primeiras alterações nos processos bioquímicos associados à deterioração ocorrem, geralmente, antes que sejam verificados declínios na capacidade germinativa (Delouche $\&$ Baskin, 1973). Por este motivo, o uso de testes de vigor é de grande utilidade no monitoramento da qualidade das sementes, a partir da maturidade (Dias \& Marcos Filho, 1995).

Os problemas referentes à padronização de testes de vigor vêm sendo discutidos por vários autores. A Association of Official Seed Analysts - AOSA (1983), ressaltou a importância da precisão dos procedimentos utilizados para a condução desses testes, dos problemas enfrentados para a padronização dos procedimentos e a apresentação dos resultados.

No entanto, além da necessidade de padronização da metodologia e de interpretação dos resultados, para possibilitar a comparação entre resultados obtidos por diferentes analistas e 
laboratórios os testes de vigor devem preencher outras caracteristicas, como: a) relação com a emergência de plântulas em campo; b) rapidez; c) objetividade, eliminando interpretações subjetivas; d) simplicidade e e) viabilidade econômica (Delouche, 1976; AOSA, 1983 e TeKrony, 1983). Consequentemente, o sucesso no emprego desses métodos depende, dentre outros fatores, das relações entre as informações provenientes do laboratório e o desempenho das sementes em campo, além da capacidade de diferenciar lotes quanto ao nivel de vigor.

Perry (1981) enfatizou a importância da padronização dos testes de vigor pois, à medida que as técnicas de manejo cultural tornam-se mais sofisticadas, aumenta a necessidade de se utilizarem sementes de qualidade diferenciada. Neste sentido, Hampton \& Coolbear (1990) afirmaram que os testes de vigor são cada vez mais relevantes para muitas espécies de hortaliças, viabilizando a prática da semeadura de precisão, a eliminação do desbaste e a obtenção da maturação uniforme. Para tanto, as sementes devem ser de potencial fisiológico superior, o que exige o uso rotineiro de testes de vigor em programas de controle de qualidade.

O cultivo de hortaliças é realizado de maneira intensiva e deve ser estabelecido com o uso de sementes que germinem rápida $\mathrm{e}$ uniformemente (Marcos Filho, 1999a), o que ressalta a importância do vigor de sementes e a necessidade de avaliá-lo. Isso permite, para espécies onde a condução da cultura comercial envolve o transplante de mudas, que estas sejam de tamanho e qualidade uniformes, com reflexos no desenvolvimento das plantas e, possivelmente, na produção final.

Globirson (1981) destacou que a uniformidade na emergência é de grande importância para as hortaliças, em razão do alto custo das sementes e da mão-de-obra exigida durante o seu cultivo. Na cultura da 
alface, a desuniformidade na emergência pode resultar na necessidade de serem efetuadas colheitas sucessivas e acarretar irregularidade de tamanho do produto colhido (Gray, 1976 e Wurr \& Fellous, 1983).

Por outro lado, as prioridades da pesquisa sobre os testes de vigor estão sendo reavaliadas, haja vista que um único teste, quer seja fisiológico, bioquimico ou de resistência a estresses, não se tem mostrado suficiente, mesmo que para uma única espécie, para avaliar o potencial de desempenho das sementes sob todas condições ambientais (Hampton \& Coolbear, 1990). O vigor é função de um conjunto de caracteristicas que determinam o potencial para emergência rápida e uniforme de plântulas normais, sob ampla diversidade de condições de ambiente (AOSA, 1983). A tendência predominante, por conseguinte, é a combinação de dados de diferentes testes, levando-se sempre em consideração a finalidade do uso dos resultados e as suas limitações.

\subsection{Avaliação do vigor de sementes}

\subsubsection{Condutividade elêtrica}

A organização das membranas celulares é máxima por ocasiāo da maturidade fisiológica (Abdul-Baki, 1980). Com a dessecação, sofrem processo de desorganização estrutural, estando tanto mais desorganizadas quanto menor for o grau de umidade da semente, perdendo, temporariamente, a sua integridade (Bewley \& Black, 1994).

Por outro lado, a integridade das membranas celulares, determinada pelo grau de alterações bioquimicas deteriorativas e/ou 
danos fisicos, pode ser considerada como causa fundamental de diferenças no vigor de sementes (Powell, 1988).

$\mathrm{Na}$ fase inicial do processo de embebição, a capacidade da semente de reorganizar o sistema de membranas celulares e de reparar danos físicos e/ou biológicos, que podem ter ocorrido durante o processo de produção, irá influenciar a quantidade e natureza de lixiviados liberados para o meio externo (Simon \& Raja Harun, 1972; Bewley \& Black, 1994 e Vieira \& Krzyzanowski, 1999).

A condutividade elétrica foi proposta como um teste para avaliar o vigor de sementes, considerando que sementes com baixo vigor geralmente apresentam menor velocidade para restabelecer a integridade das membranas celulares, exibindo aumento na lixiviação de solutos durante a embebição. Decorre disso, maior perda de lixiviados, tais como açúcares, aminoácidos, ácidos graxos, enzimas e ions inorgânicos, como $\mathrm{K}^{+}, \mathrm{Ca}^{++}, \mathrm{Mg}^{++}$e $\mathrm{Na}^{+}$(Short \& Lacy, 1976; AOSA, 1983; Givelberg et al., 1984; Doijode, 1988; Woodstock, 1988; Cortes \& Spaeth, 1994 e Taylor et al., 1995).

Neste teste, a qualidade das sementes é avaliada indiretamente através da determinação da condutividade elétrica na solução de embebição das sementes. Os menores valores, correspondentes à menor liberação de exsudatos, indicam alto potencial fisiológico (maior vigor), revelando menor intensidade de desorganização dos sistemas membranais das células.

Considerando que os testes de vigor fornecem indices mais sensiveis do potencial fisiológico, quando comparados ao teste de germinação (AOSA, 1983), qualquer evento que preceda a perda do poder germinativo pode servir como base para o desenvolvimento de testes de vigor. Entretanto, acredita-se que, quanto mais próximo da maturidade fisiológica (ou mais distante da perda do poder germinativo) 
estiver a variável avaliada, mais sensivel será o teste. Neste sentido, como a degradaçāo das membranas celulares se constitui, hipoteticamente, no primeiro evento do processo de deterioraçāo (Delouche \& Baskin, 1973), os testes que avaliam a integridade das membranas seriam, teoricamente, os mais sensiveis para estimar o vigor (Marcos Filho, 1999a).

Dentre os fatores que podem afetar os resultados da condutividade elétrica, destacam-se: o genótipo dentro de uma mesma espécie e/ou cultivar (Short \& Lacy, 1976; Schmidt \& Tracy, 1989; Vieira et al., 1996; Panobianco \& Vieira, 1996; Vieira et al., 1998 e Panobianco et al., 1999); o estádio de desenvolvimento no momento da colheita (Powell, 1986); as mudanças na estrutura e composiçāo da semente durante o desenvolvimento (Styer \& Cantliffe, 1983) e a desestruturação das membranas (Givelberg et al., 1984 e Powell, 1986).

Os resultados da condutividade podem também ser influenciados pelos seguintes fatores: a) tamanho da semente (Tao, 1978; Loeffler, 1981 e Deswal \& Sheoran, 1993); b) massa da semente (Hepburn et al., 1984 e Siddique \& Goodwin, 1985); c) temperatura de embebiçāo (Leopold, 1980; Murphy \& Noland, 1982 e Givelberg et al., 1984); d) periodo de embebiçāo (Loeffler et al., 1988; Schmidt \& Tracy, 1989 e Wang et al., 1994); e) volume de água utilizado (Tao, 1978; Loeffler et al., 1988 e Hampton et al., 1994); f) teor de água inicial das sementes (Tao, 1978; McDonald \& Wilson, 1979; Loeffler et al., 1988; Hampton et al., 1992; Hampton et al., 1994; Carvalho, 1994 e Penariol, 1997); g) presença de sementes danificadas fisicamente (Tao, 1978); h) integridade do tegumento (Samad \& Pearce, 1978 e Duke \& Kakefuda, 1981) e sua permeabilidade (Powell \& Matthews , 1979); i) cor da semente (Short \& Lacy, 1976); j) tamanho do recipiente de embebição (Loeffler et al., 1988); l) qualidade da água (Tao, 1978 e Loeffler et al., 
1988); m) número de sementes constituintes da amostra avaliada (Hampton et al., 1994); n) equipamento usado para a leitura da condutividade (Hepburn et al., 1984) e o) expressão dos resultados (Mullet \& Wilkinson, 1979 e Siddique \& Goodwin, 1985).

$O$ periodo de embebição das sementes exerce efeito marcante na capacidade do teste distinguir diferenças de qualidade entre lotes. Tradicionalmente, o teste de condutividade elétrica tem sido realizado com 24 horas de imersão; entretanto, devido à necessidade de obtenção de respostas mais rápidas, tem-se tentado reduzir o periodo de embebição para a leitura de condutividade.

É importante observar que, no caso das hortaliças, o tempo de embebição poderá ser reduzido. O estudo com sementes de cenoura, desenvolvido por Andrade et al. (1995), revelou resultados promissores para as sementes submetidas a periodos curtos de embebição, de 30 minutos e quatro horas, antes das leituras de condutividade elétrica. Segundo Simon \& Mathavan (1986), a perda de solutos é mais intensa no início do processo de embebição, sendo que em sementes de cenoura, após uma hora de embebição, já ocorre estabilização do processo.

Loomis \& Smith (1980), buscando a definição do protocolo do teste para avaliação do vigor de sementes de repolho, obtiveram as melhores respostas após quatro horas de embebição. Em outro estudo, Guimarães et al. (1993) verificaram que, para sementes de alface, o periodo de quatro horas de embebição foi o mais adequado para distinguir lotes de sementes de alto e baixo vigor.

Com o objetivo de verificar a possibilidade de redução do periodo de condicionamento das sementes de maxixe no teste de condutividade elétrica, Torres et al. (1998) realizaram leituras após 2, 4, $8,12,16,20$ e 24 horas de embebição, concluindo que é possivel reduzir para quatro horas o periodo de condicionamento das sementes. 
Dias et al. (1998), estudando a metodologia do teste para avaliação rápida do vigor de sementes de quiabo e de feijāo-de-vagem, verificaram que, para sementes de quiabo, após quatro horas de condicionamento foi possivel a identificaçāo do lote com melhor desempenho. Contudo, para as duas espécies estudadas, informações mais precisas sobre o vigor dos lotes foram obtidas com 24 horas de embebição.

No caso de sementes de tomate, Krishnasamy \& Ramarajpalaniappan (1989) observaram que, dentre os periodos estudados $(2,4,6,8,10 \mathrm{e} 12 \mathrm{~h})$, o de quatro horas de embebição proporcionou resultados mais consistentes. Sá (1999), por sua vez, verificou que existe a possibilidade de redução do tempo de embebição de 24 para 6 horas no teste de condutividade elétrica de sementes de tomate.

Outro fator destacado na literatura é a temperatura de embebição, refletindo-se na velocidade de embebição e de lixiviação de eletrólitos do interior das células para o meio externo (Leopold, 1980). O efeito da temperatura sobre a lixiviação se manifesta, basicamente, sobre a quantidade e velocidade de perda de lixiviados, traduzindo-se na magnitude do valor da condutividade, sem alterar, entretanto, a classificação dos lotes (Hampton, 1995). No caso de sementes pequenas, a lixiviação máxima pode ocorrer num periodo inferior a duas horas (Murphy \& Noland, 1982), ao passo que em sementes maiores, como soja, verificou-se aumento de lixiviação até 24-30 horas após o início da embebição, a uma temperatura de $25^{\circ} \mathrm{C}$ (Loeffler et al., 1988).

Além da temperatura de embebição, a temperatura de avaliaçāo tem efeito direto e significativo sobre os resultados da condutividade elétrica. Assim, Loeffler et al. (1988), com sementes de soja, verificaram que aumentos ou reduções de $5^{\circ} \mathrm{C}$ na temperatura de 
avaliação proporcionaram alteraçōes significativas nos resultados da condutividade; recomendaram que o número de amostras retiradas da câmara $\left(25^{\circ} \mathrm{C}\right)$ deve ser suficiente para ser avaliado num espaço de, no máximo, 15 minutos.

Com relação ao número de sementes, Loeffler et al. (1988), trabalhando com sementes de soja, demostraram que o uso de 50 sementes, em comparação a 25 , proporcionou redução no coeficiente de variação, levando a maior uniformidade dos resultados. Guimarães et al. (1993) estudando a influência do número de sementes de alface $(25,50$ e 100) sobre os resultados da condutividade elétrica verificaram que a utilização de 50 sementes foi considerada mais adequada para condução do teste. No caso de sementes de tomate, Sá (1999) não observou diferenças significativas entre os valores de condutividade, em função do número de sementes empregado (25, 50 e 100 sementes).

Complementando, o volume de água utilizado poderá influir nos resultados do teste. Hampton et al. (1994), verificaram que o aumento na quantidade de água minimizou o efeito do número de sementes, ou seja, quando trabalharam com volume maior de água $(250 \mathrm{ml})$ a condutividade elétrica nāo sofreu interferência do número de sementes (50 e 100 sementes), enquanto que em menor quantidade de água $(125 \mathrm{ml})$, variou significativamente em função do número de sementes empregado.

Para sementes de hortaliças, foram observadas diferenças no volume de água utilizado para condução do teste: a) 250ml: em sementes de ervilha e grão de bico (Deswal \& Sheoran, 1993 e Powell et al., 1997); b) 100ml: em sementes de pimentão (Demir \& Ellis, 1992); c) 75ml: em sementes de alface (Guimarães et al., 1993), cebola (Torres, 1998), cenoura (Andrade et al., 1995), grão de bico (Ram et al., 1989) e tomate (Sá, 1999); d) 50ml: em sementes de cenoura (Rodo et al., 2000), 
pimentão (Trawatha et al., 1990) e tomate (Rodo et al., 1998a); e) 25ml: em sementes de cebola (Piana et al., 1995), pimentão (Torres, 1996 e Panobianco \& Marcos Filho, 1998) e tomate (Cavariani et al., 1994).

Alguns pesquisadores têm buscado a determinação do protocolo do teste de condutividade elétrica para avaliação do vigor de sementes de hortaliças. Lima (1993), trabalhando com sementes de cebola, não verificou sensibilidade do teste para separação de lotes de alto e de baixo vigor. Da mesma maneira, Argerich \& Bradford (1989) e Novembre et al. (1995) não obtiveram resultados consistentes com sementes de tomate.

Todavia, estudo com sementes de cenoura, desenvolvido por Andrade et al. (1995), revelou ser o teste de condutividade elétrica o mais indicado para estimar o vigor, em razão da sua facilidade de execução, objetividade e rapidez. Pesquisas com sementes de couve-flor, cebola e cenoura mostraram que o teste permitiu a separação dos lotes em niveis de vigor, havendo a possibilidade de redução do período de condicionamento das sementes (Dias et al., 1996).

Encontram-se disponiveis na literatura vários trabalhos com procedimentos semelhantes aos descritos para soja ou ervilha, havendo escassez de informaçōes a respeito da metodologia específica para a condução do teste de condutividade elétrica, em análise de rotina, para sementes de hortaliças.

\subsubsection{Lixiviaçāo de Potássio}

O teste de lixiviação de potássio, estudado com menor freqüência, baseia-se em principio semelhante ao de condutividade 
elétrica, com a vantagem de proporcionar informações sobre o potencial fisiológico dos lotes, em periodo de tempo consideravelmente reduzido (Dias \& Marcos Filho, 1995).

$\mathrm{O}$ teste de condutividade elétrica avalia indiretamente a quantidade de lixiviados liberados durante a embebição de sementes. Uma porção significativa desses exsudatos é constituída por ions inorgânicos; no entanto, poucos estudos têm sido conduzidos com a finalidade de identificar especificamente os cátions liberados para o meio externo durante o processo.

Dentro deste contexto, Abdel Samad \& Pearce (1978) verificaram rápida liberação de $\mathrm{K}^{+} \mathrm{e}$ outros compostos durante a primeira hora de embebição de sementes de amendoim. Perdas de $\mathrm{Ca}^{++}$, $\mathrm{Mg}^{++}, \mathrm{Mn}^{++}, \mathrm{K}^{+}$e $\mathrm{Cl}^{-}$durante a embebição de sementes de repolho, envelhecidas artificalmente, foram observadas por Loomis \& Smith (1980), ao passo que outros trabalhos mediram $\mathrm{K}^{+}$e $\mathrm{Na}^{+}$liberados (McKersie \& Stinson, 1980).

Oliveira (1990) quantificou a presença de $\mathrm{Ca}^{++}, \mathrm{Mg}^{++}, \mathrm{Na}^{+}, \mathrm{K}^{+}$ no exsudato de sementes de soja, após 90 minutos de embebição, a $28^{\circ} \mathrm{C}$, e constatou relação significativa entre a perda de germinação e o efluxo de ions, com exceção do sódio. Outrossim, estudos conduzidos por Givelberg et al. (1984) demonstraram ocorrerem perdas de $\mathrm{Ca}^{+}, \mathrm{Na}^{+}$, $\mathrm{Mg}^{++} \mathrm{e} \mathrm{K}^{+}$durante a embebição de sementes de Solanum nigrum.

Dentre os íons estudados na literatura, o potássio tem merecido especial atenção por se tratar do principal ion, em termos de quantidade lixiviada pelas sementes (Lott et al., 1991). Dados obtidos por Mullet \& Considine (1980), em sementes de ervilha e de feijão, demonstraram que 25 a $50 \%$ do total de eletrólitos liberados correspondeu ao íon $\mathrm{K}^{+}$, o mesmo ocorrendo para sementes de algodão (Woodstock et al., 1985). O estudo com sementes de cenoura, 
desenvolvido por Granqvist (1987), mostrou que as perdas de potássio e cálcio foram semelhantes, mas superiores às de sódio e magnésio.

A quantidade de potássio liberada por sementes embebidas tem sido utilizada como um indicador da integridade do sistema de membranas celulares (Halloin, 1975; McKersie \& Stinson, 1980 e Woodstock et al., 1985). Assim, essa determinação, após certo periodo de embebição, vem sendo pesquisada como um indice de avaliação rápida do vigor de sementes.

Simon \& Raja-Harun (1972), trabalhando com sementes de ervilha, verificaram estreita relação entre os resultados de condutividade elétrica e quantidade de potássio liberado após 24 horas de embebição. Halloin (1975), com sementes de algodão, observou que a concentração de ions potássio liberados após 60 minutos de embebição correspondeu à condutividade avaliada com 15 e 45 minutos. Moss \& Mullet (1982), por sua vez, utilizaram a quantidade de potássio lixiviado por sementes de feijão, após 72 horas de embebição, como parâmetro indicativo do vigor.

Com relação às sementes de soja, Marcos Filho et al. (1982) verificaram que a lixiviação de potássio decresceu à medida que se elevaram o poder germinativo e o vigor das sementes, durante o processo de maturação. Resultados obtidos por Dias et al. (1996) indicaram que a avaliação do potássio lixiviado, realizada a partir de 90 minutos de embebição, possibilitou a separação dos lotes de sementes de soja em diferentes niveis de vigor. Com a evolução do desenvolvimento da metodologia, Custódio \& Marcos Filho (1997) detectaram diferenças de vigor de sementes de soja, após 30 minutos de embebição. Esses autores destacaram que o teste apresentou vantagens, quando comparado com o de condutividade elétrica, como simplicidade, 
precisão e rapidez, permitindo a tomada de prontas decisões, principalmente em programas de controle de qualidade pós-colheita.

É importante observar que, no caso das hortaliças, espécies como aipo, alface e cenoura apresentaram $90 \%$ da lixiviação do potássio num periodo de 5 a 15 minutos (Simon \& Mathavan, 1986); no entanto, essas observações não foram efetuadas em pesquisa dirigida ao estudo da lixiviação de potássio como um teste de vigor.

Recentemente, Dias et al. (1998) procuraram adaptar a metodologia do teste de lixiviação de potássio para a avaliação rápida do vigor de sementes de feijāo-de-vagem e de quiabo, concluindo que o teste necessita ainda de estudos adicionais para adequar a metodologia e viabilizar a sua utilização mais ampla.

\subsubsection{Envelhecimento acelerado}

O teste de envelhecimento acelerado tem como principio o aumento considerável da taxa de deterioração das sementes através de sua exposição a niveis elevados de temperatura e umidade relativa do ar, considerados os fatores ambientais preponderantes na intensidade $\mathrm{e}$ velocidade de deterioração (Marcos Filho, 1999b). Assim, sementes de baixa qualidade deterioram-se mais rapidamente do que as mais vigorosas, apresentando queda acentuada de sua viabilidade, após serem submetidas ao envelhecimento artificial.

De acordo com a seqũência hipotética proposta por Delouche \& Baskin (1973), a redução do potencial de armazenamento é a primeira manifestação fisiológica da deterioração, após o decréscimo da velocidade de germinação. Consequentemente, o teste de 
envelhecimento acelerado pode ser considerado como um dos mais sensiveis para avaliação do vigor, dentre os disponiveis (Marcos Filho, 1999b).

O seu uso é extensivo à determinação do vigor de diversas hortaliças. Piana et al. (1995) concluíram que, dentre os testes estudados, o de envelhecimento acelerado foi um dos que mais se relacionou à emergência das plântulas de cebola em campo e à obtenção de mudas vigorosas, além de identificar os lotes com diferentes niveis de vigor. O estudo com sementes de cenoura, desenvolvido por Martins et al. (1996), mostrou, também, que o teste se relacionou com a emergência de plântulas em campo. Resultados semelhantes foram observados por Trigo \& Trigo (1995a,b,c) com sementes de pepino, cenoura e melancia.

Dos fatores que afetam o comportamento das sementes durante o teste, a interação temperatura/periodo de exposição merece destaque. Para algumas hortaliças, estudos indicaram a temperatura/periodo adequados à realização do teste (Quadro 1). 
Quadro 1. Temperaturas e periodos indicados para a exposição de sementes de diferentes espécies ao teste de envelhecimento acelerado.

\begin{tabular}{|c|c|c|}
\hline Espécie & Temperatura/Periodo & Referência \\
\hline alface & $41^{\circ} \mathrm{C} / 72 \mathrm{~h}$ & TeKrony (1995) \\
\hline brócolos & $45^{\circ} \mathrm{C} / 48 \mathrm{~h}$ & Tebaldi et al. (1999) \\
\hline \multirow[t]{2}{*}{ cebola } & $41^{\circ} \mathrm{C} / 72 \mathrm{~h}$ & Idiarte (1995) e TeKrony (1995) \\
\hline & $42^{\circ} \mathrm{C} / 48 \mathrm{~h}$ & Piana et al. (1995) \\
\hline \multirow[t]{2}{*}{ cenoura } & $41^{\circ} \mathrm{C} / 72 \mathrm{~h}$ & Nascimento \& Andreoli (1987) \\
\hline & $42^{\circ} \mathrm{C} / 48 \mathrm{~h}$ & Spinola et al. (1998) \\
\hline \multirow[t]{2}{*}{ ervilha } & $37^{\circ} \mathrm{C} / 72 \mathrm{~h}$ & Menêzes \& Nascimento (1988) \\
\hline & $42^{\circ} \mathrm{C} / 48 \mathrm{~h}$ & Caliari \& Marcos Filho (1990) \\
\hline feijão-de-vagem & $41^{\circ} \mathrm{C} / 48 \mathrm{~h}$ & Dias et al. (1998) \\
\hline maxixe & $41^{\circ} \mathrm{C} / 48 \mathrm{~h}$ & Silva et al. (1997) \\
\hline melancia & $45^{\circ} \mathrm{C} / 144 \mathrm{~h}$ & Delouche \& Baskin (1973) \\
\hline pimentão & $41^{\circ} \mathrm{C} / 72 \mathrm{~h}$ & $\begin{array}{l}\text { TeKrony (1995); Panobianco \& } \\
\text { Marcos Filho (1998) }\end{array}$ \\
\hline \multirow[t]{3}{*}{ quiabo } & $42^{\circ} \mathrm{C} / 72$ e $96 \mathrm{~h}$ & Lima et al. (1997) \\
\hline & $41^{\circ} \mathrm{C} / 72 \mathrm{~h}$ & Dias et al. (1998) \\
\hline & $41^{\circ} \mathrm{C} / 144 \mathrm{~h}$ & Torres \& Carvalho (1998) \\
\hline rabanete & $45^{\circ} \mathrm{C} / 48 \mathrm{~h}$ & Delouche \& Baskin (1973) \\
\hline tomate & $42^{\circ} \mathrm{C} / 72 \mathrm{~h}$ & Nascimento et al. (1993) \\
\hline
\end{tabular}


No teste de envelhecimento acelerado, as diferenças na absorção de água pelas sementes, a partir da atmosfera úmida, podem originar variações acentuadas no grau de umidade das amostras. Pesquisas conduzidas com espécies de sementes de menor tamanho, como as hortaliças, têm revelado resultados pouco consistentes para esse teste. Após 24 horas de envelhecimento acelerado (100\% de umidade relativa e $45^{\circ} \mathrm{C}$ ), Powell (1995) observou variação no grau de umidade, de 11,8 a 24,0\%, sendo que a germinação após este periodo de envelhecimento foi inversamente proporcional ao grau de umidade alcançado; assim, lotes que absorveram água mais rapidamente, atingindo grau de umidade elevado, após 24 horas de exposição às condições do teste, apresentaram germinação inferior, indicando maior grau de deterioração, em relação aos lotes que absorveram água mais lentamente.

Por esse motivo, vêm sendo estudadas alternativas para a condução do envelhecimento acelerado em espécies de sementes pequenas, como a substituição da água por soluções saturadas de sal (SSAA - "Saturated Salt Accelerated Aging"). Dependendo da solução utilizada, são obtidos niveis específicos de umidade relativa do ar, permitindo reduzir a taxa de absorção de água, a velocidade e a intensidade de deterioração das sementes.

Jianhua \& McDonald (1996), trabalhando com sementes de Impatiens wallerana Hook, utilizaram três soluções saturadas de sais, que produziram diferentes umidades relativas $(\mathrm{KCl}-87 \% \mathrm{UR}, \mathrm{NaCl}-$ $76 \%$ UR e $\mathrm{NaBr}$ - $55 \% \mathrm{UR}$ ), observando eficiência desse método para retardar a absorção de água das sementes pequenas, durante o envelhecimento acelerado, sem prejudicar a eficiência do teste.

Nesse sentido, Panobianco \& Marcos Filho (1998), com sementes de pimentão, verificaram que o grau de umidade das sementes 
expostas a solução saturada de $\mathrm{NaCl}$, menor e mais uniforme após o periodo de envelhecimento, revelou vantagens na utilização desse procedimento para sementes pequenas, em relação ao procedimento convencional, proporcionando uma taxa de deterioração menos acentuada, resultados menos drásticos e mais uniformes. Além disso, o uso de solução saturada de $\mathrm{NaCl}$ possibilitou uma melhor identificação de lotes com niveis diferentes de qualidade, em comparação ao teste sem a utilização do sal. Resultados promissores com o uso de soluções saturadas de sal, no teste de envelhecimento acelerado, também foram observados para sementes de milho doce (Bennett et al., 1998) e cenoura (Rodo et al., 2000).

Observa-se que, embora o teste de envelhecimento acelerado venha sendo amplamente estudado em termos de sua padronização para muitas espécies, encontram-se à disposição na literatura poucos trabalhos realizados com sementes de tomate.

\subsubsection{Deterioração controlada}

Diferenças no vigor de lotes de sementes também têm sido detectadas pelo teste de deterioração controlada, cujo principio é equivalente ao do envelhecimento acelerado. No entanto, a avaliação é efetuada em amostras com teores de água semelhantes, em vez da utilização de ambientes com alta umidade relativa do ar, resultando na obtenção de condições mais uniformes durante $o$ teste $e$, consequentemente, padronização mais efetiva, principalmente em espécies que produzem sementes de menor tamanho. 
De acordo com o principio do teste, o envelhecimento mais rápido de sementes ocorre quando as mesmas são armazenadas sob condições de elevado teor de água e alta temperatura (Powell, 1995). A comparação da resposta de vários lotes seria possivel através de um controle preciso da temperatura e do teor de água das sementes, de modo que o mesmo grau de envelhecimento ou deterioração seria imposto de maneira uniforme a todos os lotes. A mesma autora ponderou que, no teste de envelhecimento acelerado, as diferenças na absorção de água, a partir da atmosfera úmida, podem originar variações acentuadas no grau de umidade das amostras, o que não tem ocorrido no teste de deterioração controlada, especialmente para espécies de sementes pequenas.

Assim, o teste de deterioração controlada tem sido utilizado para detectar diferenças no vigor de lotes de sementes e para avaliar o potencial de armazenamento de sementes de várias hortaliças, como cenoura, cebola, alface e brássicas (Matthews, 1980; Powell \& Matthews, 1981; Powell \& Matthews, 1984a,b; Wang \& Hampton, 1991).

No Quadro 2 estão apresentadas, para algumas hortaliças, sugestōes de grau de umidade, temperatura e periodo de exposição das sementes às condições do teste de deterioração controlada. 
Quadro 2. Graus de umidade, temperaturas e periodos sugeridos para a exposição de sementes de diferentes espécies ao teste de deterioração controlada.

\begin{tabular}{|l|c|l|}
\hline Espécie & $\begin{array}{c}\text { Grau de umidade } \\
\text { temperatura/periodo }\end{array}$ & \multicolumn{1}{|c|}{ Referência } \\
\hline alface & $20 \% / 45^{\circ} \mathrm{C} / 24 \mathrm{~h}$ & ISTA (1995) \\
beterraba & $24 \% / 45^{\circ} \mathrm{C} / 24 \mathrm{~h}$ & ISTA (1995) \\
cebola & $19 \% / 45^{\circ} \mathrm{C} / 24 \mathrm{~h}$ & Powell et al. (1984); ISTA \\
& & $(1995)$ \\
cenoura & $24 \% / 45^{\circ} \mathrm{C} / 24 \mathrm{~h}$ & ISTA (1995) \\
couve-flor & $20 \% / 45^{\circ} \mathrm{C} / 24 \mathrm{~h}$ & ISTA (1995) \\
couve de bruxelas & $20 \% / 45^{\circ} \mathrm{C} / 24 \mathrm{~h}$ & Powell \& Matthews (1994) \\
ervilha & $20 \% / 45^{\circ} \mathrm{C} / 24 \mathrm{~h}$ & Bustamante et al. (1984) \\
& $15 \% / 45^{\circ} \mathrm{C} / 24 \mathrm{~h}$ & Powell et al. (1997) \\
melão & $21 \% / 45^{\circ} \mathrm{C} / 72 \mathrm{~h}$ & Oluoch \& Welbaum (1996) \\
pimentão & $24 \% / 45^{\circ} \mathrm{C} / 24 \mathrm{~h}$ & Panobianco \& Marcos Filho \\
& & (1998) \\
repolho & $24 \% / 45^{\circ} \mathrm{C} / 24 \mathrm{~h}$ & Strydom \& Venter (1998) \\
tomate & $19 \% / 45^{\circ} \mathrm{C} / 24 \mathrm{~h}$ & Rodo et al. (1998b) \\
\hline
\end{tabular}

Nota-se, portanto, que mesmo sendo um teste dirigido para a avaliação do potencial fisiológico de sementes de hortaliças, o teste de deterioração controlada pouco foi estudado para as de tomate. Essa observação ressalta a necessidade de pesquisas destinadas à avaliação do vigor de sementes dessa importante hortaliça. 


\section{MATERIAL E MÉTODOS}

O presente trabalho foi conduzido, em duas etapas, no Laboratório de Análise de Sementes e no Campo Experimental do Departamento de Produção Vegetal da Escola Superior de Agricultura "Luiz de Queiroz" da Universidade de São Paulo, em Piracicaba, SP. A primeira etapa, compreendeu o estudo preliminar de procedimentos alternativos para a condução dos testes de condutividade elétrica, de lixiviação de potássio, de envelhecimento acelerado e de deterioração controlada, sendo conduzida de novembro de 1998 a junho de 1999. A segunda, compreendendo os meses de julho a outubro de 1999, teve como meta a comparação entre esses testes para avaliação do potencial fisiológico das sementes, utilizando-se os protocolos considerados mais eficientes para a condução de cada um deles, com base nas informações obtidas durante a primeira etapa. Nas duas etapas, os testes foram repetidos três vezes para confirmação da consistência das informações obtidas.

\subsection{Sementes}

Foram utilizadas sementes de tomate, dos híbridos Debora Plus e Bruna (grupo Santa Cruz), cada um representado por cinco lotes. 
As sementes foram produzidas na safra 96/97, pela empresa AGROFLORA S/A.

Durante o periodo experimental, as sementes permaneceram armazenadas em embalagens de papel multifoliado, em câmara regulada a $20^{\circ} \mathrm{C}$ e $60 \%$ de Umidade Relativa do ar (UR), sendo os lotes homogeneizados periodicamente.

3.2. Estudo dos testes de condutividade elétrica, lixiviação de potássio, envelhecimento acelerado e deterioração controlada (ETAPA 1)

Esta etapa, com duraçāo de aproximadamente sete meses, compreendeu estudos especificos sobre a metodologia dos testes de condutividade elétrica, de lixiviaçāo de potássio, de envelhecimento acelerado e de deterioraçāo controlada, procurando-se identificar procedimentos eficientes, em cada um desses testes, para detectar diferentes niveis de vigor dos lotes estudados. Foram realizados os seguintes testes:

\subsubsection{Determinação do grau de umidade}

Efetuada em estufa a $105 \pm 3^{\circ} \mathrm{C}$, durante 24 horas, segundo as instruções das Regras para Análise de Sementes (Brasil, 1992), utilizando-se duas amostras para cada lote, com aproximadamente 2,0 g de sementes cada. Os resultados foram expressos em percentagem média para cada lote. 


\subsubsection{Germinação}

Utilizaram-se três repetições de 50 sementes para cada lote, colocadas para germinar sobre duas folhas de papel mata-borrão (tipo Germibox) umedecidas com quantidade de água equivalente a 2,5 vezes o peso do substrato, no interior de caixas plásticas $(11,0 \times 11,0 \mathrm{x}$ $3,5 \mathrm{~cm})$, a $25^{\circ} \mathrm{C}$. As avaliações foram realizadas aos sete e 14 dias após a semeadura, segundo os critérios estabelecidos pelas Regras para Análise de Sementes (Brasil, 1992).

\subsubsection{Condutividade elêtrica (CE)}

Nesta etapa, foram avaliados os efeitos das temperaturas de $25^{\circ} \mathrm{C}$ e $30^{\circ} \mathrm{C}$, os volumes de água de $25 \mathrm{ml}, 50 \mathrm{ml}$ e $75 \mathrm{ml}$ e os números de 25 e 50 sementes por amostra, da seguinte maneira:

\subsubsection{CE I}

Preliminarmente, foi estudada a marcha de liberação de eletrólitos de cada lote, utilizando-se os periodos de embebição de 30, 60 e 90 minutos, $2,3,4,6,8,10,16,20$ e 24 horas, variando-se a temperatura $\left(25^{\circ} \mathrm{C}\right.$ e $\left.30^{\circ} \mathrm{C}\right)$ e o volume de água $(25 \mathrm{ml}, 50 \mathrm{ml} \mathrm{e} 75 \mathrm{ml})$, mantendo-se fixo o número de sementes (50 sementes).

\subsubsection{CE II}

Depois de estabelecida as melhores combinações temperatura/ quantidade de água $\left(25^{\circ} \mathrm{C} / 25 \mathrm{ml}\right.$ e $\left.30^{\circ} \mathrm{C} / 25 \mathrm{ml}\right)$ e, identificados os periodos promissores $\left(25^{\circ} \mathrm{C} / 25 \mathrm{ml}: 1,2,4,6\right.$ e $24 \mathrm{~h} ; 30^{\circ} \mathrm{C} / 25 \mathrm{ml}: 4,6,10$, 16,20 e $24 \mathrm{~h}$ ), o número de sementes foi alterado (25 sementes). 


\subsubsection{CE III}

Após a identificação da melhor combinação número de sementes/quantidade de água/temperatura ( 50 sementes $/ 25 \mathrm{ml} / 25^{\circ} \mathrm{C}$ ), novos testes foram conduzidos, utilizando-se a referida combinação e os periodos de $1,3,6,8$ e $24 \mathrm{~h}$, com a finalidade de determinar os periodos de embebição mais adequados.

Cada fase do estudo da metodologia do teste foi conduzida com três repetições para cada lote, utilizando-se sementes pesadas com precisão de 0,0001g, colocadas para embeber em copos plásticos contendo água destilada, mantidos em germinador durante cada periodo de embebição.

Decorrido cada periodo, a condutividade elétrica da solução foi determinada através de leitura em condutivimetro DIGIMED DM-31 e os valores médios obtidos para cada lote foram expressos em $\mu \mathrm{mho} / \mathrm{cm} / \mathrm{g}$ de semente.

\subsubsection{Lixiviação de potássio}

Esta avaliação foi conduzida de modo semelhante ao descrito para o estudo sobre a condutividade elétrica (item 3.2.3). Cada fase do estudo da metodologia do teste foi conduzida com três repetições, utilizando-se sementes pesadas com precisão de 0,0001g, colocadas para embeber em copos plásticos contendo água destilada, mantidos em germinador durante cada periodo de embebição.

Preliminarmente, foram avaliados os efeitos das temperaturas de $25^{\circ} \mathrm{C}$ e $30^{\circ} \mathrm{C}$, os volumes de água de $25 \mathrm{ml}, 50 \mathrm{ml}$ e $75 \mathrm{ml}$ e os números de 25 e 50 sementes por amostra. No entanto, em função de não ter sido possivel a obtenção de leituras com essas combinações (leituras 
realizadas apresentaram valor zero), mesmo após $24 \mathrm{~h}$ de embebição, foi necessária alteração em um desses fatores, visando tornar o teste viável para avaliação da qualidade de sementes de tomate.

Assim, alterou-se para 100 o número de sementes, trabalhando-se com a temperatura mais alta $\left(30^{\circ} \mathrm{C}\right)$ e um menor volume de água $(25 \mathrm{ml})$, obtendo-se dessa maneira a melhor combinação número de sementes/temperatura/volume de água. Com relação aos periodos de embebição, somente a partir de $3 \mathrm{~h}$ houve possibilidade de obtenção de resultados consistentes, sendo então adotado o referido periodo para condução do teste.

As leituras do potássio lixiviado das sementes foram feitas em fotômetro de chama DIGIMED NK-2004, inicialmente calibrado com o padrão 5 ppm de potássio para leitura 50 , de acordo com observações preliminares.

A curva de calibração do fotõmetro de chama (padrão $5 \mathrm{ppm} \mathrm{K}$ ajustado para leitura 50) foi estabelecida através de regressão linear e avaliada com seis observações. Foi realizada uma observação com água destilada, ajustada para leitura zero; a seguir, foram feitas leituras com padrão de potássio de concentração conhecida e inferiores à calibração ajustada, para verificar a linearidade da curva (Custódio \& Marcos Filho, 1997). O padrão estudado apresentou linearidade com alto coeficiente de determinação $\left(R^{2}=0,9907\right)$, o que confirmou a adequação da curva para determinação do potássio lixiviado de sementes de tomate.

O fator de correção para cada leitura foi obtido através da regressão linear de equação $\mathrm{Y}=0,0982 \mathrm{x}$, onde $\mathrm{x}=$ leitura obtida $\epsilon \mathrm{Y}=$ $\mathrm{ppm} \mathrm{K} / \mathrm{ml}$ da amostra. Em razão da adição de $25 \mathrm{ml}$ de água por repetição, multiplicou-se o valor de $\mathrm{Y}$ por 25. Os resultados obtidos foram expressos em $\mathrm{ppm}$ de potássio/g de semente. Efetuaram-se os 
seguintes cálculos para obtenção da quantidade de $\mathrm{K}$ no teste de lixiviação:

$\mathrm{ppm} \mathrm{K} / \mathrm{ml}$ da amostra $\mathrm{x} 25 \mathrm{ml}=\mathrm{ppm} \mathrm{K} /$ repetição

ppm $\mathrm{K} /$ repetição $\div$ peso das sementes $=\mathrm{ppm} \mathrm{K/g}$

\subsubsection{Envelhecimento acelerado (procedimento tradicional)}

Conduzido com a utilização de caixas plásticas (11,0 x 11,0 × 3,5cm) como compartimento individual (mini-câmaras), possuindo em seu interior uma bandeja de tela de aluminio, onde as sementes, após pesagem (aproximadamente 3,0g), foram distribuídas de maneira a formarem camada simples sobre a superficie da tela; no interior de cada compartimento individual foram adicionados $40 \mathrm{ml}$ de água. As caixas, tampadas, foram mantidas em incubadora por três periodos de envelhecimento ( $48 \mathrm{~h}, 72 \mathrm{~h}$ e $96 \mathrm{~h}$ ), sendo utilizadas duas temperaturas $\left(38^{\circ} \mathrm{C}\right.$ e $\left.41^{\circ} \mathrm{C}\right)$, visando obter, dessa forma, as melhores combinações periodo/temperatura.

Decorrido cada periodo de envelhecimento, três amostras de 50 sementes por tratamento foram colocadas para germinar conforme descrito no item 3.2.2. A avaliação foi realizada aos sete dias após a semeadura, computando-se a percentagem de plântulas normais. Foi determinado, também, o grau de umidade das sementes antes e após o periodo de envelhecimento, visando avaliação da uniformidade das condições do teste. 
Após a identificaçāo das melhores combinaçōes periodo/temperatura $\left(48\right.$ e $72 \mathrm{~h} / 38^{\circ} \mathrm{C} ; 48$ e $\left.72 \mathrm{~h} / 41^{\circ} \mathrm{C}\right)$, novos testes foram conduzidos, usando-se estas combinaçōes, visando determinar a mais promissora.

\subsubsection{Envelhecimento acelerado (solução saturada de sal)}

Esta avaliação foi conduzida de modo semelhante à descrita para o estudo sobre o teste tradicional (item 3.2.5) adicionando-se, porém, ao fundo de cada plástica, $40 \mathrm{ml}$ de solução saturada de $\mathrm{NaCl}$, proporcionando ambiente com $76 \%$ de $\mathrm{UR}$, em vez de $40 \mathrm{ml}$ de água.

\subsubsection{Deterioração controlada}

Inicialmente, o grau de umidade das sementes foi ajustado para três niveis diferentes $(19 \%, 21 \%$ e $24 \%$ ), através do método da atmosfera úmida (Rossetto et al., 1995), conduzido em caixas plásticas $(11,0 \times 11,0 \times 3,5 \mathrm{~cm})$, com amostras contendo $3,0 \mathrm{~g}$ de sementes, colocadas sobre a tela interna mediante a distribuição de uma camada simples. Estas caixas, tampadas e contendo $40 \mathrm{ml}$ de água, foram mantidas em incubadora, a $20^{\circ} \mathrm{C}$. Durante o umedecimento artificial, os graus de umidade das sementes foram monitorados, através de pesagens sucessivas, até se obterem os valores desejados.

Uma vez obtidos os graus de umidade planejados, cada amostra foi colocada em recipiente de folha de aluminio, fechado hermeticamente, permanecendo por cinco dias em câmara fria $\left(8-10^{\circ} \mathrm{C}\right)$ para atingir o equilibrio higroscópico. Em seguida, as sementes foram 
mantidas em banho-maria, a $45^{\circ} \mathrm{C}$, durante dois periodos ( $24 \mathrm{~h}$ e $48 \mathrm{~h}$ ). Posteriormente, os recipientes foram imersos rapidamente em água fria para reduzir a temperatura, sendo instalado em seguida o teste de germinação (Powell, 1995). As interpretações do teste foram efetuadas aos sete dias após a semeadura, computando-se as percentagens de plântulas normais.

Foi determinado, também, o grau de umidade das sementes após os periodos em banho-maria.

Após a identificação das melhores combinaçōes grau de umidade/periodo $(21 \% / 48 \mathrm{~h} ; 24 \% / 24 \mathrm{~h})$ novos testes foram conduzidos, utilizando-se estas combinaçōes, visando determinar a mais promissora.

\subsubsection{Método Agroflora para avaliação de vigor em tomate}

Trata-se de um método desenvolvido pela empresa AGROFLORA S/A, para controle interno de qualidade.

A avaliação foi realizada nas instalaçōes da empresa, em Bragança Paulista, SP, utilizando-se quatro repetiçōes de 50 sementes por lote. Para semeadura foram usadas bandejas de poliestireno ("isopor") com células individuais contendo substrato comercial Plantimax PXT, acrescido de palha de arroz carbonizada e fertilizante (fórmula 04-14-08). As bandejas foram mantidas em estufa, sem controle ambiental, recebendo irrigação 3 vezes/dia. As avaliaçōes foram efetuadas no nono e 140 dias, avaliando-se o vigor nesta última contagem.

$\mathrm{Na}$ avaliação de vigor adotou-se o seguinte procedimento: a) contagem de plantas emergentes (visiveis), sem considerar qualquer critério de classificação, obtendo-se, dessa forma, a ETP (Emergência 
Total de Plântulas); b) utilização de critérios de avaliação de vigor, por meio de uma escala (Normal, Fraca e Anormal), obtendo-se o valor PP (Plântulas Problemáticas de vigor), resultado da soma das plântulas fracas e anormais; e c) cálculo da EPN (Emergência de Plântulas Normais), como indicativo de vigor, através da fỏrmula: EPN = ETP - PP.

3.2.8.1. Critérios de avaliação das plântulas

Foram adotados para avaliação de plântulas de tomate, através do Método Agroflora, os critérios descritos a seguir.

\subsection{Plântula Normal}

Cotilédones: ambos fixos; completamente expandidos (desenvolvidos); verdes; com pouco ou nenhum dano; inclui plântulas com três folhas cotiledonares.

Hipocótilo: ereto, curto, sem fendas (rachaduras) ou lesões

Epicótilo: presente; com a primeira folha verdadeira expandindo

Raiz: presente, mas não visivel.

\subsection{Plântula Normal Fraca}

Cotilédones: no minimo um (ou ambos), mas não expandido; totalmente presos pelo tegumento; verdes; com algum dano $(\leq 50 \%$ da possivel superficie cotiledonar)

Hipocótilo: ereto; curto ou levemente alongado; sem fendas ou lesōes. 
Epicótilo: presente; primeira folha verdadeira visivel, mas ainda não desenvolvida.

Raiz: presente, mas não visível.

3.2.8.1.3. Plântula Anormal

Cotilédones: ausentes ("cotilédone cego"); brancos ou amarelados; danificados ( $\geq 50 \%$ da possivel superficie cotiledonar).

Hipocótilo: encurvado; fendido; cortado; estiolado ou com aparência transparente.

Epicótilo: faltando.

Raiz: ausente ou presente acima da superficie do solo.

Na Figura 1, estão ilustrados os critérios descritos anteriormente. 


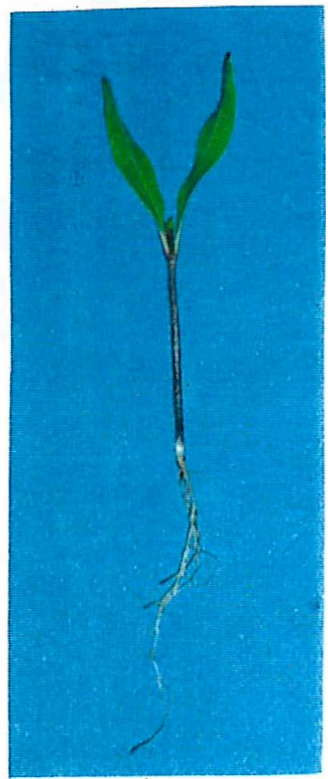

$\mathbf{N}_{\mathbf{A}}$

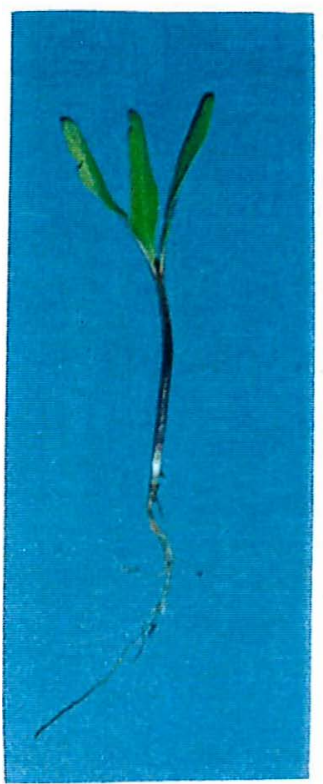

$\mathbf{N}_{\mathbf{B}}$

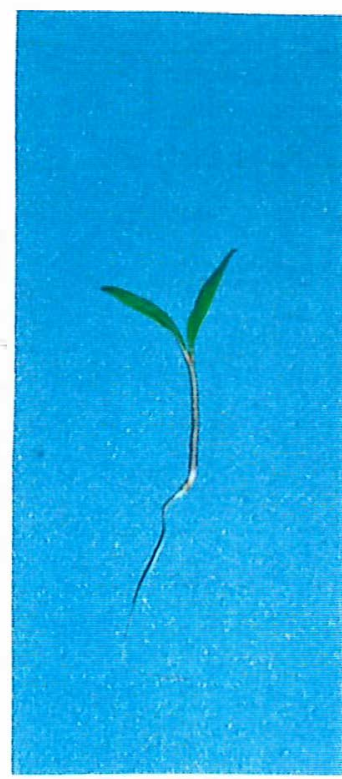

$\mathbf{F}_{\mathrm{A}}$

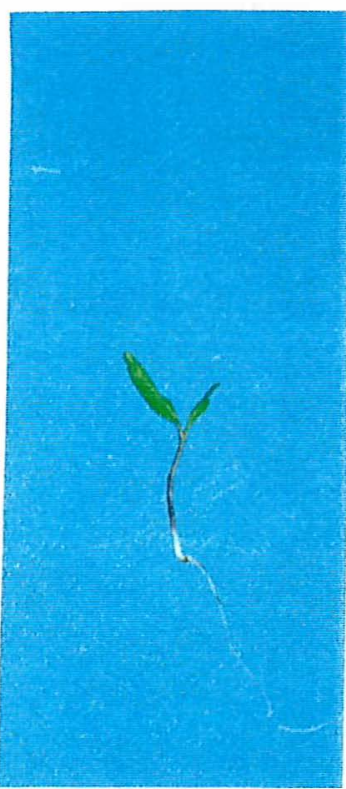

$\mathbf{F}_{\mathbf{D}}$

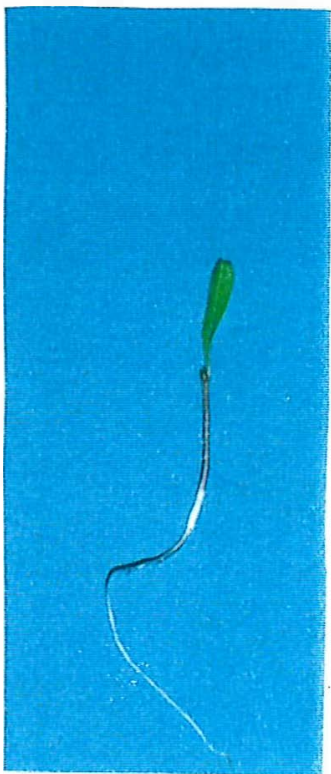

$F_{B}$

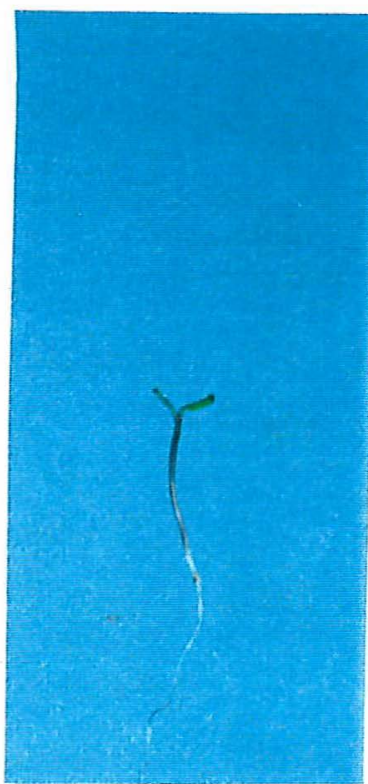

$\mathbf{A}_{\mathbf{A}}$

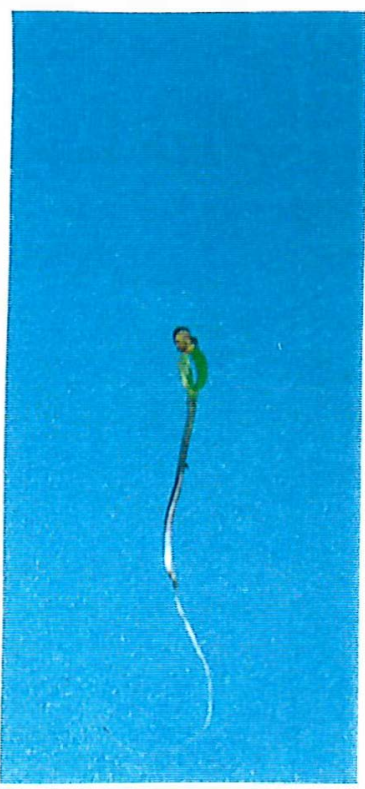

Fc

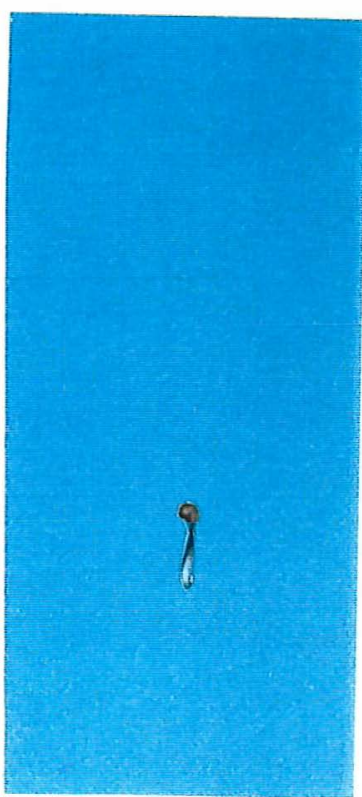

$A_{B}$

Figura 1. Critérios de avaliação de plântulas de tomate pelo Método Agroflora: $\mathrm{N}_{\mathrm{A}}$ (Normal); $\mathrm{F}_{\mathrm{A}}$ (Fraca); $\mathrm{F}_{\mathrm{B}}$ (Fraca/um cotilédone); $\mathrm{F}_{\mathrm{C}}$ (Fraca/cotilédones presos pelo tegumento); $\mathrm{N}_{\mathrm{B}}$ (Normal/tricotiledonar); $\quad \mathrm{F}_{\mathrm{D}} \quad$ (Fraca/dano $\left.\leq 50 \%\right) ; \quad \mathrm{A}_{\mathrm{A}}$ (Anormal/dano $\geq 50 \%$ ) e $A_{B}$ (Anormal/"cotilédone cego"). 


\subsubsection{Emergência de plântulas em casa de vegetação}

Para realização do teste foram utilizadas quatro repetições de 50 sementes semeadas em bandejas de poliestireno ("isopor") com células individuais, contendo substrato comercial obtido pela mistura de casca de pinus, vermiculita e fertilizante, com a seguinte composição: $57,16 \%$ de água; $25,28 \%$ de matéria orgânica e $17,56 \%$ de resíduo mineral $(12,74 \%$ de resíduo mineral insolúvel; $1,98 \%$ de carbono mineral; $0,28 \%$ de $\mathrm{N} ; 0,10 \%$ de $\mathrm{P}_{2} \mathrm{O}_{5} ; 0,40 \%$ de $\mathrm{K}_{2} \mathrm{O} ; 0,70 \%$ de Ca; 0,48\% de $\mathrm{Mg} ; 0,05 \%$ de $\mathrm{S} ; 0,0023 \%$ de $\mathrm{Cu} ; 0,6994 \%$ de $\mathrm{Fe} ; 0,0354 \%$ de $\mathrm{Mn} ; 0,0025 \%$ de $\mathrm{Zn}$ e $0,0925 \%$ de $\mathrm{Na}$ ). As bandejas foram mantidas a $25^{\circ} \mathrm{C}$, em estufa dotada de sistema de nebulização intermitente. As avaliações foram realizadas aos 14 dias após a semeadura, através da contagem de plântulas emergidas com tamanho igual ou superior a 1,0 cm.

\subsubsection{Procedimento estatistico (Etapa 1)}

Os dados provenientes dos testes de germinação, emergência de plântulas em casa de vegetação, envelhecimento acelerado, deterioração controlada e Método Agroflora foram transformados em arc sen $\sqrt{x / 100}$, enquanto que os de condutividade elétrica e de lixiviação de potássio não sofreram transformação.

Os resultados obtidos no teste de condutividade elétrica foram analisados utilizando-se delineamento inteiramente casualizado em arranjo fatorial (tratamentos $\mathrm{x}$ lotes), com três repetições, segundo os esquemas apresentados nas Tabelas 1, 2, 3 e 4 . Os tratamentos 
constaram da combinação entre quantidade de água e periodo de embebição, analisando o fator temperatura separadamente.

Tabela 1. Esquema de análise da variância do teste de condutividade elétrica (Etapa 1) para cada híbrido e temperatura de embebição, utilizando-se o número de 50 sementes (item 3.2.3.1).

\begin{tabular}{cc}
\hline Causas de variação & Graus de Liberdade \\
\hline Tratamentos & 35 \\
Lotes & 4 \\
Tratamentos x Lotes & 140 \\
Residuo & 360 \\
\hline Total & 539 \\
\hline
\end{tabular}

Tabela 2. Esquema de análise da variância do teste de condutividade elétrica (Etapa 1) para cada híbrido, utilizando-se a temperatura de $25^{\circ} \mathrm{C}$ e os números de 25 e 50 sementes (itens 3.2.3.2 e 3.2.3.3, respectivamente).

\begin{tabular}{cc}
\hline Causas de variação & Graus de Liberdade \\
\hline Tratamentos & 4 \\
Lotes & 4 \\
Tratamentos x Lotes & 16 \\
Residuo & 50 \\
\hline Total & 74 \\
\hline
\end{tabular}


Tabela 3. Esquema de análise da variância do teste de condutividade elétrica (Etapa 1) para cada híbrido, utilizando-se a temperatura de $30^{\circ} \mathrm{C}$ e o número de 25 sementes (item 3.2.3.2).

\begin{tabular}{cc}
\hline Causas de variação & Graus de Liberdade \\
\hline Tratamentos & 5 \\
Lotes & 4 \\
Tratamentos x Lotes & 20 \\
Residuo & 60 \\
\hline Total & 89 \\
\hline
\end{tabular}

Os resultados obtidos nos testes de germinação e de lixiviação de potássio foram analisados utilizando-se delineamento inteiramente casualizado, com três repetições, segundo esquema apresentado na Tabela 4.

Tabela 4. Esquema de análise da variância dos testes de germinação e de lixiviação de potássio para cada híbrido, na Etapa 1.

\begin{tabular}{cc}
\hline Causas de variação & Graus de Liberdade \\
\hline Lotes & 4 \\
Resíduo & 10 \\
\hline Total & 14 \\
\hline
\end{tabular}

Os dados provenientes dos testes de emergência de plântulas em casa de vegetação e Método Agroflora foram analisados utilizando-se delineamento inteiramente casualizado, com quatro repetições, segundo esquema apresentado na Tabela 5. 
Tabela 5. Esquema de anâlise da variância do teste de emergência de plântulas e do Método Agroflora para cada híbrido, na Etapa 1.

\begin{tabular}{cc}
\hline Causas de variação & Graus de Liberdade \\
\hline Lotes & 4 \\
Resíduo & 15 \\
\hline Total & 19 \\
\hline
\end{tabular}

Os resultados obtidos no teste de envelhecimento acelerado (procedimento tradicional e com solução salina) foram analisados utilizando-se delineamento inteiramente casualizado em arranjo fatorial (tratamentos $\mathrm{x}$ lotes), com três repetiçōes. Os tratamentos constaram da combinação entre temperatura e periodo de envelhecimento, da seguinte maneira: preliminarmente, totalizaram seis tratamentos $(2 \times 3)$ e, após, identificação das melhores combinações, quatro tratamentos (2 $\times 2)$, segundo esquemas apresentados nas Tabelas 6 e 7 , respectivamente.

Tabela 6. Esquema de anâlise da variância do teste de envelhecimento acelerado (procedimento tradicional e com solução salina) para cada hibrido, preliminarmente, na Etapa 1.

\begin{tabular}{cc}
\hline Causas de variação & Graus de Liberdade \\
\hline Tratamentos & 5 \\
Lotes & 4 \\
Tratamentos x Lotes & 20 \\
Resíduo & 60 \\
\hline Total & 89 \\
\hline
\end{tabular}


Tabela 7. Esquema de análise da variância do teste de envelhecimento acelerado (procedimento tradicional e com solução salina) para cada hibrido, após identificação das melhores combinações, na Etapa 1.

\begin{tabular}{cc}
\hline Causas de variação & Graus de Liberdade \\
\hline Tratamentos & 3 \\
Lotes & 4 \\
Tratamentos x Lotes & 12 \\
Residuo & 40 \\
\hline Total & 59 \\
\hline
\end{tabular}

Com relação ao teste de deterioração controlada, os dados obtidos foram analisados utilizando-se delineamento inteiramente casualizado em arranjo fatorial (tratamentos $\mathrm{x}$ lotes), com três repetições. Preliminarmente, os tratamentos constaram da combinação entre grau de umidade e periodo em banho-maria, totalizando seis tratamentos (2 × 3); após identificação das melhores combinações, foram constituidos por dois tratamentos, segundo esquemas apresentados nas Tabelas 8 e 9 , respectivamente. 
Tabela 8. Esquema de análise da variância do teste de deterioração controlada para cada híbrido, preliminarmente, na Etapa 1.

\begin{tabular}{cc}
\hline Causas de variação & Graus de Liberdade \\
\hline Tratamentos & 5 \\
Lotes & 4 \\
Tratamentos x Lotes & 20 \\
Resíduo & 60 \\
\hline Total & 89 \\
\hline
\end{tabular}

Tabela 9. Esquema de análise da variância do teste de deterioração controlada para cada híbrido, após identificação das melhores combinações, na Etapa 1.

\begin{tabular}{cc}
\hline Causas de variação & Graus de Liberdade \\
\hline Tratamentos & 1 \\
Lotes & 4 \\
Tratamentos x Lotes & 4 \\
Residuo & 20 \\
\hline Total & 29
\end{tabular}

Para comparação múltipla de médias foi utilizado o teste de Tukey, a 5\% de probabilidade. Os cálculos estatísticos foram realizados através do "Sistema de Análise Estatística - SANEST" (Zonta \& Machado, 1984). 


\subsection{Comparação entre testes para avaliação do potencial fisiológico das sementes (ETAPA 2)}

Os procedimentos já mencionados como mais promissores, durante a primeira etapa de estudos da metodologia dos testes de condutividade elétrica, lixiviação de potássio, envelhecimento acelerado e deterioração controlada, foram avaliados comparativamente, constituindo a segunda etapa da pesquisa. Cabe ressaltar que foram utilizados os mesmos lotes empregados na primeira fase.

\subsubsection{Determinação do gran de umidade}

Foi adotado o mesmo procedimento descrito no item 3.2.1.

\subsubsection{Teste de germinação}

Foi adotado o mesmo procedimento descrito no item 3.2.2.

\subsubsection{Condutividade elétrica}

Utilizaram-se três repetições de 50 sementes para cada lote, pesadas com precisão de 0,0001g e colocadas para embeber em copos plásticos contendo $25 \mathrm{ml}$ de água destilada, mantidos em germinador a $25^{\circ} \mathrm{C}$, durante os periodos de 6 e $24 \mathrm{~h}$ de embebição.

Decorrido cada periodo, a condutividade elétrica da solução foi determinada através de leitura em condutivimetro DIGIMED DM-31 e os 
valores médios obtidos para cada lote foram expressos em $\mu \mathrm{mho} / \mathrm{cm} / \mathrm{g}$ de semente.

\subsubsection{Lixiviação de potássio}

Nesta avaliação foram utilizadas três repetições de 100 sementes para cada lote, pesadas com precisão de 0,0001 e colocadas para embeber em copos plásticos contendo $25 \mathrm{ml}$ de água destilada, mantidos em germinador a $30^{\circ} \mathrm{C}$, durante $3 \mathrm{~h}$ de embebição.

As leituras do potássio lixiviado das sementes foram feitas em fotômetro de chama DIGIMED NK-2004, inicialmente calibrado com o padrāo 5 ppm de potássio para leitura 50 , seguindo-se os procedimentos adotados no item 3.2.4. Os resultados obtidos foram expressos em ppm de potássio/g de semente.

\subsubsection{Envelhecimento acelerado (procedimento tradicional)}

O teste foi conduzido com a utilização de caixas plásticas (11,0 x 11,0 × 3,5cm) como compartimento individual (mini-câmaras), possuindo em seu interior uma bandeja de tela de aluminio, onde as sementes, após pesagem (aproximadamente 3,0g), foram distribuídas de maneira a formarem camada simples; no interior de cada compartimento individual foram adicionados $40 \mathrm{ml}$ de água. As caixas, tampadas, foram mantidas em incubadora, a $41^{\circ} \mathrm{C}$, durante $72 \mathrm{~h}$; em seguida, foi efetuado o teste de germinação, conforme descrito no item 3.2.2, avaliando-se a percentagem de plântulas normais no sétimo dia após a semeadura. Foi determinado, também, o grau de umidade das 
sementes antes e após o periodo de envelhecimento, visando avaliação da uniformidade das condiçōes do teste.

\subsubsection{Envelhecimento acelerado (solução saturada de sal)}

Foram utilizadas caixas plásticas como compartimento individual, sendo as sementes de cada lote, após pesagem (aproximadamente $3,0 \mathrm{~g}$ ), colocadas sobre a tela de aluminio interna da caixa, de maneira a formarem camada simples. As caixas, tampadas e contendo $40 \mathrm{ml}$ de solução saturada de $\mathrm{NaCl}$, foram mantidas em incubadora, a $41^{\circ} \mathrm{C}$, durante $72 \mathrm{~h}$.

Decorrido o periodo de envelhecimento, três amostras de 50 sementes por lote foram colocadas para germinar conforme descrito no item 3.2.2. Foi determinado, também, o grau de umidade das sementes antes e após o periodo de envelhecimento.

\subsubsection{Deterioração controlada}

Inicialmente, foi elevado o grau de umidade das sementes para $24 \%$ de água, através do método descrito no item 3.2.7.

Uma vez obtido o grau de umidade desejado, cada amostra foi colocada em recipiente de folha de aluminio, fechado hermeticamente, permanecendo por cinco dias em câmara fria $\left(8-10^{\circ} \mathrm{C}\right)$ para atingir o equilibrio higroscópico. Em seguida, as sementes foram mantidas em banho-maria, a $45^{\circ} \mathrm{C}$, durante $24 \mathrm{~h}$. Posteriormente, os recipientes foram imersos rapidamente em água fria para reduzir a temperatura, sendo instalado em seguida o teste de germinação (Powell, 1995). As 
interpretaçōes do teste foram efetuadas aos 7 dias após a semeadura, computando-se as percentagens de plântulas normais. Foi determinado, também, o grau de umidade das sementes após o periodo em banhomaria.

3.3.8. Método Agroflora para avaliação de vigor em tomate

Esta avaliação foi conduzida do mesmo modo descrito no item 3.2.8, sendo realizada em outubro/1999.

\subsubsection{Emergência de plântulas em casa de vegetação}

Foi adotado o mesmo procedimento descrito no item 3.2.9.

\subsubsection{Determinaçōes complementares}

\subsubsection{Lixiviação de sódio}

Esta avaliação foi conduzida com três repetições de 100 sementes para cada lote, pesadas com precisão de $0,0001 \mathrm{~g}$ e colocadas para embeber em copos plásticos contendo $25 \mathrm{ml}$ de água destilada, a $30^{\circ} \mathrm{C}$. As leituras do sódio lixiviado das sementes foram realizadas após 3h de embebição, em fotômetro de chama DIGIMED NK-2004, sendo os resultados obtidos expressos em ppm de sódio/g de semente.

Para calibração do aparelho foram utilizadas duas curvas: padrão 30 ppm de sódio ajustado para leitura 50 (avaliação de lixiviação 
de sódio das sementes do lote 1 , híbrido Debora Plus) e padrão $5 \mathrm{ppm}$ de sódio ajustado para leitura 50 (avaliação das sementes dos demais lotes).

Foi adotado o mesmo procedimento do item 3.2.4 para o estabelecimento das curvas de calibração do fotômetro, sendo que os padrōes utilizados apresentaram linearidade com alto coeficiente de determinação: $R^{2}=0,9995$ (padrão $30 \mathrm{ppm} \mathrm{Na/leitura} \mathrm{50)} \mathrm{e} R^{2}=0,9815$ (padrão 5 ppm Na/leitura 50), estando adequados para determinação do sódio lixiviado de sementes de tomate.

Os fatores de correção para cada leitura foram obtidos através das equaçōes: $Y=0,5997 x$ (padrão $30 \mathrm{ppm} \mathrm{Na/leitura} \mathrm{50)} \mathrm{e} Y=0,0984 x$ (padrão $5 \mathrm{ppm} \mathrm{Na/leitura} \mathrm{50),} \mathrm{onde} \mathrm{x}=$ leitura obtida e $\mathrm{Y}=\mathrm{ppm} \mathrm{Na} / \mathrm{ml}$ da amostra. Como foram adicionados $25 \mathrm{ml}$ de água por repetição, multiplicou-se o valor de $\mathrm{Y}$ por 25. Os resultados obtidos foram expressos em ppm de sódio/g de semente. Os seguintes cálculos foram efetuados para obtenção da quantidade de $\mathrm{Na}$ no teste de lixiviação:

$\mathrm{ppm} \mathrm{Na/ml} \mathrm{da} \mathrm{amostra} \times 25 \mathrm{ml}=\mathrm{ppm} \mathrm{Na} /$ repetição

ppm $\mathrm{Na} /$ repetição $\div$ peso das sementes $=\mathrm{ppm} \mathrm{Na/g}$

\subsubsection{Composição química das sementes}

Esta análise foi realizada no Depto. de Solos e Nutrição de Plantas da Escola Superior de Agricultura "Luiz de Queiroz". Foram 
utilizadas $10 \mathrm{~g}$ de sementes por lote e a determinação seguiu o método analitico descrito por Sarruge \& Haag (1974), exceto para o nitrogênio, que foi determinado seguindo metodologia descrita por Tedesco et al. (1995).

\subsubsection{Composição quimica do exsudato das sementes}

A análise foi realizada no Departamento. de Solos e Nutrição de Plantas da Escola Superior de Agricultura "Luiz de Queiroz". Foram utilizados $25 \mathrm{ml}$ de exsudato de sementes por lote, obtidos após a embebição de 100 sementes em $25 \mathrm{ml}$ de água destilada, durante $3 \mathrm{~h}$, a $30^{\circ} \mathrm{C}$. A determinação seguiu o método analítico descrito por Sarruge 8 Haag (1974).

\subsubsection{Morfologia da semente}

Utilizando-se o microscópio eletrônico de varredura Jeol JSM5410 foi observada a morfologia das sementes dos cincos lotes de tomate, hibrido Debora Plus. As amostras foram aderidas aos suportes e metalizadas, sendo em seguida examinadas e fotografadas (Santos, 1996).

\subsubsection{Procedimento estatistico (Etapa 2)}

Todos os dados obtidos nesta etapa foram analisados utilizando-se delineamento inteiramente casualizado, segundo esquemas apresentados nas Tabelas 10 e 11. 
Tabela 10. Esquema de análise da variância dos dados de germinação, condutividade elétrica, envelhecimento acelerado, deterioração controlada, lixiviação de potássio e lixiviação de sódio, para cada híbrido, na Etapa 2.

\begin{tabular}{cc}
\hline Causas de variação & Graus de Liberdade \\
\hline Lotes & 4 \\
Resíduo & 10 \\
\hline Total & 14 \\
\hline
\end{tabular}

Tabela 11. Esquema de análise da variância dos dados de emergência de plântulas e Método Agroflora, para cada híbrido, na Etapa 2.

\begin{tabular}{cc}
\hline Causas de variação & Graus de Liberdade \\
\hline Lotes & 4 \\
Resíduo & 15 \\
\hline Total & 19 \\
\hline
\end{tabular}

Os dados provenientes dos testes de germinação, emergência de plântulas, envelhecimento acelerado, deterioração controlada e Método Agroflora foram transformados em arc sen $\sqrt{x / 100}$, enquanto que os de condutividade elétrica, de lixiviação de potássio e de lixiviação de sódio não sofreram transformação.

Para comparação múltipla de médias foi utilizado o teste de Tukey, a 5\% de probabilidade. Os cálculos estatísticos foram realizados através do "Sistema de Análise Estatística - SANEST" (Zonta \& Machado, 1984). 


\section{RESULTADOS E discUSSÃo}

4.1. Etapa 1 - Estudo preliminar de procedimentos alternativos para condução dos testes de condutividade elétrica, lixiviação de potássio, envelhecimento acelerado e deterioração controlada.

\subsubsection{Avaliação inicial da qualidade dos lotes}

\subsubsection{Hibrido Debora Plus}

Observando-se os dados referentes ao híbrido Debora Plus, apresentados na Tabela 12, constatou-se que houve separação dos lotes em diferentes níveis de potencial fisiológico.

$O$ teste de germinação revelou o melhor desempenho dos lotes 1 e 2, em relação aos lotes 3 , 4 e 5 . Pelos resultados de emergência de plântulas em casa de vegetação pode-se notar que os lotes 1 e 2 , não diferentes entre si, foram superiores aos lotes 4 e 5; em contrapartida, o lote 4 apresentou menor percentagem de emergência, não diferindo significativamente do lote 5 , enquanto que para o lote 3 foi encontrado valor intermediário. Vale ressaltar, que a percentagem de germinação geralmente superou a de emergência das plântulas. 
Tabela 12. Valores médios de grau de umidade, germinação, emergência em casa de vegetação e método Agroflora de sementes de cinco lotes de tomate, híbrido Debora Plus.

\begin{tabular}{ccccc}
\hline $\begin{array}{c}\text { Debora } \\
\text { Plus }\end{array}$ & $\begin{array}{c}\text { Grau de } \\
\text { umidade }\end{array}$ & Germinação & $\begin{array}{c}\text { Emergência } \\
\text { de Plântulas }\end{array}$ & $\begin{array}{c}\text { Método } \\
\text { Agroflora }\end{array}$ \\
\hline Lotes & $\ldots \ldots \ldots \ldots \ldots \ldots \ldots \ldots \ldots \ldots \ldots \ldots \ldots \ldots \ldots \ldots \ldots \ldots \ldots \ldots \ldots \ldots \ldots \ldots \ldots \ldots \ldots \ldots \ldots \ldots \ldots \ldots \ldots \ldots \ldots$ \\
1 & 8,6 & $97 \mathrm{a}^{*}$ & $97 \mathrm{a}$ & $84 \mathrm{ab}$ \\
2 & 8,1 & $97 \mathrm{a}$ & $92 \mathrm{ab}$ & $88 \mathrm{a}$ \\
3 & 8,3 & $88 \mathrm{~b}$ & $86 \mathrm{bc}$ & $74 \mathrm{bc}$ \\
4 & 8,4 & $85 \mathrm{~b}$ & $73 \mathrm{~d}$ & $66 \mathrm{c}$ \\
5 & 8,4 & $86 \mathrm{~b}$ & $80 \mathrm{~cd}$ & $65 \mathrm{c}$ \\
\hline C.V. (\%) & - & 3,42 & 5,26 & 6,81 \\
\hline
\end{tabular}

*Comparação de médias em cada coluna, pelo teste de Tukey a $5 \%$ de probabilidade.

O método Agroflora para avaliação do vigor de sementes de tomate classificou os lotes de maneira semelhante à emergência das plântulas, apontando o melhor desempenho dos lotes 1 e 2 e o pior desempenho dos lotes 4 e 5 , sendo o lote 3 considerado como de qualidade intermediária.

Assim, de modo geral, os resultados da Tabela 12 indicaram uma tendência da maioria dos testes em destacar os lotes 1 e 2 como de potencial fisiológico superior, os lotes 4 e 5 como inferior, ficando o lote 3 entre esses extremos.

Os dados referentes ao grau de umidade das sementes foram semelhantes para os cinco lotes estudados; este fato é importante na execução dos testes, uma vez que a uniformização do grau de umidade das sementes é fundamental para a padronização das avaliações e 
obtenção de resultados consistentes (Marcos Filho et al., 1987 e Loeffler et al., 1988).

\subsubsection{Hibrido Bruna}

Os dados obtidos para grau de umidade, germinação, emergência de plântulas em casa de vegetação e método Agroflora, hibrido Bruna, encontram-se na Tabela 13.

Tabela 13. Valores médios de grau de umidade, germinação, emergência de plântulas em casa de vegetação e método Agroflora de sementes de cinco lotes de tomate, hibrido Bruna.

\begin{tabular}{ccccc}
\hline Bruna & $\begin{array}{c}\text { Grau de } \\
\text { umidade }\end{array}$ & Germinação & $\begin{array}{c}\text { Emergência } \\
\text { de Plântulas }\end{array}$ & $\begin{array}{c}\text { Método } \\
\text { Agroflora }\end{array}$ \\
\hline Lotes & $\ldots \ldots \ldots \ldots \ldots \ldots \ldots \ldots \ldots \ldots \ldots \ldots \ldots \ldots \ldots \ldots \ldots \ldots \ldots \ldots \ldots \ldots \ldots \ldots \ldots \ldots \ldots \ldots \ldots \ldots \ldots \ldots \ldots$ \\
1 & 8,4 & $97 \mathrm{a}^{*}$ & $94 \mathrm{a}$ & $80 \mathrm{a}$ \\
2 & 8,2 & $94 \mathrm{ab}$ & $89 \mathrm{ab}$ & $82 \mathrm{a}$ \\
3 & 8,2 & $85 \mathrm{c}$ & $76 \mathrm{c}$ & $63 \mathrm{~b}$ \\
4 & 8,3 & $94 \mathrm{ab}$ & $93 \mathrm{a}$ & $79 \mathrm{a}$ \\
5 & 8,3 & $88 \mathrm{bc}$ & $78 \mathrm{bc}$ & $73 \mathrm{ab}$ \\
\hline C.V. (\%) & - & 3,60 & 5,95 & 6,94
\end{tabular}

*Comparação de médias em cada coluna, pelo teste de Tukey a $5 \%$ de probabilidade.

O grau de umidade das sementes foi semelhante para todos os lotes, da mesma maneira relatada para o hibrido Debora Plus. 
Em termos de germinação, o lote 1 mostrou-se superior, apesar de estatisticamente semelhante aos lotes 2 e 4, que não diferiram do lote 5. Este, por sua vez, foi significativamente semelhante ao lote 3 , de poder germinativo mais baixo.

$O$ teste de emergência em casa de vegetação promoveu separação semelhante ao de germinação. Os lotes 1 e 4 revelaram-se como de melhor qualidade, apesar de estatisticamente semelhantes ao lote 2, o qual não diferiu do lote 5; este, por sua vez, foi significativamente semelhante ao lote 3 , revelado como o de pior desempenho. Vale destacar que, também para o híbrido Bruna, o teste de germinação apresentou maior percentagem de plântulas normais que o de emergência.

O método Agroflora identificou os lotes 1,2 e 4 como de potencial fisiológico superior, embora não diferindo do lote 5 , que mostrou-se semelhante ao lote 3 , apontado como o de pior desempenho.

A análise comparativa dos dados indicou que, de uma maneira geral, os resultados de germinação, emergência em casa de vegetação e método Agroflora foram semelhantes em termos de ordenação dos lotes, classificando os lotes 1, 2 e 4 como de qualidade mais alta e, o lote 3, como de mais baixa, identificando o lote 5 como de nivel intermediário de qualidade.

Assim, podem-se observar diferenças no potencial fisiológico entre os lotes, dos dois hibridos, suficientes para permitir o estudo proposto. Todos os lotes apresentaram germinação superior a $80 \%$, estando situados, portanto, na Fase I da curva de perda de viabilidade da semente (Powell, 1986). 


\subsubsection{Condutividade elétrica - CE I}

Nesta fase de estudo do teste foram utilizadas duas temperaturas, variando a quantidade de água $e$ mantendo fixo o número de sementes.

\subsubsection{Hibrido Debora Plus}

Os dados obtidos para condutividade elétrica, empregando-se a metodologia de 50 sementes por repetição, embebidas em $75 \mathrm{ml}$ de água, a $25^{\circ} \mathrm{C}$ e $30^{\circ} \mathrm{C}$, encontram-se, respectivamente, nas Tabelas $14 \mathrm{e}$ 15.

Nas duas temperaturas estudadas, observou-se aumento na quantidade de eletrólitos liberados pelas sementes como o decorrer da embebição, fato também constatado por outros autores para a mesma espécie (Rodo et al., 1998 e Sá, 1999). De modo geral, com exceção do lote 1 , foi constatada maior lixiviação de exsudatos a $30^{\circ} \mathrm{C}$ que a $25^{\circ} \mathrm{C}$, a partir de 6 horas de condicionamento. A maior temperatura de embebição provoca o aumento da energia de ativação das moléculas, alterando a viscosidade da água e, consequentemente, elevando os valores de condutividade (Murphy \& Noland, 1982).

Examinando os resultados obtidos com a combinação 50 sementes $/ 75 \mathrm{ml} / 25^{\circ} \mathrm{C}$ (Tabela 14), verificou-se que todos os periodos de embebição estudados forneceram informaçōes semelhantes, indicando a inferioridade do lote 1 em relação aos demais. O mesmo ocorreu quando foi utilizada a combinação 50 sementes $/ 75 \mathrm{ml} / 30^{\circ} \mathrm{C}$ (Tabela 15). 
Tabela 14. Dados médios obtidos para o teste de condutividade elétrica de sementes de cinco lotes de tomate, hibrido Debora Plus, após vários periodos de embebição, utilizando-se a combinação 50 sementes por repetição, $75 \mathrm{ml}$ de água e $25^{\circ} \mathrm{C}$ (CE I).

\begin{tabular}{|c|c|c|c|c|c|c|}
\hline \multirow{2}{*}{$\begin{array}{c}\text { Debora } \\
\text { Plus }\end{array}$} & \multicolumn{6}{|c|}{ Periodos de embebição } \\
\hline & 30min & $1 \mathrm{~h}$ & 1h $30 \mathrm{~min}$ & $2 \mathrm{~h}$ & $3 \mathrm{~h}$ & $4 \mathrm{~h}$ \\
\hline Lotes & \multicolumn{6}{|c|}{ 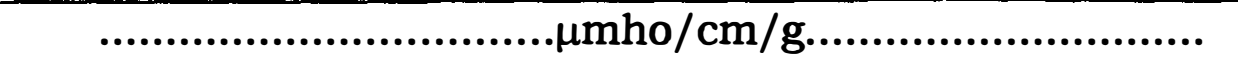 } \\
\hline 1 & $161,0 b^{*}$ & $174,4 b$ & $178,1 \mathrm{~b}$ & $181,8 b$ & $185,5 b$ & $188,5 b$ \\
\hline 2 & $13,1 \mathrm{a}$ & $14,2 \mathrm{a}$ & $14,6 a$ & $15,1 \mathrm{a}$ & $16,4 a$ & $17,1 \mathrm{a}$ \\
\hline 3 & $14,0 \mathrm{a}$ & $14,9 a$ & $15,4 a$ & $15,6 a$ & $17,1 \mathrm{a}$ & $18,1 \mathrm{a}$ \\
\hline 4 & $23,1 a$ & $24,2 a$ & $25,2 a$ & $26,1 a$ & $27,5 a$ & $29,5 a$ \\
\hline 5 & $15,0 a$ & $16,3 a$ & $16,8 a$ & $18,0 \mathrm{a}$ & $18,8 \mathbf{a}$ & $19,7 a$ \\
\hline Debora & \multicolumn{6}{|c|}{ Períodos de embebição } \\
\hline Plus & $6 \mathrm{~h}$ & $8 \mathrm{~h}$ & $10 \mathrm{~h}$ & $16 \mathrm{~h}$ & $20 \mathrm{~h}$ & $24 \mathrm{~h}$ \\
\hline Lotes & \multicolumn{6}{|c|}{ …............................. $\mu \mathrm{mh}$} \\
\hline 1 & $195,7 b$ & $198,9 b$ & $203,8 b$ & $211,6 b$ & $212,4 b$ & $219,5 b$ \\
\hline 2 & $17,8 \mathbf{a}$ & $19,0 \mathrm{a}$ & $19,9 a$ & $23,1 a$ & $23,2 a$ & $24,0 a$ \\
\hline 3 & $19,2 \mathrm{a}$ & $20,2 a$ & $21,0 a$ & $22,0 a$ & $22,0 a$ & $22,2 a$ \\
\hline 4 & $31,5 a$ & $33,6 a$ & $35,4 a$ & $40,2 a$ & $40,5 a$ & $46,0 a$ \\
\hline 5 & $20,6 a$ & $21,2 \mathrm{a}$ & $22,2 a$ & $22,7 a$ & $22,8 a$ & $24,4 a$ \\
\hline C.V.(\%) & 8,28 & & & & & \\
\hline
\end{tabular}

*Comparação de médias em cada coluna, pelo teste de Tukey a $5 \%$ de probabilidade. 
Tabela 15. Dados médios obtidos para o teste de condutividade elétrica de sementes de cinco lotes de tomate, hibrido Debora Plus, após vários periodos de embebição, utilizando-se a combinação 50 sementes por repetição, $75 \mathrm{ml}$ de água e $30^{\circ} \mathrm{C}$ (CE I).

\begin{tabular}{|c|c|c|c|c|c|c|}
\hline \multirow{2}{*}{$\begin{array}{c}\text { Debora } \\
\text { Plus }\end{array}$} & \multicolumn{6}{|c|}{ Períodos de embebição } \\
\hline & $30 \mathrm{~min}$ & $1 \mathrm{~h}$ & 1h 30min & $2 \mathrm{~h}$ & $3 \mathrm{~h}$ & $4 \mathrm{~h}$ \\
\hline Lotes & \multicolumn{6}{|c|}{ 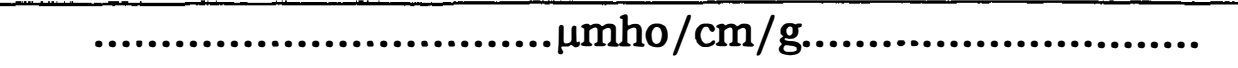 } \\
\hline 1 & $147,7 b^{*}$ & $153,2 b$ & $156,0 \mathrm{~b}$ & $157,5 b$ & $162,0 \mathrm{~b}$ & $165,2 b$ \\
\hline 2 & $13,8 \mathrm{a}$ & $14,6 a$ & $15,7 a$ & $16,2 \mathrm{a}$ & $17,3 a$ & $19,8 a$ \\
\hline 3 & $13,7 a$ & $14,7 a$ & $15,3 a$ & $16,1 \mathrm{a}$ & $17,2 a$ & $17,9 a$ \\
\hline 4 & $22,0 a$ & $23,4 a$ & $25,0 \mathrm{a}$ & $26,2 a$ & $27,7 a$ & $28,8 a$ \\
\hline 5 & $14,4 a$ & $15,1 \mathrm{a}$ & $16,3 a$ & $17,2 \mathrm{a}$ & $18,3 a$ & $18,9 a$ \\
\hline Debora & \multicolumn{6}{|c|}{ Períodos de embebição } \\
\hline Plus & $6 \mathrm{~h}$ & $8 \mathrm{~h}$ & $10 \mathrm{~h}$ & $16 \mathrm{~h}$ & $20 \mathrm{~h}$ & $24 \mathrm{~h}$ \\
\hline Lotes & \multicolumn{6}{|c|}{ 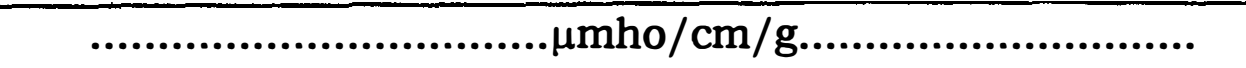 } \\
\hline 1 & $171,5 b$ & $175,6 \mathrm{~b}$ & $180,0 \mathrm{~b}$ & $183,0 b$ & $183,3 b$ & $185,7 \mathrm{~b}$ \\
\hline 2 & $19,9 \mathrm{a}$ & $20,7 a$ & $21,8 a$ & $23,3 a$ & $23,5 a$ & $24,5 a$ \\
\hline 3 & $19,5 a$ & $20,1 a$ & $21,4 a$ & $22,6 a$ & $22,9 a$ & $23,2 a$ \\
\hline 4 & $31,9 a$ & $34,3 a$ & $36,6 a$ & $43,1 \mathrm{a}$ & $43,3 a$ & $46,6 a$ \\
\hline 5 & $20,9 a$ & $21,8 a$ & $22,5 a$ & $29,5 a$ & $29,6 a$ & $30,0 a$ \\
\hline
\end{tabular}

\section{C.V.(\%) 9,06}

${ }^{*}$ Comparação de médias em cada coluna, pelo teste de Tukey a $5 \%$ de probabilidade. 
Assim, constatou-se que ambos os procedimentos de condutividade estudados indicaram o lote 1 como de baixa qualidade e, os demais, como de qualidade superior, desde os primeiros 30 minutos de embebição. Vale ressaltar o comportamento diferenciado do lote 1 no teste de condutividade elétrica, uma vez que o mesmo foi classificado como de potencial fisiológico elevado nos testes de germinação, emergência de plântulas em casa de vegetação e método Agroflora (Tabela 12).

Os dados obtidos para o teste de condutividade elétrica, hạbrido Debora Plus, usando-se a combinação 50 sementes por repetição, embebidas em $50 \mathrm{ml}$ de água, a $25^{\circ} \mathrm{C}$ e $30^{\circ} \mathrm{C}$, estão apresentados, respectivamente, nas Tabelas 16 e 17 .

Quanto à temperatura, observou-se maior liberação de exsudatos a $30^{\circ} \mathrm{C}$ do que a $25^{\circ} \mathrm{C}$, para todos os lotes, a partir de 8 horas de embebição. Além disso, houve aumento na quantidade de lixiviados com o decorrer do periodo de condicionamento, para as duas temperaturas utilizadas.

Com a combinação 50 sementes $/ 50 \mathrm{ml} / 25^{\circ} \mathrm{C}$ (Tabela 16) verificou-se separação mais definida dos lotes, após 24 horas de embebição. As leituras realizadas neste periodo indicaram, em geral, o melhor desempenho dos lotes 2,3 e 5 e o pior desempenho do lote 1 , sendo o lote 4 considerado como de qualidade intermediária.

A combinação 50 sementes $/ 50 \mathrm{ml} / 30^{\circ} \mathrm{C}$ (Tabela 17), por sua vez, proporcionou a classificação dos lotes em dois niveis de vigor, em todos os periodos de embebição avaliados. O lote 1 apresentou comportamento inferior aos lotes $2,3,4$ e 5, os quais não diferiram entre si. 
Tabela 16. Dados médios obtidos para o teste de condutividade elétrica de sementes de cinco lotes de tomate, híbrido Debora Plus, após vários periodos de embebição, utilizando-se a combinação 50 sementes por repetição, $50 \mathrm{ml}$ de água e $25^{\circ} \mathrm{C}$ (CE I).

\begin{tabular}{|c|c|c|c|c|c|c|}
\hline \multirow{2}{*}{$\begin{array}{c}\text { Debora } \\
\text { Plus }\end{array}$} & \multicolumn{6}{|c|}{ Períodos de embebição } \\
\hline & $30 \mathrm{~min}$ & $1 \mathrm{~h}$ & 1h $30 \mathrm{~min}$ & $2 \mathrm{~h}$ & $3 \mathrm{~h}$ & $4 \mathrm{~h}$ \\
\hline Lotes & \multicolumn{6}{|c|}{ 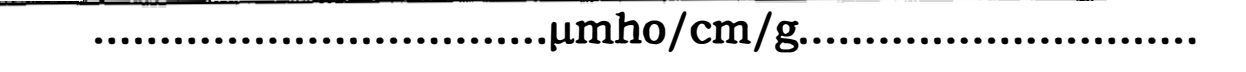 } \\
\hline 1 & $255,1 b *$ & $260,5 b$ & $262,7 \mathrm{~b}$ & $265,0 b$ & $269,2 b$ & $271,4 \mathrm{~b}$ \\
\hline 2 & $17,4 a$ & $18,6 a$ & $19,3 a$ & $19,8 \mathrm{a}$ & $21,0 a$ & $21,8 a$ \\
\hline 3 & $18,3 a$ & $19,7 a$ & $20,7 a$ & $21,0 \mathrm{a}$ & $22,6 a$ & $23,3 a$ \\
\hline 4 & $30,0 a$ & $31,7 a$ & $32,5 a$ & $33,8 \mathrm{a}$ & $35,4 a$ & $36,9 a$ \\
\hline 5 & $18,7 a$ & $20,0 a$ & $21,0 a$ & $21,5 a$ & $22,7 a$ & $23,6 a$ \\
\hline
\end{tabular}

\begin{tabular}{ccccccc}
\hline Debora & \multicolumn{5}{c}{ Periodos de embebição } \\
\cline { 2 - 7 } Plus & $6 \mathrm{~h}$ & $8 \mathrm{~h}$ & $10 \mathrm{~h}$ & $16 \mathrm{~h}$ & $20 \mathrm{~h}$ & $24 \mathrm{~h}$
\end{tabular}

\begin{tabular}{crrrrrc}
\hline Lotes & \multicolumn{2}{c}{$\ldots \ldots \ldots \ldots \ldots \ldots \ldots \ldots \ldots \ldots . . \ldots m h o / \mathrm{cm} / \mathrm{g} \ldots \ldots \ldots \ldots \ldots \ldots \ldots \ldots . . . \ldots \ldots$} \\
1 & $278,0 \mathrm{~b}$ & $279,3 \mathrm{~b}$ & $289,2 \mathrm{~b}$ & $290,7 \mathrm{~b}$ & $291,4 \mathrm{~b}$ & $333,0 \mathrm{c}$ \\
2 & $23,5 \mathrm{a}$ & $23,7 \mathrm{a}$ & $24,8 \mathrm{a}$ & $26,5 \mathrm{a}$ & $25,8 \mathrm{a}$ & $22,1 \mathrm{a}$ \\
3 & $25,4 \mathrm{a}$ & $25,9 \mathrm{a}$ & $26,5 \mathrm{a}$ & $27,3 \mathrm{a}$ & $27,3 \mathrm{a}$ & $28,0 \mathrm{ab}$ \\
4 & $40,0 \mathrm{a}$ & $41,0 \mathrm{a}$ & $41,9 \mathrm{a}$ & $46,3 \mathrm{a}$ & $49,1 \mathrm{a}$ & $50,3 \mathrm{~b}$ \\
5 & $25,4 \mathrm{a}$ & $25,7 \mathrm{a}$ & $26,8 \mathrm{a}$ & $27,4 \mathrm{a}$ & $27,7 \mathrm{a}$ & $28,0 \mathrm{ab}$
\end{tabular}

C.V.(\%) 8,28

*Comparação de médias em cada coluna, pelo teste de Tukey a $5 \%$ de probabilidade. 
Tabela 17. Dados médios obtidos para o teste de condutividade elétrica de sementes de cinco lotes de tomate, hibrido Debora Plus, após vários periodos de embebição, utilizando-se a combinação 50 sementes por repetição, $50 \mathrm{ml}$ de água e $30^{\circ} \mathrm{C}(\mathrm{CE} \mathrm{I})$.

\begin{tabular}{crrrrrr}
\hline Debora & \multicolumn{5}{c}{ Periodos de embebição } \\
\cline { 2 - 7 } Plus & 30min & $1 \mathrm{~h}$ & $1 \mathrm{~h} 30 \mathrm{~min}$ & \multicolumn{1}{c}{$2 \mathrm{~h}$} & \multicolumn{1}{c}{$3 \mathrm{~h}$} & $4 \mathrm{~h}$ \\
\hline Lotes & $\ldots \ldots \ldots \ldots \ldots \ldots \ldots \ldots \ldots \ldots . \ldots \mathrm{mho} / \mathrm{cm} / \mathrm{g} \ldots \ldots \ldots \ldots \ldots \ldots \ldots \ldots \ldots$ \\
1 & $244,1 \mathrm{~b}^{*}$ & $253,1 \mathrm{~b}$ & $256,5 \mathrm{~b}$ & $260,1 \mathrm{~b}$ & $260,8 \mathrm{~b}$ & $263,0 \mathrm{~b}$ \\
2 & $17,9 \mathrm{a}$ & $19,0 \mathrm{a}$ & $19,9 \mathrm{a}$ & $20,7 \mathrm{a}$ & $21,8 \mathrm{a}$ & $22,9 \mathrm{a}$ \\
3 & $18,2 \mathrm{a}$ & $19,8 \mathrm{a}$ & $21,1 \mathrm{a}$ & $21,9 \mathrm{a}$ & $23,5 \mathrm{a}$ & $24,3 \mathrm{a}$ \\
4 & $29,5 \mathrm{a}$ & $31,1 \mathrm{a}$ & $32,6 \mathrm{a}$ & $33,4 \mathrm{a}$ & $35,5 \mathrm{a}$ & $36,9 \mathrm{a}$ \\
5 & $20,8 \mathrm{a}$ & $22,6 \mathrm{a}$ & $24,2 \mathrm{a}$ & $25,2 \mathrm{a}$ & $27,0 \mathrm{a}$ & $27,8 \mathrm{a}$
\end{tabular}

\begin{tabular}{crrrrrr}
\hline Debora & \multicolumn{6}{c}{ Periodos de embebição } \\
\cline { 2 - 7 } Plus & \multicolumn{1}{c}{$6 \mathrm{~h}$} & \multicolumn{1}{c}{$8 \mathrm{~h}$} & $10 \mathrm{~h}$ & $16 \mathrm{~h}$ & $20 \mathrm{~h}$ & $24 \mathrm{~h}$ \\
\hline Lotes & $\ldots \ldots \ldots \ldots \ldots \ldots \ldots \ldots \ldots \ldots . \mu \mathrm{mho} / \mathrm{cm} / \mathrm{g} \ldots \ldots \ldots \ldots \ldots \ldots \ldots \ldots . \ldots \ldots \ldots$ \\
1 & $270,8 \mathrm{~b}$ & $282,8 \mathrm{~b}$ & $291,8 \mathrm{~b}$ & $320,8 \mathrm{~b}$ & $326,3 \mathrm{~b}$ & $328,4 \mathrm{~b}$ \\
2 & $25,1 \mathrm{a}$ & $25,5 \mathrm{a}$ & $26,2 \mathrm{a}$ & $28,7 \mathrm{a}$ & $29,0 \mathrm{a}$ & $31,2 \mathrm{a}$ \\
3 & $26,9 \mathrm{a}$ & $27,5 \mathrm{a}$ & $28,3 \mathrm{a}$ & $28,8 \mathrm{a}$ & $29,0 \mathrm{a}$ & $33,2 \mathrm{a}$ \\
4 & $41,1 \mathrm{a}$ & $43,1 \mathrm{a}$ & $44,8 \mathrm{a}$ & $54,3 \mathrm{a}$ & $56,6 \mathrm{a}$ & $59,3 \mathrm{a}$ \\
5 & $31,3 \mathrm{a}$ & $32,5 \mathrm{a}$ & $32,0 \mathrm{a}$ & $33,3 \mathrm{a}$ & $33,3 \mathrm{a}$ & $34,4 \mathrm{a}$ \\
& & & & & & \\
\hline C.V.(\%) & 9,06 & & & & & \\
\hline
\end{tabular}

*Comparaçāo de médias em cada coluna, pelo teste de Tukey a $5 \%$ de probabilidade. 
Pode-se observar, através da análise comparativa das combinações com o emprego dos volumes de $75 \mathrm{ml}$ e $50 \mathrm{ml}$, em ambas as temperaturas, que houve concordância em indicar o lote 1 como de potencial fisiológico inferior aos demais. Vale salientar, ainda, que com o uso do volume de $50 \mathrm{ml}$ foram obtidas leituras mais altas de condutividade elétrica em relação ao volume de $75 \mathrm{ml}$, o que já era esperado, uma vez que a embebição em um volume maior de água implica em maior diluição dos lixiviados, como observado por Loeffler (1981).

Os resultados obtidos para condutividade elétrica, híbrido Debora Plus, utilizando-se a combinação 50 sementes por repetição, embebidas em $25 \mathrm{ml}$ de água, a $25^{\circ} \mathrm{C}$ e $30^{\circ} \mathrm{C}$, estão apresentados, respectivamente, nas Tabelas 18 e 19.

Examinando a Tabela 18 observou-se que através da combinação 50 sementes $/ 25 \mathrm{ml} / 25^{\circ} \mathrm{C}$ foi possivel a ordenação dos lotes já nos primeiros 30 minutos de embebição, sendo obtida separação mais nítida em três niveis de potencial fisiológico a partir de $1 \mathrm{~h} 30$ minutos. Os lotes 2,3 e 5 mostraram valores mais baixos de condutividade elétrica (menor liberação de exsudatos), indicando que essas sementes apresentam maior vigor, enquanto o lote 1 mostrou valores mais elevados de condutividade, relacionados a sementes de qualidade inferior; o lote 4 , por sua vez, pode ser identificado como de médio vigor.

A mesma classificação dos lotes foi verificada para a combinação 50 sementes $/ 25 \mathrm{ml} / 30^{\circ} \mathrm{C}$ (Tabela 19), porém, a partir de 4 horas de embebição. As leituras realizadas após esse periodo indicaram a superioridade dos lotes 2,3 e 5 e a inferioridade do lote 1; o lote 4 revelou desempenho intermediário. 
Tabela 18. Dados médios obtidos para o teste de condutividade elétrica de sementes de cinco lotes de tomate, híbrido Debora Plus, após vários periodos de embebição, utilizando-se a combinação 50 sementes por repetição, $25 \mathrm{ml}$ de água e $25^{\circ} \mathrm{C}(\mathrm{CE} \mathrm{I})$.

\begin{tabular}{|c|c|c|c|c|c|c|}
\hline \multirow{2}{*}{$\begin{array}{c}\text { Debora } \\
\text { Plus }\end{array}$} & \multicolumn{6}{|c|}{ Períodos de embebição } \\
\hline & $30 \mathrm{~min}$ & $1 \mathrm{~h}$ & 1h $30 \mathrm{~min}$ & $2 \mathrm{~h}$ & $3 \mathrm{~h}$ & $4 \mathrm{~h}$ \\
\hline Lotes & \multicolumn{6}{|c|}{.................................. $\mu \mathrm{mh}$} \\
\hline 1 & $471,1 c^{*}$ & $490,5 c$ & $496,9 c$ & $503,2 c$ & $507,3 c$ & $513,3 c$ \\
\hline 2 & $26,0 a$ & $28,4 a$ & $31,3 a$ & $33,0 a$ & $35,5 a$ & $37,0 a$ \\
\hline 3 & $27,7 a$ & $30,5 a$ & $33,5 a$ & $35,1 \mathrm{a}$ & $37,1 a$ & $39,0 a$ \\
\hline 4 & $53,4 b$ & $56,6 b$ & $61,3 b$ & $62,9 b$ & $68,0 b$ & $71,8 b$ \\
\hline 5 & $30,6 a b$ & $33,4 a b$ & $36,6 a$ & $37,6 a$ & $39,7 a$ & $41,1 \mathrm{a}$ \\
\hline
\end{tabular}

\begin{tabular}{|c|c|c|c|c|c|c|}
\hline \multirow{2}{*}{$\begin{array}{c}\text { Debora } \\
\text { Plus }\end{array}$} & \multicolumn{6}{|c|}{ Períodos de embebição } \\
\hline & $6 \mathrm{~h}$ & $8 \mathrm{~h}$ & $10 \mathrm{~h}$ & $16 \mathrm{~h}$ & $20 \mathrm{~h}$ & $24 \mathrm{~h}$ \\
\hline Lotes & \multicolumn{6}{|c|}{ 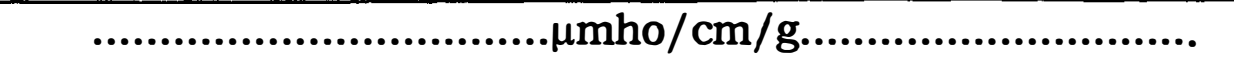 } \\
\hline 1 & $518,9 c$ & $524,2 c$ & $534,5 c$ & $545,0 \mathrm{c}$ & $547,1 c$ & $595,2 c$ \\
\hline 2 & $39,4 a$ & $40,0 a$ & $41,2 a$ & $43,4 a$ & $43,7 a$ & $45,5 a$ \\
\hline 3 & $40,2 a$ & $40,7 a$ & $41,6 a$ & $43,1 \mathrm{a}$ & $43,5 a$ & $43,6 a$ \\
\hline 4 & $75,1 b$ & $79,9 b$ & $83,0 \mathrm{~b}$ & $92,2 b$ & $103,5 b$ & $114,8 b$ \\
\hline 5 & $42,4 a$ & $43,3 a$ & $44,2 a$ & $50,7 a$ & $52,0 \mathrm{a}$ & $55,7 a$ \\
\hline C.V.(\%) & 8,28 & & & & & \\
\hline
\end{tabular}

*Comparação de médias em cada coluna, pelo teste de Tukey a $5 \%$ de probabilidade. 
Tabela 19. Dados médios obtidos para o teste de condutividade elétrica de sementes de cinco lotes de tomate, hibrido Debora Plus, após vários periodos de embebição, utilizando-se a combinação 50 sementes por repetição, $25 \mathrm{ml}$ de água e $30^{\circ} \mathrm{C}$ (CE I).

\begin{tabular}{|c|c|c|c|c|c|c|}
\hline \multirow{2}{*}{$\begin{array}{c}\text { Debora } \\
\text { Plus }\end{array}$} & \multicolumn{6}{|c|}{ Periodos de embebição } \\
\hline & $30 \mathrm{~min}$ & $1 \mathrm{~h}$ & $1 \mathrm{~h} 30 \mathrm{~min}$ & $2 \mathrm{~h}$ & $3 \mathrm{~h}$ & $4 \mathrm{~h}$ \\
\hline Lotes & \multicolumn{6}{|c|}{ 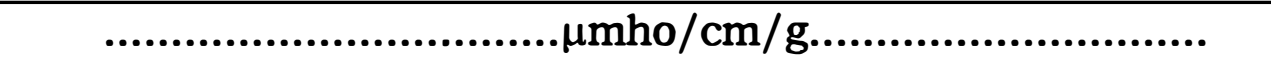 } \\
\hline 1 & $474,0 b^{*}$ & $485,2 b$ & $499,5 b$ & $502,0 b$ & $514,6 b$ & $518,2 \mathrm{c}$ \\
\hline 2 & $27,6 a$ & $28,2 a$ & $32,2 a$ & $34,0 a$ & $35,6 a$ & $36,6 a$ \\
\hline 3 & $28,7 a$ & $29,8 a$ & $33,6 a$ & $35,3 a$ & $36,6 a$ & $37,7 a b$ \\
\hline 4 & $50,5 a$ & $53,9 a$ & $60,6 a$ & $62,3 a$ & $65,1 \mathrm{a}$ & $67,3 b$ \\
\hline 5 & $33,5 a$ & $36,2 a$ & $40,3 a$ & $41,5 a$ & $43,2 a$ & $44,4 a b$ \\
\hline Debora & \multicolumn{6}{|c|}{ Periodos de embebição } \\
\hline Plus & $6 \mathrm{~h}$ & $8 \mathrm{~h}$ & $10 \mathrm{~h}$ & $16 \mathrm{~h}$ & $20 \mathrm{~h}$ & $24 \mathrm{~h}$ \\
\hline Lotes & \multicolumn{6}{|c|}{ 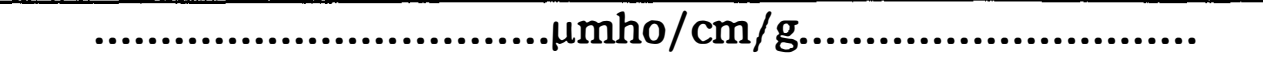 } \\
\hline 1 & $527,5 c$ & $537,7 \mathrm{c}$ & $544,9 c$ & $584,6 c$ & $603,8 c$ & $611,5 c$ \\
\hline 2 & $39,7 a$ & $40,3 a$ & $41,2 a$ & $44,5 a$ & $44,8 \mathrm{a}$ & $46,4 a$ \\
\hline 3 & $41,2 a$ & $42,4 a$ & $42,9 a$ & $46,3 a$ & $46,9 a$ & $50,3 a$ \\
\hline 4 & $78,7 \mathrm{~b}$ & $85,3 b$ & $92,0 \mathrm{~b}$ & $143,1 b$ & $148,6 b$ & $149,6 b$ \\
\hline 5 & $46,8 a$ & $48,3 a$ & $49,3 a$ & $53,7 a$ & $55,2 \mathrm{a}$ & $56,5 a$ \\
\hline C.V.(\%) & 9,06 & & & & & \\
\hline
\end{tabular}

*Comparação de médias em cada coluna, pelo teste de Tukey a $5 \%$ de probabilidade. 
Pelas Tabelas 18 e 19, verificou-se, em ambos os estudos, um aumento da quantidade de exsudatos liberados pelas sementes com o decorrer da embebição. É importante observar que após 6 horas de condicionamento constatou-se, para todos os lotes, liberação mais intensa a $30^{\circ} \mathrm{C}$ que a $25^{\circ} \mathrm{C}$.

Diante do exposto, notou-se que a melhor combinação temperatura/ quantidade de água foi estabelecida com a utilização do volume de $25 \mathrm{ml}\left(25^{\circ} \mathrm{C} / 25 \mathrm{ml} \mathrm{e} 30^{\circ} \mathrm{C} / 25 \mathrm{ml}\right)$, proporcionando a separação dos lotes em diferentes niveis de vigor, em periodos de embebição mais curtos.

Contudo, foram observadas variações na ordenação dos lotes quanto ao vigor, em comparação aos testes de germinação, emergência em casa de vegetação e método agroflora (Tabela 12). Durante toda essa fase de estudo do teste de condutividade elétrica (CE I), para o híbrido Debora Plus, o lote 1 foi classificado, nitidamente, como de potencial fisiológico inferior, ao contrário do verificado nos outros testes. A mesma contradição foi observada para o lote 5, apontado em geral, pelas avaliações iniciais, como de baixo vigor, ao passo que na condutividade elétrica sempre exibiu desempenho superior.

Convém ressaltar que o comportamento diferenciado do lote 1 , híbrido Debora Plus, não era esperado, razão pelo qual foi motivo de maior exploração, que será relatada posteriormente.

\subsubsection{Híbrido Brona}

Os resultados obtidos para condutividade elétrica, empregando-se a combinação 50 sementes por repetição, embebidas em $75 \mathrm{ml}$ de água, a $25^{\circ} \mathrm{C} \mathrm{e} 30^{\circ} \mathrm{C}$, estão apresentados, respectivamente, nas Tabelas 20 e 21. 
Tabela 20. Dados médios obtidos para o teste de condutividade elétrica de sementes de cinco lotes de tomate, hibrido Bruna, após vários periodos de embebição, utilizando-se a combinação 50 sementes por repetiçāo, $75 \mathrm{ml}$ de água e $25^{\circ} \mathrm{C}(\mathrm{CE} \mathrm{I})$.

\begin{tabular}{|c|c|c|c|c|c|c|}
\hline \multirow[t]{2}{*}{ Bruna } & \multicolumn{6}{|c|}{ Períodos de embebição } \\
\hline & $30 \mathrm{~min}$ & $1 \mathrm{~h}$ & $1 \mathrm{~h} 30 \mathrm{~min}$ & $2 \mathrm{~h}$ & $3 \mathrm{~h}$ & $4 h$ \\
\hline Lotes & \multicolumn{6}{|c|}{ …............................... } \\
\hline 1 & $17,0 a^{*}$ & $17,7 a$ & $18,9 a$ & $20,2 a$ & $21,1 \mathrm{a}$ & $21,9 a$ \\
\hline 2 & $19,7 \mathrm{a}$ & $21,2 a$ & $22,0 a$ & $23,0 a$ & $23,5 a$ & $24,4 a$ \\
\hline 3 & $18,3 a$ & $19,6 a$ & $20,3 a$ & $21,3 a$ & $22,2 \mathrm{a}$ & $23,0 a$ \\
\hline 4 & $17,3 a$ & $18,6 a$ & $19,2 \mathrm{a}$ & $19,7 a$ & $20,7 a$ & $21,2 \mathrm{a}$ \\
\hline 5 & $16,6 a$ & $18,1 \mathrm{a}$ & $19,2 a$ & $20,2 a$ & $21,5 a$ & $22,9 a$ \\
\hline
\end{tabular}

\begin{tabular}{|c|c|c|c|c|c|c|}
\hline \multirow[t]{2}{*}{ Bruna } & \multicolumn{6}{|c|}{ Períodos de embebiçāo } \\
\hline & $6 \mathrm{~h}$ & $8 \mathrm{~h}$ & $10 \mathrm{~h}$ & $16 \mathrm{~h}$ & $20 \mathrm{~h}$ & $24 \mathrm{~h}$ \\
\hline Lotes & \multicolumn{6}{|c|}{ 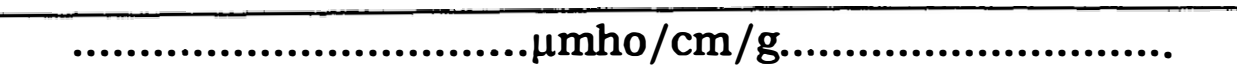 } \\
\hline 1 & $23,7 a$ & $24,6 a$ & $25,5 a$ & $27,6 a$ & $28,7 a$ & $30,1 \mathrm{ab}$ \\
\hline 2 & $26,1 \mathrm{a}$ & $28,7 a$ & $27,7 a$ & $27,7 a$ & $27,8 a$ & $27,9 a$ \\
\hline 3 & $24,7 a$ & $26,1 a$ & $27,0 a$ & $29,0 a$ & $29,0 a$ & $29,2 a b$ \\
\hline 4 & $23,2 a$ & $24,4 a$ & $24,8 a$ & $25,4 a$ & $27,0 a$ & $28,2 a$ \\
\hline 5 & $25,2 a$ & $27,0 a$ & $27,6 a$ & $29,4 a$ & $32,3 a$ & $35,8 b$ \\
\hline
\end{tabular}

C.V.(\%) 7,93

*Comparação de mêdias em cada coluna, pelo teste de Tukey a $5 \%$ de probabilidade. 
Tabela 21. Dados médios obtidos para o teste de condutividade elétrica de sementes de cinco lotes de tomate, híbrido Bruna, após vários periodos de embebição, utilizando-se a combinação 50 sementes por repetição, $75 \mathrm{ml}$ de água e $30^{\circ} \mathrm{C}(\mathrm{CE} \mathrm{I})$.

\begin{tabular}{ccccccc}
\hline Bruna & \multicolumn{5}{c}{ Periodos de embebição } \\
\cline { 2 - 7 } & $30 \mathrm{~min}$ & $1 \mathrm{~h}$ & $1 \mathrm{~h} \mathrm{30min}$ & $2 \mathrm{~h}$ & $3 \mathrm{~h}$ & $4 \mathrm{~h}$ \\
\hline Lotes & $\ldots \ldots \ldots \ldots \ldots \ldots \ldots \ldots \ldots \ldots . \ldots \mathrm{mho} / \mathrm{cm} / \mathrm{g} \ldots \ldots \ldots \ldots \ldots \ldots \ldots \ldots \ldots$ \\
1 & $16,9 \mathrm{a}^{*}$ & $17,6 \mathrm{\ldots}$ & $18,4 \mathrm{a}$ & $18,9 \mathrm{a}$ & $20,2 \mathrm{a}$ & $20,7 \mathrm{a}$ \\
2 & $19,9 \mathrm{a}$ & $20,4 \mathrm{a}$ & $21,6 \mathrm{a}$ & $21,9 \mathrm{a}$ & $23,2 \mathrm{a}$ & $23,5 \mathrm{a}$ \\
3 & $18,8 \mathrm{a}$ & $19,6 \mathrm{a}$ & $21,1 \mathrm{a}$ & $21,7 \mathrm{a}$ & $22,9 \mathrm{a}$ & $23,7 \mathrm{a}$ \\
4 & $19,1 \mathrm{a}$ & $19,8 \mathrm{a}$ & $21,0 \mathrm{a}$ & $21,5 \mathrm{a}$ & $22,8 \mathrm{a}$ & $23,6 \mathrm{a}$ \\
5 & $17,7 \mathrm{a}$ & $18,6 \mathrm{a}$ & $19,7 \mathrm{a}$ & $20,5 \mathrm{a}$ & $21,9 \mathrm{a}$ & $23,2 \mathrm{a}$
\end{tabular}

\begin{tabular}{|c|c|c|c|c|c|c|}
\hline \multirow[t]{2}{*}{ Bruna } & \multicolumn{6}{|c|}{ Periodos de embebição } \\
\hline & $6 \mathrm{~h}$ & $8 \mathrm{~h}$ & $10 \mathrm{~h}$ & $16 \mathrm{~h}$ & $20 \mathrm{~h}$ & $24 \mathrm{~h}$ \\
\hline Lotes & \multicolumn{6}{|c|}{ …............................. } \\
\hline 1 & $21,9 a$ & $22,4 a$ & $23,5 a$ & $27,7 a$ & $27,8 \mathrm{a}$ & $28,7 a$ \\
\hline 2 & $24,7 a$ & $25,4 a$ & $26,1 a$ & $28,7 a$ & $28,9 \mathrm{ab}$ & $28,8 a$ \\
\hline 3 & $24,7 a$ & $25,6 a$ & $26,5 a$ & $30,7 a$ & $31,7 a b$ & $31,9 a b$ \\
\hline 4 & $25,5 a$ & $26,3 a$ & $28,0 a$ & $29,7 a$ & $29,8 \mathrm{ab}$ & $30,2 \mathrm{ab}$ \\
\hline 5 & $25,0 a$ & $26,5 a$ & $28,6 a$ & $34,0 a$ & $34,3 b$ & $36,2 b$ \\
\hline C.V.(\%) & 7,95 & & & & & \\
\hline
\end{tabular}


Comparando-se as duas temperaturas, em termos de lixiviação de solutos, pode-se verificar, de maneira geral, maior liberação a $30^{\circ} \mathrm{C}$, com exceção do lote 1 , que demonstrou desde os periodos iniciais de condicionamento valores ligeiramente mais elevados a $25^{\circ} \mathrm{C}$. Além disso, constatou-se aumento na quantidade de eletrólitos liberados pelas sementes com o decorrer da embebição, tanto a $25^{\circ} \mathrm{C}$ quanto a $30^{\circ} \mathrm{C}$.

Com base nos resultados obtidos, verificou-se que a combinação 50 sementes $/ 75 \mathrm{ml} / 25^{\circ} \mathrm{C}$ (Tabela 20) mostrou-se mais sensivel às diferenças de qualidade entre os lotes somente após 24 horas de embebição, ocorrendo um agrupamento das médias, destacando os lotes 2 e 4 como de melhor desempenho e o lote 5 como deficiente; os lotes 1 e 3 apresentaram qualidade intermediária.

Analisando os dados encontrados para a combinação 50 sementes $/ 75 \mathrm{ml} / 30^{\circ} \mathrm{C}$ (Tabela 21 ), verificou-se que apenas a partir de 20 horas de embebição foi possivel obter ordenação de lotes quanto ao vigor, especialmente no periodo de 24 horas, o qual identificou os lotes 1 e 2 como de qualidade superior, o lote 5 como de inferior e, os lotes 3 e 4, como de qualidade intermediária.

Assim, através das informaçōes fornecidas pelos dois procedimentos, pode-se inferir apenas que o lote 2 apresentou potencial fisiológico superior e o lote 5 inferior, uma vez que os demais mostraram posicionamento variável, dependendo da temperatura utilizada.

Os dados obtidos para condutividade elétrica, híbrido Bruna, empregando-se a combinação 50 sementes por repetição, embebidas em $50 \mathrm{ml}$ de água, a $25^{\circ} \mathrm{C}$ e $30^{\circ} \mathrm{C}$, encontram-se, respectivamente, nas Tabelas 22 e 23 . 
Tabela 22. Dados médios obtidos para o teste de condutividade elétrica de sementes de cinco lotes de tomate, híbrido Bruna, após vários periodos de embebição, utilizando-se a combinação 50 sementes por repetição, $50 \mathrm{ml}$ de água e $25^{\circ} \mathrm{C}$ (CE I).

\begin{tabular}{|c|c|c|c|c|c|c|}
\hline \multirow[t]{2}{*}{ Bruna } & \multicolumn{6}{|c|}{ Períodos de embebição } \\
\hline & $30 \mathrm{~min}$ & $1 \mathrm{~h}$ & $1 \mathrm{~h} 30 \mathrm{~min}$ & $2 \mathrm{~h}$ & $3 \mathrm{~h}$ & $4 \mathrm{~h}$ \\
\hline Lotes & \multicolumn{6}{|c|}{ 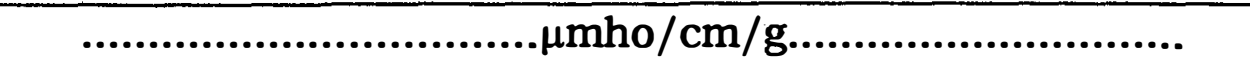 } \\
\hline 1 & $21,8 a^{*}$ & $22,8 a$ & $23,7 a$ & $24,0 \mathrm{a}$ & $25,0 \mathrm{a}$ & $25,5 a$ \\
\hline 2 & $27,7 a$ & $28,4 a$ & $29,2 a$ & $29,8 a$ & $30,8 a$ & $31,7 \mathrm{ab}$ \\
\hline 3 & $25,6 a$ & $27,4 a$ & $28,4 a$ & $29,5 a$ & $30,7 a$ & $32,4 b$ \\
\hline 4 & $25,2 a$ & $26,2 a$ & $27,2 a$ & $27,7 a$ & $28,8 a$ & $29,7 a b$ \\
\hline 5 & $24,0 \mathrm{a}$ & $25,6 a$ & $26,7 a$ & $28,0 \mathrm{a}$ & $29,2 a$ & $30,7 a b$ \\
\hline \multirow[t]{2}{*}{ Bruna } & \multicolumn{6}{|c|}{ Períodos de embebição } \\
\hline & $6 \mathrm{~h}$ & $8 \mathrm{~h}$ & $10 \mathrm{~h}$ & $16 \mathrm{~h}$ & $20 \mathrm{~h}$ & $24 \mathrm{~h}$ \\
\hline Lotes & \multicolumn{6}{|c|}{ 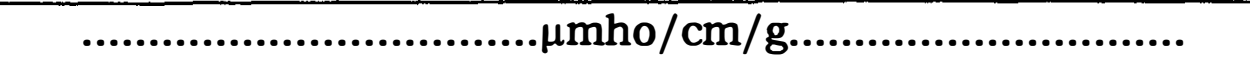 } \\
\hline 1 & $27,2 a$ & $27,5 a$ & $29,2 a$ & $31,2 a$ & $34,0 a$ & $37,0 \mathrm{a}$ \\
\hline 2 & $33,4 \mathrm{ab}$ & $33,6 a b$ & $34,7 a b$ & $36,0 \mathrm{ab}$ & $36,2 a$ & $36,8 a$ \\
\hline 3 & $35,0 \mathrm{~b}$ & $35,9 b$ & $36,5 b$ & $38,8 b$ & $43,7 b$ & $45,5 b$ \\
\hline 4 & $31,4 a b$ & $34,7 b$ & $36,0 \mathrm{~b}$ & $37,9 b$ & $42,6 b$ & $44,9 b$ \\
\hline 5 & $33,5 a b$ & $34,2 b$ & $35,6 b$ & $40,3 b$ & $45,3 b$ & $46,0 \mathrm{~b}$ \\
\hline ) & 3 & & & & & \\
\hline
\end{tabular}

*Comparação de médias em cada coluna, pelo teste de Tukey a $5 \%$ de probabilidade. 
Tabela 23. Dados médios obtidos para o teste de condutividade elétrica de sementes de cinco lotes de tomate, híbrido Bruna, após vários periodos de embebição, utilizando-se a combinação 50 sementes por repetição, $50 \mathrm{ml}$ de água e $30^{\circ} \mathrm{C}(\mathrm{CE} \mathrm{I})$.

\begin{tabular}{|c|c|c|c|c|c|c|}
\hline \multirow[t]{2}{*}{ Bruna } & \multicolumn{6}{|c|}{ Períodos de embebição } \\
\hline & 30min & $1 \mathrm{~h}$ & 1h 30min & $2 \mathrm{~h}$ & $3 \mathrm{~h}$ & $4 \mathrm{~h}$ \\
\hline Lotes & \multicolumn{6}{|c|}{ 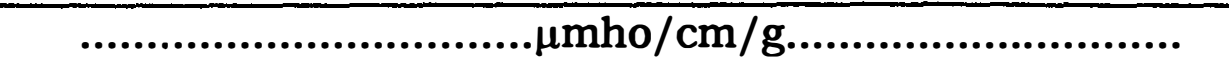 } \\
\hline 1 & $23,2 a^{*}$ & $24,2 a$ & $26,2 a$ & $27,1 \mathrm{a}$ & $28,8 a$ & $29,3 a$ \\
\hline 2 & $27,3 a$ & $28,7 a$ & $30,2 a$ & $30,8 \mathbf{a}$ & $31,9 a$ & $32,4 a$ \\
\hline 3 & $25,9 a$ & $26,6 a$ & $28,0 a$ & $29,0 a$ & $30,3 a$ & $30,7 a$ \\
\hline 4 & $24,3 a$ & $25,4 a$ & $26,5 a$ & $27,5 a$ & $28,4 a$ & $29,3 a$ \\
\hline 5 & $27,1 \mathrm{a}$ & $28,6 a$ & $30,1 \mathrm{a}$ & $30,9 a$ & $33,4 a$ & $34,1 \mathrm{a}$ \\
\hline
\end{tabular}

\begin{tabular}{ccccccc}
\hline Bruna & \multicolumn{6}{c}{ Periodos de embebição } \\
\cline { 2 - 7 } & $6 \mathrm{~h}$ & $8 \mathrm{~h}$ & $10 \mathrm{~h}$ & $16 \mathrm{~h}$ & $20 \mathrm{~h}$ & $24 \mathrm{~h}$ \\
\hline Lotes & $\ldots \ldots \ldots \ldots \ldots \ldots \ldots \ldots \ldots . . \ldots \mathrm{mho} / \mathrm{cm} / \mathrm{g} \ldots \ldots \ldots \ldots \ldots \ldots \ldots \ldots$ \\
1 & $33,5 \mathrm{a}$ & $34,9 \mathrm{ab}$ & $35,9 \mathrm{ab}$ & $40,4 \mathrm{ab}$ & $40,7 \mathrm{a}$ & $41,4 \mathrm{ab}$ \\
2 & $35,4 \mathrm{a}$ & $36,1 \mathrm{ab}$ & $36,9 \mathrm{ab}$ & $37,9 \mathrm{ab}$ & $38,0 \mathrm{a}$ & $39,3 \mathrm{a}$ \\
3 & $34,0 \mathrm{a}$ & $34,7 \mathrm{ab}$ & $35,6 \mathrm{ab}$ & $36,7 \mathrm{a}$ & $37,5 \mathrm{a}$ & $39,9 \mathrm{a}$ \\
4 & $32,0 \mathrm{a}$ & $32,9 \mathrm{a}$ & $33,3 \mathrm{a}$ & $36,7 \mathrm{a}$ & $37,3 \mathrm{a}$ & $38,8 \mathrm{a}$ \\
5 & $37,5 \mathrm{a}$ & $39,3 \mathrm{~b}$ & $40,9 \mathrm{~b}$ & $43,1 \mathrm{~b}$ & $43,4 \mathrm{a}$ & $47,2 \mathrm{~b}$ \\
& & & & & & \\
\hline C.V.(\%) & 7,95 & & & & &
\end{tabular}

*Comparação de médias em cada coluna, pelo teste de Tukey a $5 \%$ de probabilidade. 
Para as duas combinaçōes estudadas foi verificado aumento na quantidade de eletrólitos liberados pelas sementes à medida que se prolongava o periodo de condicionamento. De modo geral, não foi constatada, para todos os lotes, maior lixiviação de exsudatos a $30^{\circ} \mathrm{C}$ do que a $25^{\circ} \mathrm{C}$.

Na temperatura de $25^{\circ} \mathrm{C}$ (Tabela 22), pode-se observar uma tendência de separação dos lotes após 4 horas de embebição, sendo que resultados mais consistentes foram obtidos a partir de 8 horas de condicionamento, quando então os lotes 3, 4 e 5 revelaram-se como de menor potencial fisiológico, em relação aos lotes 1 e 2. É importante salientar que a ordenação dos lotes encontrada diferiu daquela obtida pelos testes de germinaçāo, emergência de plântulas em casa de vegetação e método Agroflora (Tabela 13), principalmente em razão do comportamento do lote 4.

No caso do procedimento a $30^{\circ} \mathrm{C}$ (Tabela 23), observaram-se variações na classificação dos lotes quanto ao vigor, a partir de 8 horas de embebição, sendo que após o periodo de 24 horas os lotes 2,3 e 4 mostraram-se como de qualidade superior e o lote 5 como de menor qualidade, ficando o lote 1 entre os extremos. Vale ressaltar que nos outros testes (Tabela 13) o lote 3 foi considerado como o de menor potencial fisiológico.

Ainda para o hibrido Bruna, os dados obtidos para condutividade elétrica, empregando-se a combinação 50 sementes por repetição, embebidas em $25 \mathrm{ml}$ de água, a $25^{\circ} \mathrm{C}$ e $30^{\circ} \mathrm{C}$, estão apresentados, respectivamente, nas Tabelas 24 e 25. 
Tabela 24. Dados médios obtidos para o teste de condutividade elêtrica de sementes de cinco lotes de tomate, hibrido Bruna, após vários periodos de embebição, utilizando-se a combinação 50 sementes por repetição, $25 \mathrm{ml}$ de água e $25^{\circ} \mathrm{C}(\mathrm{CE} \mathrm{I})$.

\begin{tabular}{|c|c|c|c|c|c|c|}
\hline \multirow[t]{2}{*}{ Bruna } & \multicolumn{6}{|c|}{ Periodos de embebição } \\
\hline & 30min & $1 \mathrm{~h}$ & 1h 30min & $2 \mathrm{~h}$ & $3 \mathrm{~h}$ & $4 \mathrm{~h}$ \\
\hline Lotes & \multicolumn{6}{|c|}{ 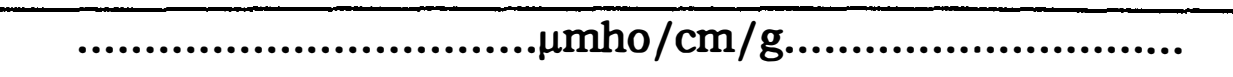 } \\
\hline 1 & $30,3 a^{*}$ & $32,9 a$ & $34,9 a$ & $36,9 a$ & $39,3 a$ & $40,2 a$ \\
\hline 2 & $29,8 a$ & $33,1 a$ & $35,4 a$ & $37,6 \mathbf{a}$ & $39,7 a$ & $40,5 a$ \\
\hline 3 & $42,6 \mathrm{bc}$ & $43,5 b$ & $46,2 b$ & $47,3 b$ & $50,5 b$ & $51,7 \mathrm{~b}$ \\
\hline 4 & $36,9 b$ & $37,0 a$ & $38,3 a$ & $39,0 a$ & $40,2 a$ & $41,5 a$ \\
\hline 5 & $46,0 c$ & $50,0 c$ & $53,8 c$ & $54,5 \mathrm{c}$ & $56,9 c$ & $59,3 c$ \\
\hline \multirow[t]{2}{*}{ Bruna } & \multicolumn{6}{|c|}{ Períodos de embebição } \\
\hline & $6 \mathrm{~h}$ & $8 \mathrm{~h}$ & $10 \mathrm{~h}$ & $16 \mathrm{~h}$ & $20 \mathrm{~h}$ & $24 \mathrm{~h}$ \\
\hline Lotes & \multicolumn{6}{|c|}{ 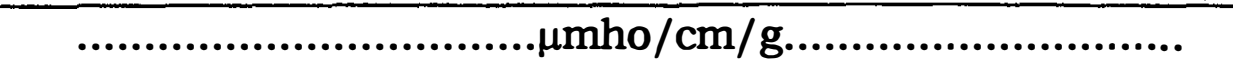 } \\
\hline 1 & $43,0 a$ & $44,3 a$ & $46,1 \mathrm{a}$ & $52,7 a$ & $54,5 a$ & $62,6 a$ \\
\hline 2 & $43,3 a$ & $45,1 \mathrm{a}$ & $47,6 a$ & $52,9 a$ & $54,3 a$ & $61,8 a$ \\
\hline 3 & $54,9 b$ & $56,7 \mathrm{~b}$ & $58,2 \mathrm{~b}$ & $62,8 \mathrm{~b}$ & $64,7 b$ & $74,9 b$ \\
\hline 4 & $44,6 a$ & $46,0 a$ & $48,5 a$ & $53,0 \mathrm{a}$ & $54,1 a$ & $61,6 a$ \\
\hline 5 & $62,7 c$ & $64,0 c$ & $66,8 c$ & $70,5 c$ & $71,3 c$ & $83,0 \mathrm{c}$ \\
\hline
\end{tabular}

*Comparação de médias em cada coluna, pelo teste de Tukey a $5 \%$ de probabilidade. 
Tabela 25. Dados médios obtidos para o teste de condutividade elétrica de sementes de cinco lotes de tomate, hibrido Bruna, após vários periodos de embebição, utilizando-se a combinação 50 sementes por repetição, $25 \mathrm{ml}$ de água e $30^{\circ} \mathrm{C}(\mathrm{CE} \mathrm{I})$.

\begin{tabular}{|c|c|c|c|c|c|c|}
\hline \multirow[t]{2}{*}{ Bruna } & \multicolumn{6}{|c|}{ Períodos de embebição } \\
\hline & 30min & $1 \mathrm{~h}$ & 1h $30 \mathrm{~min}$ & $2 \mathrm{~h}$ & $3 \mathrm{~h}$ & $4 \mathrm{~h}$ \\
\hline Lotes & \multicolumn{6}{|c|}{ 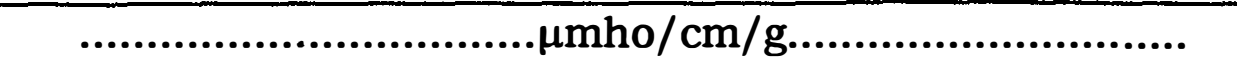 } \\
\hline 1 & $32,0 a^{*}$ & $34,4 a$ & $37,3 a$ & $38,0 \mathrm{a}$ & $40,1 \mathrm{a}$ & $41,5 a$ \\
\hline 2 & $45,6 c$ & $47,7 \mathrm{~b}$ & $50,8 b$ & $51,5 b$ & $54,1 b$ & $54,8 b$ \\
\hline 3 & $41,9 b c$ & $44,1 b$ & $49,1 \mathrm{~b}$ & $52,4 b$ & $52,6 b$ & $53,1 b$ \\
\hline 4 & $36,8 a b$ & $40,7 b$ & $43,6 b$ & $44,3 a$ & $46,4 b$ & $45,2 a$ \\
\hline 5 & $40,8 b c$ & $43,5 b$ & $48,2 \mathrm{~b}$ & $51,7 \mathrm{~b}$ & $51,9 b$ & $52,2 b$ \\
\hline
\end{tabular}

\begin{tabular}{|c|c|c|c|c|c|c|}
\hline \multirow[t]{2}{*}{ Bruna } & \multicolumn{6}{|c|}{ Períodos de embebição } \\
\hline & $6 \mathrm{~h}$ & $8 \mathrm{~h}$ & 10h & $16 \mathrm{~h}$ & $20 \mathrm{~h}$ & $24 \mathrm{~h}$ \\
\hline Lotes & \multicolumn{6}{|c|}{ 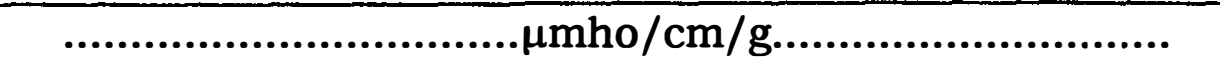 } \\
\hline 1 & $43,6 a$ & $45,8 a$ & $47,7 a$ & $52,4 a$ & $57,9 a$ & $66,2 \mathrm{a}$ \\
\hline 2 & $56,8 b$ & $57,6 b$ & $58,9 b$ & $62,2 b$ & $65,4 b$ & $73,6 b$ \\
\hline 3 & $57,7 \mathrm{~b}$ & $60,6 b$ & $62,2 \mathrm{~b}$ & $66,1 \mathrm{bc}$ & $72,2 \mathrm{c}$ & $80,4 c$ \\
\hline 4 & $47,5 a$ & $48,8 a$ & $50,3 a$ & $54,6 a$ & $57,3 a$ & $65,6 a$ \\
\hline 5 & $57,1 b$ & $59,4 b$ & $61,8 b$ & $69,7 \mathrm{c}$ & $80,4 d$ & $86,9 d$ \\
\hline
\end{tabular}

C.V.(\%) $\quad 7,95$

${ }^{*}$ Comparaçāo de médias em cada coluna, pelo teste de Tukey a $5 \%$ de probabilidade. 
Nas duas metodologias estudadas verificou-se aumento na quantidade de eletrólitos liberados pelas sementes com o decorrer da embebição. Constatou-se, também, de maneira geral, maior liberação a $30^{\circ} \mathrm{C}$.

A combinação com o uso da temperatura de $25^{\circ} \mathrm{C}$ (Tabela 24) revelou, desde 1 h de embebição, a superioridade dos lotes 1,2 e 4 e a inferioridade do lote 5 , identificando o lote 3 como de qualidade intermediária.

Os resultados obtidos com o emprego da temperatura de $30^{\circ} \mathrm{C}$ (Tabela 25), por sua vez, indicaram, a partir de 16 horas de embebição, uma classificação mais nítida dos lotes em diferentes niveis de potencial fisiológico. Assim, destacaram-se os lotes 1 e 4 como de melhor desempenho, os lotes 3 e 5 como de qualidade mais baixa, ficando o lote 2 entre o extremos.

Pode-se observar, ainda, que as duas metodologias estudadas demonstraram, em geral, tendências semelhantes na separação dos lotes, comparativamente àquelas observadas nos testes de germinação e emergência de plântulas em casa de vegetação (Tabela 13), apesar da alteração na classificação dos piores lotes, ou seja, pela maioria dos testes o lote 3 foi apontado como o de qualidade mais baixa e o lote 5 como de qualidade intermediária, o mesmo não ocorrendo para a condutividade elétrica.

\subsubsection{Consideraçôs gerais}

Com base nos resultados obtidos verificou-se, de maneira geral, que as melhores combinaçōes temperatura/quantidade de água, para os dois híbridos, foram as de $25^{\circ} \mathrm{C} / 25 \mathrm{ml}$ e $30^{\circ} \mathrm{C} / 25 \mathrm{ml}$, 
demonstrando aptidão para separar os lotes em diferentes niveis de potencial fisiológico, com possibilidade ainda de redução no período de embebição para a leitura de condutividade.

Analisando-se a sensibilidade dos periodos de embebição, em detectar diferenças entre os lotes, notou-se que a combinação 50 sementes $/ 25 \mathrm{ml} / 25^{\circ} \mathrm{C}$ forneceu indicações consistentes a respeito da qualidade das sementes a partir de 1 h 30 minutos de embebição, para o hibrido Debora Plus (Tabela 18) e, 1h, para o hibrido Bruna (Tabela 24).

É importante ressaltar que, no caso do hibrido Debora Plus, ocorreram variações quanto à classificação dos lotes, em comparação aos testes de germinação, emergência de plântulas em casa de vegetação e método Agroflora (Tabela 12). Contudo, independentemente da combinaçāo temperatura/quantidade de água utilizada, as informações fornecidas pela condutividade elétrica, para o referido hibrido, mostraram-se sempre pouco relacionadas com os demais testes, especialmente para o lote 1 , onde se pode observar discrepância marcante entre os resultados.

A combinação 50 sementes $/ 25 \mathrm{ml} / 30^{\circ} \mathrm{C}$, por sua vez, possibilitou a ordenação mais nitida dos lotes, em diferentes niveis de vigor, a partir de 6 horas de embebição, para o híbrido Debora Plus (Tabela 19) e, 16 horas, para o híbrido Bruna (Tabela 25). No entanto, desde 4 horas de condicionamento já foi possivel observar tendência de separação dos lotes, para os dois hibridos.

Diante do exposto, foram escolhidos os periodos promissores de $1,2,4,6$ e 24 horas de embebição $\left(25^{\circ} \mathrm{C} / 25 \mathrm{ml}\right)$ e 4, 6, 10, 16, 20 e 24 horas de embebição $\left(30^{\circ} \mathrm{C} / 25 \mathrm{ml}\right)$ para o estudo da metodologia do teste de condutividade elétrica, desta feita, alterando-se para 25 o número de sementes. 


\subsubsection{Condutividade elétrica - CE II}

Após estabelecida as melhores combinações temperatura/ quantidade de água e, identificados os periodos mais promissores, o número de sementes foi alterado.

\subsubsection{Hibrido Debora Plus}

Os dados obtidos para condutividade elétrica, utilizando-se a combinação 25 sementes por repetição, embebidas em $25 \mathrm{ml}$ de água, a $25^{\circ} \mathrm{C}$ e $30^{\circ} \mathrm{C}$, encontram-se, respectivamente, nas Tabelas 26 e 27.

Examinando os resultados da combinação 25 sementes $/ 25^{\circ} \mathrm{C} / 25 \mathrm{ml}$ (Tabela 26 ) verificou-se que os periodos de $1,2,4$ e 6 horas forneceram informaçōes semelhantes, indicando a superioridade dos lotes $2,3,4$ e 5 e a inferioridade do lote 1 . Já as leituras realizadas após 24 horas de condicionamento mostraram maior agrupamento das médias, classificando os lotes 2,3 e 5 como superiores, o lote 1 como inferior e o lote 4 como de qualidade intermediária.

Comparando-se esses dados com os obtidos através da combinação 50 sementes $/ 25^{\circ} \mathrm{C} / 25 \mathrm{ml}$ (Tabela 18) pode-se observar que a utilização desta alternativa possibilitou a ordenação dos lotes, em diferentes níveis de vigor, já no início do processo de embebição, o mesmo não ocorrendo com o emprego de 25 sementes. 
Tabela 26. Dados médios obtidos para o teste de condutividade elétrica de sementes de cinco lotes de tomate, hibrido Debora Plus, após vários periodos de embebição, utilizando-se a combinação 25 sementes por repetição, $25 \mathrm{ml}$ de água e $25^{\circ} \mathrm{C}$ (CE II).

\begin{tabular}{|c|c|c|c|c|c|}
\hline \multirow{2}{*}{$\begin{array}{c}\text { Debora } \\
\text { Plus }\end{array}$} & \multicolumn{5}{|c|}{ Períodos de embebição } \\
\hline & $1 \mathrm{~h}$ & $2 \mathrm{~h}$ & $4 \mathrm{~h}$ & $6 \mathrm{~h}$ & $24 \mathrm{~h}$ \\
\hline Lotes & \multicolumn{5}{|c|}{...............................mhho/cm/g.......................... } \\
\hline 1 & $483,3 b^{*}$ & $489,9 b$ & $494,3 b$ & $502,8 b$ & $578,4 \mathrm{c}$ \\
\hline 2 & $17,4 a$ & $18,9 a$ & $23,1 \mathrm{a}$ & $25,9 a$ & $28,5 a$ \\
\hline 3 & $27,9 a$ & $30,4 a$ & $36,1 \mathrm{a}$ & $38,7 a$ & $37,9 a$ \\
\hline 4 & $51,6 a$ & $55,0 a$ & $60,9 a$ & $66,9 a$ & $108,9 b$ \\
\hline 5 & $22,2 \mathrm{a}$ & $24,4 a$ & $28,9 a$ & $32,3 a$ & $39,8 a$ \\
\hline C.V. $(\%)$ & 8,87 & & & & \\
\hline
\end{tabular}

${ }^{*}$ Comparação de médias em cada coluna, pelo teste de Tukey a $5 \%$ de probabilidade.

Com referência à combinação 25 sementes $/ 30^{\circ} \mathrm{C} / 25 \mathrm{ml}$ (Tabela 27), notou-se, a partir de 6 horas de embebição, o melhor desempenho dos lotes 2,3 e 5 e o pior desempenho para o lote 1, ficando o lote 2 entre os extremos. Essa separação dos lotes está de acordo com a obtida pelo combinação 50 sementes $/ 30^{\circ} \mathrm{C} / 25 \mathrm{ml}$ (Tabela 19); porém, para a combinação utilizando 50 sementes, foi observada maior sensibilidade a partir de 4 horas de condicionamento. 
Tabela 27. Dados médios obtidos para o teste de condutividade elétrica de sementes de cinco lotes de tomate, híbrido Debora Plus, após vários periodos de embebição, utilizando-se a combinação 25 sementes por repetição, $25 \mathrm{ml}$ de água e $30^{\circ} \mathrm{C}$ (CE II).

\begin{tabular}{|c|c|c|c|c|c|c|}
\hline \multirow{2}{*}{$\begin{array}{c}\text { Debora } \\
\text { Plus }\end{array}$} & \multicolumn{6}{|c|}{ Periodos de embebição } \\
\hline & $4 \mathrm{~h}$ & $6 h$ & $10 \mathrm{~h}$ & $16 \mathrm{~h}$ & $20 \mathrm{~h}$ & $24 \mathrm{~h}$ \\
\hline Lotes & p.......... & .............. & $\ldots \ldots \ldots \mu \mathrm{mh}$ & $/ \mathrm{cm} / \mathrm{g} \ldots$ & .............. & .......... \\
\hline 1 & $490,2 b^{*}$ & $512,4 c$ & $524,6 c$ & $554,3 c$ & $575,7 c$ & $586,5 c$ \\
\hline 2 & $18,7 a$ & $21,6 a$ & $30,4 a$ & $32,5 a$ & $35,8 a$ & $36,7 a$ \\
\hline 3 & $20,2 a$ & $23,6 a$ & $31,0 a$ & $36,3 a$ & $42,2 a$ & $47,4 a$ \\
\hline 4 & $41,1 \mathrm{a}$ & $57,1 b$ & $83,4 b$ & $125,4 b$ & $133,9 b$ & $135,7 \mathrm{~b}$ \\
\hline 5 & $17,0 \mathrm{a}$ & $18,1 \mathrm{a}$ & $29,5 a$ & $46,1 \mathrm{a}$ & $53,5 a$ & $55,4 a$ \\
\hline
\end{tabular}

*Comparação de médias em cada coluna, pelo teste de Tukey a $5 \%$ de probabilidade.

Vale destacar que embora se tenha alterado o número de sementes, o lote 1 foi identificado, novamente, como de potencial fisiológico inferior e, o lote 5 , como superior, contrariando informações obtidas nos testes de germinação, emergência de plântulas em casa de vegetação e método Agroflora (Tabela 12).

\subsubsection{Hibrido Brana}

Os resultados obtidos para condutividade elétrica, empregando-se a combinação 25 sementes por repetição, embebidas em 
$25 \mathrm{ml}$ de água, a $25^{\circ} \mathrm{C}$ e $30^{\circ} \mathrm{C}$, estão apresentados, respectivamente, nas Tabelas 28 e 29.

Analisando os dados da combinação 25 sementes $/ 25^{\circ} \mathrm{C} / 25 \mathrm{ml}$ (Tabela 28) constatou-se que, somente após 24 horas de embebição, observaram-se diferenças entre os lotes, indicando a inferioridade do lote 5 em relação aos demais. É importante salientar que na combinação 50 sementes $/ 25^{\circ} \mathrm{C} / 25 \mathrm{ml}$ (Tabela 24) já foi possivel a separação dos lotes em diferentes niveis de vigor desde $1 \mathrm{~h}$ de embebiçāo.

Tabela 28. Dados médios obtidos para o teste de condutividade elétrica de sementes de cinco lotes de tomate, híbrido Bruna, após vários periodos de embebição, utilizando-se a combinaçāo 25 sementes por repetição, $25 \mathrm{ml}$ de água e $25^{\circ} \mathrm{C}$ (CE II).

\begin{tabular}{|c|c|c|c|c|c|}
\hline \multirow[t]{2}{*}{ Bruna } & \multicolumn{5}{|c|}{ Períodos de embebição } \\
\hline & $1 \mathrm{~h}$ & $2 \mathrm{~h}$ & $4 \mathrm{~h}$ & $6 \mathrm{~h}$ & $24 \mathrm{~h}$ \\
\hline Lotes & \multicolumn{5}{|c|}{. } \\
\hline 1 & $25,2 a^{*}$ & $27,3 a$ & $31,0 a$ & $34,0 \mathrm{a}$ & $46,3 a$ \\
\hline 2 & $25,6 a$ & $28,1 a$ & $31,3 a$ & $35,6 a$ & $42,0 a$ \\
\hline 3 & $31,0 a$ & $32,9 a$ & $36,8 a$ & $39,0 a$ & $51,7 a$ \\
\hline 4 & $28,3 a$ & $30,7 a$ & $34,5 a$ & $37,2 a$ & $44,8 a$ \\
\hline 5 & $33,7 a$ & $35,7 a$ & $40,4 a$ & $44,0 \mathrm{a}$ & $66,1 b$ \\
\hline C.V.(\%) & 6,85 & & & & \\
\hline
\end{tabular}

*Comparação de médias em cada coluna, pelo teste de Tukey a $5 \%$ de probabilidade. 
Tabela 29. Dados médios obtidos para o teste de condutividade elétrica de sementes de cinco lotes de tomate, híbrido Bruna, após vários periodos de embebição, utilizando-se a combinação 25 sementes por repetição, $25 \mathrm{ml}$ de água e $30^{\circ} \mathrm{C}$ (CE II).

\begin{tabular}{|c|c|c|c|c|c|c|}
\hline \multirow[t]{2}{*}{ Bruna } & \multicolumn{6}{|c|}{ Períodos de embebição } \\
\hline & $4 \mathrm{~h}$ & $6 h$ & $10 \mathrm{~h}$ & $16 \mathrm{~h}$ & $20 \mathrm{~h}$ & $24 \mathrm{~h}$ \\
\hline Lotes & \multicolumn{6}{|c|}{ } \\
\hline 1 & $18,7 a^{*}$ & $21,2 a$ & $22,9 a$ & $31,1 \mathrm{a}$ & $32,5 a$ & $33,6 a$ \\
\hline 2 & $24,4 a$ & $27,3 a$ & $37,8 b$ & $43,7 \mathrm{bc}$ & $52,4 b$ & $56,0 \mathrm{~b}$ \\
\hline 3 & $23,2 \mathrm{a}$ & $26,2 a$ & $42,5 b$ & $52,0 \mathrm{c}$ & $66,7 c$ & $72,9 c$ \\
\hline 4 & $19,0 \mathrm{a}$ & $21,0 a$ & $22,1 a$ & $35,3 a b$ & $37,6 a$ & $39,9 a$ \\
\hline 5 & $22,7 a$ & $26,7 a$ & $44,2 b$ & $66,5 d$ & $79,7 d$ & $88,9 d$ \\
\hline$\overline{\%)}$ & T, & & & & & \\
\hline
\end{tabular}

Os dados referentes à combinação 25 sementes $/ 30^{\circ} \mathrm{C} / 25 \mathrm{ml}$ (Tabela 29) mostraram-se mais consistentes a partir das 20 horas de condicionamento, indicando os lotes 1 e 4 como de melhor qualidade e os lotes 3 e 5 como inferiores; o lote 2 pode ser considerado como de comportamento intermediário.

Comparando-se esses resultados com os obtidos através da combinação 50 sementes $/ 30^{\circ} \mathrm{C} / 25 \mathrm{ml}$ (Tabela 25) constatou-se, de modo geral, semelhança quanto à identificação do potencial fisiológico dos lotes, sendo que em ambos os procedimentos os periodos de 20 e 24 horas de embebição mostraram-se mais eficientes para a avaliação do vigor. 


\subsubsection{Considerações gerais}

Diante do exposto, pode-se verificar que a melhor combinação obtida, para os dois hibridos, foi a que utilizou 50 sementes $/ 25 \mathrm{ml} / 25^{\circ} \mathrm{C}$ (Tabelas 18 e 24), demonstrando sensibilidade para detectar diferenças entre os lotes, com possibilidade de redução no período de embebição das sementes.

Vale ressaltar que, com exceção dos lotes 1 e 5 (híbrido Debora Plus) e dos lotes 3 e 5 (híbrido Bruna), os demais lotes mostraram a mesma tendência de classificação revelada pela maioria dos testes de avaliação inicial da qualidade (Tabelas 12 e 13).

Decorre disso, que novo teste foi conduzido, constituindo-se a última fase de estudo do método (CE III - Etapa 1), visando a determinação do periodo de embebição mais adequado. Para tanto, utilizou-se a combinação 50 sementes $/ 25 \mathrm{ml} / 25^{\circ} \mathrm{C}$, envolvendo os periodos de condicionamento mais promissores para os dois híbridos (1, $3,6,8$ e 24 horas).

\subsubsection{Condutividade elétrica - CE III}

Os resultados obtidos para o hibrido Debora Plus (Tabela 30) revelaram que desde a primeira hora de embebição já foi possivel detectar diferenças entre a qualidade dos lotes, sendo que em todos os periodos estudados foi observada a mesma ordenação dos lotes. Assim, verificou-se a superioridade dos lotes 2,3 e 5 e a inferioridade do lote 1; o lote 4 apresentou qualidade intermediária.

Comparando-se esses dados de condutividade elétrica, com os obtidos nos testes de germinação, emergência de plântulas em casa de 
vegetação e método Agroflora (Tabela 12), verificou-se, novamente, discrepância quanto à classificação dos lotes 1 e 5: o lote 1 foi classificado como de potencial fisiológico inferior, ao contrário do verificado nos outros testes; a mesma contradição foi observada para o lote 5 , apontado pelas avaliaçōes iniciais como de baixo vigor, ao passo que na condutividade elétrica sempre exibiu desempenho superior.

Tabela 30. Dados médios obtidos para o teste de condutividade elétrica de sementes de cinco lotes de tomate, híbrido Debora Plus, após os periodos de embebição mais promissores, utilizandose a combinação 50 sementes por repetição, $25 \mathrm{ml}$ de água e $25^{\circ} \mathrm{C}$ (CE III).

\begin{tabular}{|c|c|c|c|c|c|}
\hline \multirow{2}{*}{$\begin{array}{c}\text { Debora } \\
\text { Plus }\end{array}$} & \multicolumn{5}{|c|}{ Períodos de embebição } \\
\hline & $1 \mathrm{~h}$ & $3 \mathrm{~h}$ & $6 h$ & $8 \mathrm{~h}$ & $24 \mathrm{~h}$ \\
\hline Lotes & .............. & .............. & $\mu \mathrm{mho} / \mathrm{c}$ & ............... & ............. \\
\hline 1 & $486,8 c^{*}$ & $494,8 c$ & $529,6 c$ & $536,9 c$ & $550,6 c$ \\
\hline 2 & $32,6 a$ & $41,8 a$ & $46,0 a$ & $47,8 \mathrm{a}$ & $48,1 \mathrm{a}$ \\
\hline 3 & $32,8 a$ & $40,8 a$ & $45,8 a$ & $49,4 a$ & $51,1 \mathrm{a}$ \\
\hline 4 & $59,6 b$ & $70,9 b$ & $79,9 b$ & $85,8 b$ & $98,9 b$ \\
\hline 5 & $33,5 a$ & $42,0 a$ & $46,3 a$ & $51,5 a$ & $53,5 a$ \\
\hline
\end{tabular}

*Comparação de médias em cada coluna, pelo teste de Tukey a $5 \%$ de probabilidade.

Com relação ao híbrido Bruna (Tabela 31), a separação dos lotes obtida após 6, 8 e 24 horas de embebição indicou a possibilidade de redução no período de condicionamento das sementes. O melhor desempenho foi observado para os lotes 1,2 e 4 e a pior qualidade para o lote 5 , ficando o lote 3 entre os extremos. De modo geral, houve 
coerência entre os resultados de condutividade elétrica e dos demais testes (Tabela 13), apesar da alteração, novamente, na classificação dos lotes 3 e 5 .

Tabela 31. Dados médios obtidos para o teste de condutividade elétrica de sementes de cinco lotes de tomate, híbrido Bruna, após os periodos de embebição mais promissores, utilizando-se a combinação 50 sementes por repetição, $25 \mathrm{ml}$ de água e $25^{\circ} \mathrm{C}$ (CE III).

\begin{tabular}{|c|c|c|c|c|c|}
\hline \multirow[t]{2}{*}{ Bruna } & \multicolumn{5}{|c|}{ Periodos de embebição } \\
\hline & $1 \mathrm{~h}$ & $3 \mathrm{~h}$ & $6 \mathrm{~h}$ & $8 \mathrm{~h}$ & $24 \mathrm{~h}$ \\
\hline Lotes & ........... & ........... & $\mathrm{mho} / \mathrm{cr}$ & ............. & ......... \\
\hline 1 & $34,2 a^{*}$ & $41,3 a$ & $45,6 a$ & $47,0 \mathrm{a}$ & $51,4 a$ \\
\hline 2 & $35,7 a$ & $42,6 a$ & $47,9 a$ & $49,8 a$ & $52,6 a$ \\
\hline 3 & $46,5 b$ & $53,2 b$ & $61,9 b$ & $66,3 b$ & $73,0 b$ \\
\hline 4 & $35,9 a$ & $42,4 a$ & $46,8 a$ & $48,5 a$ & $52,3 a$ \\
\hline 5 & $50,3 b$ & $57,4 b$ & $70,6 c$ & $74,6 c$ & $92,9 c$ \\
\hline
\end{tabular}

*Comparação de médias em cada coluna, pelo teste de Tukey a $5 \%$ de probabilidade.

Assim, com relação à sensibilidade dos periodos de embebição em detectar diferenças entre os lotes foram considerados como mais adequados, em concordãncia com os dois híbridos, os periodos superiores a 6 horas de embebição.

É importante ressaltar, ainda, que o comportamento dos lotes do híbrido Debora Plus foi semelhante durante toda a fase de estudo da condutividade elétrica, revelando sempre diferenças marcantes quanto à classificação dos lotes 1 e 5, em relação aos demais testes (Tabela 12). 


\subsubsection{Lixiviação de Potássio ( $\left.\mathrm{K}^{+}\right)$}

\subsubsection{Hibrido Debora Plus}

Analisando-se os resultados do teste de lixiviação de potássio, para o híbrido Debora Plus (Tabela 32), observou-se que a combinação utilizada (100 sementes $/ 25 \mathrm{ml} / 30^{\circ} \mathrm{C} / 3 \mathrm{~h}$ ) identificou os lotes 1,2 e 3 como superiores e o lote 4 como de pior desempenho. O lote 5 , por sua vez, foi classificado como de qualidade intermediária.

Tabela 32. Dados médios obtidos para o teste de lixiviação de potássio de sementes de cinco lotes de tomate, híbrido Debora Plus, utilizando-se a combinação 100 sementes por repetição, $25 \mathrm{ml}$ de água, 3 horas de embebição e $30^{\circ} \mathrm{C}$.

\begin{tabular}{cc}
\hline Debora Plus & Lixiviação de $\mathrm{K}^{+}$ \\
\hline Lotes & $\ldots \ldots \ldots \ldots . . . \mathrm{ppm} / \mathrm{g} \ldots \ldots \ldots \ldots . . . . .$. \\
1 & $12 \mathrm{a}^{*}$ \\
2 & $12 \mathrm{a}$ \\
3 & $12 \mathrm{a}$ \\
4 & $152 \mathrm{c}$ \\
5 & $34 \mathrm{~b}$ \\
\hline C.V.(\%) & 8,81
\end{tabular}

*Comparaçāo de médias em cada coluna, pelo teste de Tukey a $5 \%$ de probabilidade.

Esses resultados indicaram, ainda, que a avaliação do potássio lixiviado mostrou, de modo geral, a mesma tendência verificada pelo teste de emergência de plântulas em casa de vegetação e método 
Agroflora (Tabela 12), que apontaram também os lotes 4 e 5 como de potencial fisiológico mais baixo.

Por outro lado, os resultados de lixiviação de potássio não se relacionaram aos de condutividade elétrica (Tabela 30) quanto à classificação obtida para os lotes 1 e 5 , apesar de ambos os testes apresentarem principios semelhantes. Os demais lotes, por sua vez, revelaram desempenho similar, ou seja, o lote 4 apresentou qualidade inferior aos lotes 2 e 3. Cabe ressaltar, novamente, o comportamento diferenciado dos lotes 1 e 5, hibrido Debora Plus.

\subsubsection{Híbrido Bruna}

Os dados apresentados na Tabela 33 revelaram que o teste de lixiviaçāo de potássio, para o híbrido Bruna, indicou a inferioridade do lote 3 em relaçāo aos demais, os quais não diferiram entre si.

Destacando as informações obtidas no teste e estabelecendo relações com a germinação, emergência de plântulas em casa de vegetação e método Agroflora (Tabela 13), verificou-se, em geral, concordância quanto à indicação da baixa qualidade do lote 3 , apesar da lixiviação de potássio não ter classificado também, nesta categoria, o lote 5 . 
Tabela 33. Dados médios obtidos para o teste de lixiviação de potássio de sementes de cinco lotes de tomate, híbrido Bruna, utilizando-se a combinação 100 sementes por repetição, $25 \mathrm{ml}$ de água, 3 horas de embebição e $30^{\circ} \mathrm{C}$.

\begin{tabular}{cc}
\hline Bruna & Lixiviação de $\mathrm{K}^{+}$ \\
\hline Lotes & $\ldots \ldots \ldots \ldots . . . \mathrm{ppm} / \mathrm{g} \ldots \ldots \ldots \ldots . . . .$. \\
1 & $25 \mathrm{a}^{*}$ \\
2 & $44 \mathrm{a}$ \\
3 & $118 \mathrm{~b}$ \\
4 & $37 \mathrm{a}$ \\
5 & $32 \mathrm{a}$ \\
\hline C.V.(\%) & 7,34
\end{tabular}

"Comparação de médias em cada coluna, pelo teste de Tukey a $5 \%$ de probabilidade.

O teste de condutividade elétrica (Tabela 31), por sua vez, apontou qualidade intermediária do lote 3 e o pior desempenho do lote 5, enquanto a avaliação do potássio lixiviado destacou apenas a inferioridade do lote 3.

Pode-se observar, portanto, comportamento diferenciado do lote 5, híbrido Bruna, nos testes de lixiviação de potássio e de condutividade elétrica, sendo que os demais lotes apresentaram desempenho semelhante. 


\subsubsection{Considerações gerais}

De um modo geral, o teste de lixiviação de potássio revelou eficiência no sentido de identificar os lotes de pior qualidade: lotes 4 e 5 (hibrido Debora Plus) e lote 3 (híbrido Bruna).

Comparando-se esses resultados com os de condutividade elétrica ( $\mathrm{CE}$ III) pode-se constatar, em geral, que houve discordância entre os testes quanto à classificação dos lotes 1 e 5 (híbrido Debora Plus) e lote 5 (hibrido Bruna); os demais lotes apresentaram qualidade semelhante.

Esse fato pode indicar que, apesar de ambos os testes apresentarem principios similares (indicadores da integridade do sistema de membranas celulares), a forma de avaliação pode estar influenciando os resultados: o teste de condutividade elêtrica avalia a quantidade de lixiviados (conjunto de ions) liberados durante a embebição das sementes, ao passo que o teste de lixiviação de potássio avalia somente a quantidade de potássio liberado pelas sementes embebidas, não recebendo interferência de outro ion.

\subsubsection{Envelhecimento acelerado (procedimento tradicional)}

\subsubsection{Hibrido Debora Plus}

Os resultados do teste de envelhecimento acelerado (procedimento tradicional), híbrido Debora Plus, utilizando-se duas temperaturas e três periodos de condicionamento, estão apresentados na Tabela 34.

Verificou-se que os periodos de 48 e 72 horas de envelhecimento, a $41^{\circ} \mathrm{C}$, proporcionaram a identificação dos lotes de 
menor potencial fisiológico, mostrando concordância com a emergência de plântulas em casa de vegetaçāo, método Agroflora (Tabela 12) e lixiviaçâo de potássio (Tabela 32). Dessa forma, apontaram os lotes $4 \mathrm{e}$ 5 como os de pior qualidade.

Tabela 34. Dados médios obtidos para o teste de envelhecimento acelerado (procedimento tradicional) de sementes de cinco lotes de tomate, híbrido Debora Plus.

\begin{tabular}{|c|c|c|c|c|c|c|}
\hline \multirow{3}{*}{$\begin{array}{c}\text { Debora } \\
\text { Plus }\end{array}$} & \multicolumn{6}{|c|}{ Envelhecimento acelerado (tradicional) } \\
\hline & \multicolumn{3}{|c|}{$41^{\circ} \mathrm{C}$} & \multicolumn{3}{|c|}{$38^{\circ} \mathrm{C}$} \\
\hline & $48 \mathrm{~h}$ & $72 \mathrm{~h}$ & $96 \mathrm{~h}$ & $48 \mathrm{~h}$ & $72 h$ & $96 \mathrm{~h}$ \\
\hline Lotes & .... & 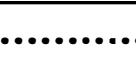 & 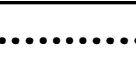 & .......... & 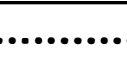 & $\ldots . .$. \\
\hline 1 & $94 a^{*}$ & $87 a$ & $73 a$ & $90 a$ & $87 a$ & $79 a$ \\
\hline 2 & $93 a$ & $82 a b$ & $61 b$ & $85 a b$ & $84 a b$ & $47 b$ \\
\hline 3 & $95 a$ & $81 \mathrm{ab}$ & $70 \mathrm{ab}$ & $79 b$ & $77 \mathrm{bc}$ & $77 a$ \\
\hline 4 & $78 \mathrm{~b}$ & $72 \mathrm{c}$ & $50 c$ & $68 d$ & $60 d$ & $51 b$ \\
\hline 5 & $85 b$ & 79bc & $79 a$ & $73 \mathrm{~cd}$ & $72 c$ & $72 a$ \\
\hline
\end{tabular}

C.V.(\%) 4,34

*Comparação de médias em cada coluna, pelo teste de Tukey a 5\% de probabilidade.

Com referência à temperatura de $38^{\circ} \mathrm{C}$, também pode ser observado que os periodos de 48 e 72 horas de envelhecimento exibiram maior sensibilidade para identificação dos lotes de potencial fisiológico mais baixo (lotes 4 e 5 ).

O periodo de 96 horas de envelhecimento, tanto a $41^{\circ} \mathrm{C}$ quanto a $38^{\circ} \mathrm{C}$, mostrou concordância com os outros testes apenas quanto à indicação de superioridade do lote 1 . 
Os dados referentes ao grau de umidade das sementes, após os periodos de condicionamento (Tabela 35), variaram entre os lotes de 3,6 a 4,4 \%, dependendo da combinação periodo/temperatura utilizada. O maior valor foi sempre encontrado para o lote 1 , confirmando a tendência observada para o mesmo lote, antes da realização dos testes (Tabela 12). Interessante notar que o lote 1 era o mais úmido, mas as metodologias de envelhecimento acelerado estudadas o identificaram como o mais vigoroso; portanto, essa pequena diferença inicial no grau de umidade não foi suficiente para mascarar os resultados obtidos.

Tabela 35. Dados médios de grau de umidade obtidos após os periodos de envelhecimento (procedimento tradicional) de sementes de cinco lotes de tomate, hibrido Debora Plus.

\begin{tabular}{|c|c|c|c|c|c|c|}
\hline \multirow{3}{*}{$\begin{array}{c}\text { Debora } \\
\text { Plus }\end{array}$} & \multicolumn{6}{|c|}{ Grau de umidade após EA (tradicional) } \\
\hline & \multicolumn{3}{|c|}{$41^{\circ} \mathrm{C}$} & \multicolumn{3}{|c|}{$38^{\circ} \mathrm{C}$} \\
\hline & $48 \mathrm{~h}$ & $72 \mathrm{~h}$ & $96 \mathrm{~h}$ & $48 \mathrm{~h}$ & $72 \mathrm{~h}$ & $96 h$ \\
\hline Lotes & ..... & ......... & $\ldots \ldots$ & $\ldots . . . . . .$. & ......... & $\ldots . . .$. \\
\hline 1 & 42,1 & 43,4 & 45,2 & 39,2 & 41,6 & 43,0 \\
\hline 2 & 38,3 & 39,2 & 40,8 & 35,6 & 37,4 & 38,7 \\
\hline 3 & 38,6 & 39,5 & 41,0 & 37,8 & 38,3 & 39,3 \\
\hline 4 & 39,4 & 41,1 & 41,6 & 38,8 & 40,1 & 41,5 \\
\hline 5 & 38,8 & 40,6 & 41,3 & 38,4 & 39,4 & 40,6 \\
\hline
\end{tabular}

Segundo Marcos Filho (1999b), se amostras de sementes de soja apresentam teores iniciais de água muito distintos (diferença superior a $2 \%$ ), há variação acentuada na velocidade de umedecimento durante o envelhecimento e, certamente, diferenças na intensidade de deterioração. Por outro lado, um dos principais indicadores da 
uniformidade das condiçōes do envelhecimento acelerado é o teor de água ao final do teste, sendo que variaçōes de 3 a $4 \%$ entre as amostras são consideradas toleráveis (Tomes et al., 1988); estes autores trabalharam com maior periodo de envelhecimento (72 horas), o que justifica a aparente discrepância de informaçōes.

Com base no exposto, novos testes foram conduzidos, utilizando-se as melhores combinaçōes temperatura/periodo $\left(41^{\circ} \mathrm{C} / 48 \mathrm{e}\right.$ 72 horas; $38^{\circ} \mathrm{C} / 48$ e 72 horas), com a finalidade de determinar a metodologia mais adequada. Na Tabela 36 encontram-se os dados referentes a essa fase de estudo do protocolo do teste de envelhecimento acelerado.

Tabela 36. Dados médios obtidos para o teste de envelhecimento acelerado (procedimento tradicional) de sementes de cinco lotes de tomate, híbrido Debora Plus.

\begin{tabular}{|c|c|c|c|c|}
\hline \multirow{3}{*}{$\begin{array}{c}\text { Debora } \\
\text { Plus }\end{array}$} & \multicolumn{4}{|c|}{ Envelhecimento acelerado (tradicional) } \\
\hline & \multicolumn{2}{|c|}{$41^{\circ} \mathrm{C}$} & \multicolumn{2}{|c|}{$38^{\circ} \mathrm{C}$} \\
\hline & $48 \mathrm{~h}$ & $72 \mathrm{~h}$ & $48 \mathrm{~h}$ & $72 \mathrm{~h}$ \\
\hline Lotes & \multicolumn{2}{|c|}{................\%............. } & \multicolumn{2}{|c|}{...............\%............ } \\
\hline 1 & $84 a b^{*}$ & $88 a$ & $90 a$ & $87 a$ \\
\hline 2 & $84 a b$ & $83 a b$ & 82ab & $87 a$ \\
\hline 3 & $90 a$ & $75 b c$ & $83 a b$ & $88 a$ \\
\hline 4 & $63 c$ & $70 c$ & $78 b$ & $65 b$ \\
\hline 5 & $78 b$ & $73 \mathrm{bc}$ & $78 b$ & $68 b$ \\
\hline C.V.(\%) & \multicolumn{2}{|l|}{5,07} & & \\
\hline
\end{tabular}


De maneira geral, os resultados obtidos com as melhores combinaçōes revelaram tendências semelhantes na separação dos lotes, comparativamente àquelas observadas preliminarmente (Tabela 34), embora pequenas variaçōes tenham ocorrido.

Pode-se verificar, ainda, que o periodo de 72 horas, a $41^{\circ} \mathrm{C}$, mostrou maior concordância com os resultados dos testes de germinação, emergência de plântulas em casa de vegetação e método Agroflora (Tabela 12), revelando o melhor desempenho dos lotes 1 e 2 em relação aos demais.

Quanto ao grau de umidade obtido após os periodos de envelhecimento (Tabela 37 ) verificou-se que os valores, em geral, mostraram-se semelhantes, com uma variação entre lotes de 1,3 a $3,7 \%$, dependendo da combinação utilizada.

Tabela 37. Dados médios de grau de umidade obtidos após os periodos de envelhecimento (procedimento tradicional) de sementes de cinco lotes de tomate, híbrido Debora Plus.

\begin{tabular}{|c|c|c|c|c|}
\hline \multirow{3}{*}{$\begin{array}{c}\text { Debora } \\
\text { Plus }\end{array}$} & \multicolumn{4}{|c|}{ Grau de umidade após EA (tradicional) } \\
\hline & \multicolumn{2}{|c|}{$41^{\circ} \mathrm{C}$} & \multicolumn{2}{|c|}{$38^{\circ} \mathrm{C}$} \\
\hline & $48 \mathrm{~h}$ & $72 \mathrm{~h}$ & $48 \mathrm{~h}$ & $72 \mathrm{~h}$ \\
\hline Lotes & \multicolumn{2}{|c|}{.................\%............... } & \multicolumn{2}{|c|}{ ….............\%............. } \\
\hline 1 & 40,3 & 41,0 & 38,5 & 39,4 \\
\hline 2 & 36,9 & 37,3 & 35,9 & 36,1 \\
\hline 3 & 37,1 & 38,3 & 36,9 & 37,2 \\
\hline 4 & 38,1 & 39,5 & 37,4 & 38,0 \\
\hline 5 & 38,1 & 38,3 & 37,1 & 37,6 \\
\hline
\end{tabular}




\subsubsection{Hibrido Brona}

Na Tabela 38 estão apresentados os resultados do teste de envelhecimento acelerado (procedimento tradicional), hibrido Bruna.

Examinando-se os resultados, observou-se que as diferentes metodologias estudadas para o envelhecimento acelerado classificaram os lotes em niveis de potencial fisiológico, destacando a pior qualidade para o lote 3.

Tabela 38. Dados médios obtidos para o teste de envelhecimento acelerado (procedimento tradicional) de sementes de cinco lotes de tomate, híbrido Bruna.

\begin{tabular}{|c|c|c|c|c|c|c|}
\hline \multirow[t]{3}{*}{ Bruna } & \multicolumn{6}{|c|}{ Envelhecimento acelerado (tradicional) } \\
\hline & \multicolumn{3}{|c|}{$41^{\circ} \mathrm{C}$} & \multicolumn{3}{|c|}{$38^{\circ} \mathrm{C}$} \\
\hline & $48 \mathrm{~h}$ & $72 \mathrm{~h}$ & $96 \mathrm{~h}$ & $48 \mathrm{~h}$ & $72 \mathrm{~h}$ & $96 \mathrm{~h}$ \\
\hline Lotes & \multicolumn{3}{|c|}{ …...............\%............... } & \multicolumn{3}{|c|}{ …................\%................ } \\
\hline 1 & 91ab* & $88 a$ & $80 a$ & $93 a$ & $88 a$ & $83 a b$ \\
\hline 2 & $87 \mathrm{bc}$ & $82 a$ & $67 b$ & $75 \mathrm{bc}$ & $80 \mathrm{ab}$ & $87 a$ \\
\hline 3 & $75 d$ & $61 b$ & $53 c$ & $65 d$ & $72 b$ & $53 d$ \\
\hline 4 & $95 a$ & $84 a$ & $63 \mathrm{bc}$ & $91 \mathrm{a}$ & $80 a b$ & $73 c$ \\
\hline 5 & $83 \mathrm{~cd}$ & $68 b$ & $64 \mathrm{bc}$ & $68 c d$ & $76 b$ & $75 \mathrm{bc}$ \\
\hline.$(\%)$ & 4,50 & & & & & \\
\hline
\end{tabular}

*Comparação de médias em cada coluna, pelo teste de Tukey a $5 \%$ de probabilidade.

No entanto, as informações fornecidas pelos periodos de $48 \mathrm{e}$ 72 horas mostraram-se mais relacionadas com os demais testes, indicando desempenho superior para os lotes 1 e 4 e inferior para os 
lotes 3 e 5; o lote 2 apresentou, de maneira geral, qualidade intermediária.

Com relação ao grau de umidade das sementes após os periodos de condicionamento (Tabela 39), verificou-se que os valores foram relativamente semelhantes para todos os lotes, com variaçāo de 1,1 a $2,4 \%$, dependendo do método empregado.

Tabela 39. Dados médios de grau de umidade obtidos após os periodos de envelhecimento (procedimento tradicional) de sementes de cinco lotes de tomate, híbrido Bruna.

\begin{tabular}{|c|c|c|c|c|c|c|}
\hline \multirow{3}{*}{ Bruna } & \multicolumn{6}{|c|}{ Grau de umidade após EA (tradicional) } \\
\hline & \multicolumn{3}{|c|}{$41^{\circ} \mathrm{C}$} & \multicolumn{3}{|c|}{$38^{\circ} \mathrm{C}$} \\
\hline & $48 \mathrm{~h}$ & $72 \mathrm{~h}$ & $96 \mathrm{~h}$ & $48 \mathrm{~h}$ & $72 \mathrm{~h}$ & $96 \mathrm{~h}$ \\
\hline Lotes & \multicolumn{3}{|c|}{................\%............. } & \multicolumn{3}{|c|}{................\%............. } \\
\hline 1 & 38,2 & 39,1 & 40,3 & 37,3 & 38,8 & 39,1 \\
\hline 2 & 36,5 & 38,1 & 39,2 & 35,0 & 36,5 & 38,1 \\
\hline 3 & 37,3 & 38,0 & 39,2 & 36,9 & 37,4 & 39,0 \\
\hline 4 & 36,1 & 37,5 & 38,9 & 35,9 & 36,5 & 37,6 \\
\hline 5 & 37,8 & 38,4 & 39,4 & 37,4 & 38,2 & 38,9 \\
\hline
\end{tabular}

Assim, novos testes foram conduzidos empregando-se as melhores combinações temperatura/periodo $\left(41^{\circ} \mathrm{C} / 48\right.$ e 72 horas; $38^{\circ} \mathrm{C} / 48$ e 72 horas), com o objetivo de determinar o procedimento mais promissor. Na Tabela 40 estão apresentados os dados referentes a essas avaliações. 
Tabela 40. Dados médios obtidos para o teste de envelhecimento acelerado (procedimento tradicional) de sementes de cinco lotes de tomate, híbrido Bruna.

\begin{tabular}{|c|c|c|c|c|}
\hline \multirow[t]{3}{*}{ Bruna } & \multicolumn{4}{|c|}{ Envelhecimento acelerado (tradicional) } \\
\hline & \multicolumn{2}{|c|}{$41^{\circ} \mathrm{C}$} & \multicolumn{2}{|c|}{$38^{\circ} \mathrm{C}$} \\
\hline & $48 \mathrm{~h}$ & $72 \mathrm{~h}$ & $48 \mathrm{~h}$ & $72 \mathrm{~h}$ \\
\hline Lotes & \multicolumn{2}{|c|}{................\%.............. } & \multicolumn{2}{|c|}{ 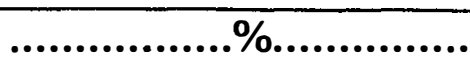 } \\
\hline 1 & $92 a^{*}$ & $94 a$ & $94 a$ & $96 a$ \\
\hline 2 & $83 b$ & $88 a b$ & $85 b$ & $91 \mathrm{ab}$ \\
\hline 3 & $71 \mathrm{c}$ & $78 c$ & $77 \mathrm{~b}$ & $77 \mathrm{c}$ \\
\hline 4 & $92 a$ & $92 a$ & $92 a$ & $86 b c$ \\
\hline 5 & $77 \mathrm{bc}$ & $82 \mathrm{bc}$ & $82 b$ & $85 b c$ \\
\hline C.V.(\%) & 4,73 & & & \\
\hline
\end{tabular}

${ }^{*}$ Comparação de médias em cada coluna, pelo teste de Tukey a $5 \%$ de probabilidade.

A análise comparativa indicou que os resultados obtidos foram, de maneira geral, semelhantes às informaçōes fornecidas anteriormente (Tabela 38), com a utilização das mesmas combinaçōes temperatura/periodo de envelhecimento.

No entanto, o periodo de 72 horas, a $41^{\circ} \mathrm{C}$, mostrou-se mais relacionado com os testes de germinação, emergência de plântulas em casa de vegetação e método Agroflora (Tabela 13), especialmente quanto à identificação de lotes de potencial fisiológico elevado.

Os dados referentes ao grau de umidade das sementes após os periodos de envelhecimento (Tabela 41) foram semelhantes para os cinco lotes estudados, com uma variação de 1,7 a 2,4\%, dependendo da metodologia estudada. 
Tabela 41. Dados médios de grau de umidade obtidos após os periodos de envelhecimento (procedimento tradicional) de sementes de cinco lotes de tomate, híbrido Bruna

\begin{tabular}{ccccc}
\hline \multirow{2}{*}{ Bruna } & \multicolumn{3}{c}{ Grau de umidade após EA (tradicional) } \\
\cline { 2 - 5 } & \multicolumn{2}{c}{$41^{\circ} \mathrm{C}$} & \multicolumn{2}{c}{$38^{\circ} \mathrm{C}$} \\
\cline { 2 - 5 } & $48 \mathrm{~h}$ & $72 \mathrm{~h}$ & $\ldots \ldots \ldots \ldots \ldots \ldots \ldots \ldots \ldots$ \\
\hline Lotes & $\ldots \ldots \ldots \ldots \ldots . \ldots \ldots \ldots \ldots$ & 37,5 & 38,1 \\
1 & 38,4 & 39,9 & 35,6 & 37,2 \\
2 & 37,6 & 38,3 & 35,1 & 36,4 \\
3 & 36,5 & 37,8 & 35,7 & 37,9 \\
4 & 37,1 & 38,8 & 36,2 & 37,8 \\
5 & 37,9 & 38,1 & & \\
\hline
\end{tabular}

\subsubsection{Consideraçōes gerais}

Diante do exposto, verificou-se que, para os dois hibridos, a combinação $41^{\circ} \mathrm{C} / 72$ horas de condicionamento foi a mais eficiente para realização do teste de envelhecimento acelerado, proporcionando a separação adequada dos lotes em niveis de vigor e fornecendo informações compativeis com os resultados dos testes de germinação, emergência de plântulas em casa de vegetação e método Agroflora.

Os resultados obtidos estão, ainda, de acordo com ISTA (1995), que recomendou a mesma combinação para condução do teste com sementes de tomate.

As combinações com a utilização da temperatura de $38^{\circ} \mathrm{C}$ revelaram resultados menos consistentes quanto à identificação dos 
lotes de menor potencial fisiológico, especialmente para o híbrido Bruna.

\subsubsection{Envelhecimento acelerado (solução saturada de sal)}

\subsubsection{Hîbrido Debora Plus}

Os dados obtidos para o teste de envelhecimento acelerado (com solução salina), utilizando-se duas temperaturas e três periodos de condicionamento, híbrido Debora Plus, encontram-se na Tabela 42.

Tabela 42. Dados médios obtidos para o teste de envelhecimento acelerado, com solução salina, de sementes de cinco lotes de tomate, híbrido Debora Plus.

\begin{tabular}{|c|c|c|c|c|c|c|}
\hline \multirow{3}{*}{$\begin{array}{c}\text { Debora } \\
\text { Plus }\end{array}$} & \multicolumn{6}{|c|}{ Envelhecimento acelerado (com solução salina) } \\
\hline & \multicolumn{3}{|c|}{$41^{\circ} \mathrm{C}$} & \multicolumn{3}{|c|}{$38^{\circ} \mathrm{C}$} \\
\hline & $48 \mathrm{~h}$ & $72 \mathrm{~h}$ & $96 \mathrm{~h}$ & $48 \mathrm{~h}$ & $72 \mathrm{~h}$ & $96 \mathrm{~h}$ \\
\hline Lotes & \multicolumn{6}{|c|}{ 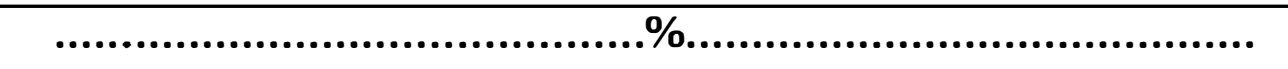 } \\
\hline 1 & $98 a^{*}$ & $95 a$ & $90 a$ & $95 a$ & $93 a$ & $91 \mathrm{a}$ \\
\hline 2 & $92 \mathrm{ab}$ & $86 b$ & $82 b$ & 92ab & $88 \mathrm{~b}$ & $83 a b$ \\
\hline 3 & $92 a b$ & 72c & 69c & 93ab & $82 \mathrm{bc}$ & $62 c$ \\
\hline 4 & $85 b c$ & $60 d$ & $60 c$ & $83 c$ & $74 c$ & $57 c$ \\
\hline 5 & $82 c$ & $67 \mathrm{~cd}$ & $80 b$ & $87 \mathrm{bc}$ & 79c & $76 b$ \\
\hline C.V.(\%) & 4,66 & & & & & \\
\hline
\end{tabular}


Analisando-se os resultados, notou-se que os periodos de $48 \mathrm{e}$ 72 horas, em ambas as temperaturas, revelaram, de modo geral, tendências semelhantes aos testes de germinação, emergência de plântulas em casa de vegetação e método Agroflora (Tabela 12), em termos de identificação dos lotes de menor potencial fisiológico (lotes $4 \mathrm{e}$ 5), o mesmo não ocorrendo para o periodo de 96 horas de envelhecimento, nas duas temperaturas.

Com relação ao grau de umidade das sementes após os periodos de condicionamento (Tabela 43), os resultados mostraram-se, em geral, semelhantes para os cinco lotes estudados.

Tabela 43. Dados médios referentes ao grau de umidade obtidos após os periodos de envelhecimento, com solução salina, de sementes de cinco lotes de tomate, híbrido Debora Plus.

\begin{tabular}{|c|c|c|c|c|c|c|}
\hline \multirow{3}{*}{$\begin{array}{c}\text { Debora } \\
\text { Plus }\end{array}$} & \multicolumn{6}{|c|}{ Grau de umidade após EA (com solução salina) } \\
\hline & \multicolumn{3}{|c|}{$41^{\circ} \mathrm{C}$} & \multicolumn{3}{|c|}{$38^{\circ} \mathrm{C}$} \\
\hline & $48 \mathrm{~h}$ & $72 \mathrm{~h}$ & $96 \mathrm{~h}$ & $48 \mathrm{~h}$ & $72 \mathrm{~h}$ & $96 \mathrm{~h}$ \\
\hline Lotes & \multicolumn{6}{|c|}{ 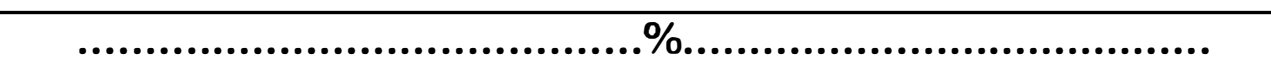 } \\
\hline 1 & 10,0 & 10,3 & 10,7 & 9,2 & 10,1 & 10,5 \\
\hline 2 & 9,3 & 9,7 & 10,2 & 8,9 & 9,2 & 10,0 \\
\hline 3 & 9,5 & 9,8 & 10,3 & 8,9 & 9,3 & 10,1 \\
\hline 4 & 9,8 & 10,2 & 10,7 & 9,1 & 9,9 & 10,3 \\
\hline 5 & 9,3 & 9,8 & 10,3 & 9,0 & 9,5 & 10,2 \\
\hline
\end{tabular}

Por outro lado, as sementes expostas à solução saturada do sal apresentaram valores menores e mais uniformes, após os periodos de condicionamento, do que os observados para as envelhecidas sem o uso de solução salina (Tabela 35), revelando que o método conseguiu 
retardar a absorção de água das sementes no teste de envelhecimento acelerado. Assim, é possivel supor que as condiçōes de envelhecimento com o uso de solução salina promoveriam efeitos menos drásticos, pois ao atingir menores teores de água, o grau de deterioração das sementes seria atenuado em relação ao normalmente verificado com o uso do método tradicional.

Uma vantagem da utilização de soluções saturadas de sais é que os valores de umidade relativa permanecem em niveis inferiores, suficientes para impedir o crescimento de microrganismos, minimizando, assim, a preocupação com efeitos de patógenos associados às sementes sobre os resultados do teste de envelhecimento acelerado (Jianhua \& McDonald, 1996).

Dessa forma, novos testes foram conduzidos, utilizando-se as combinaçōes mais promissoras de temperatura/periodo de condicionamento $\left(41^{\circ} \mathrm{C} / 48\right.$ e 72 horas; $38^{\circ} \mathrm{C} / 48$ e 72 horas), visando determinar o procedimento mais adequado. Os resultados estão apresentados na Tabela 44.

Pode-se observar que o periodo de 72 horas, tanto a $41^{\circ} \mathrm{C}$ quanto a $38^{\circ} \mathrm{C}$, forneceu de maneira geral informaçōes mais compativeis com a emergência de plântulas em casa de vegetação e método Agroflora (Tabela 12), quanto à classificação dos lotes em niveis de vigor, destacando o melhor desempenho do lote 1 e a qualidade inferior dos lotes 4 e 5 ; os lotes 2 e 3 foram identificados como de nivel intermediário, porém, com tendência de inferioridade para o lote 3.

A descrição do teste de envelhecimento cita a possibilidade da utilização de temperaturas de 40 a $45^{\circ} \mathrm{C}$; mais recentemente, grande parte dos pesquisadores que se dedicam a estudos sobre o teste indicam o uso de $41^{\circ} \mathrm{C}$ (Marcos Filho, 1999b). Dessa forma, foi considerada como mais adequada a combinação de $41^{\circ} \mathrm{C} / 72$ horas de 
condicionamento para a condução do teste de envelhecimento acelerado, com o uso de solução saturada de sal, híbrido Debora Plus.

Tabela 44. Dados médios obtidos para o teste de envelhecimento acelerado, com solução salina, de sementes de cinco lotes de tomate, híbrido Debora Plus.

\begin{tabular}{|c|c|c|c|c|}
\hline \multirow{3}{*}{$\begin{array}{c}\text { Debora } \\
\text { Plus }\end{array}$} & \multicolumn{4}{|c|}{ Envelhecimento acelerado (com solução salina) } \\
\hline & \multicolumn{2}{|c|}{$41^{\circ} \mathrm{C}$} & \multicolumn{2}{|c|}{$38^{\circ} \mathrm{C}$} \\
\hline & $48 \mathrm{~h}$ & $72 \mathrm{~h}$ & $48 \mathrm{~h}$ & $72 \mathrm{~h}$ \\
\hline Lotes & \multicolumn{2}{|c|}{$. \% \ldots . . . . . . . . . . .}$. & \multicolumn{2}{|c|}{................. } \\
\hline 1 & $94 a^{*}$ & $94 a$ & $95 a$ & $96 a$ \\
\hline 2 & $96 a$ & $85 b$ & $93 a$ & $87 \mathrm{~b}$ \\
\hline 3 & $92 \mathrm{ab}$ & $76 \mathrm{bc}$ & $87 a b$ & $78 \mathrm{bc}$ \\
\hline 4 & $80 c$ & $63 c$ & $78 b$ & $67 c$ \\
\hline 5 & $85 b c$ & $70 c$ & $83 b$ & $75 c$ \\
\hline C.V.(\%) & 5,59 & & & \\
\hline
\end{tabular}

*Comparacaáo de médias em cada coluna, pelo teste de Tukey a $5 \%$ de probabilidade.

O grau de umidade das sementes após os periodos de envelhecimento (Tabela 45) foi, de maneira geral, semelhante para todos os lotes, concordando com o obtido preliminarmente (Tabela 43), revelando, portanto, a eficiência do método em retardar a absorção de âgua pelas sementes. 
Tabela 45. Dados médios referentes ao grau de umidade obtidos após os periodos de envelhecimento, com solução salina, de sementes de cinco lotes de tomate, híbrido Debora Plus.

\begin{tabular}{|c|c|c|c|c|}
\hline \multirow{3}{*}{$\begin{array}{c}\text { Debora } \\
\text { Plus }\end{array}$} & \multicolumn{4}{|c|}{ Grau de umidade após EA (com solução salina) } \\
\hline & \multicolumn{2}{|c|}{$41^{\circ} \mathrm{C}$} & \multicolumn{2}{|c|}{$38^{\circ} \mathrm{C}$} \\
\hline & $48 \mathrm{~h}$ & $72 \mathrm{~h}$ & $48 \mathrm{~h}$ & $72 \mathrm{~h}$ \\
\hline Lotes & \multicolumn{2}{|c|}{ 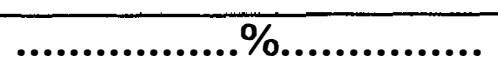 } & \multicolumn{2}{|c|}{ 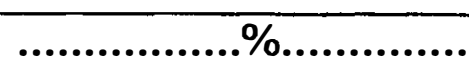 } \\
\hline 1 & 10,0 & 10,6 & 9,8 & 10,4 \\
\hline 2 & 9,7 & 9,8 & 9,0 & 9,3 \\
\hline 3 & 9,9 & 9,8 & 9,4 & 9,7 \\
\hline 4 & 9,8 & 10,3 & 9,7 & 10,2 \\
\hline 5 & 9,6 & 10,1 & 9,6 & 9,8 \\
\hline
\end{tabular}

\subsubsection{Hibrido Bruna}

Os resultados obtidos para o teste de envelhecimento acelerado (com solução salina), híbrido Bruna, utilizando-se duas temperaturas e três períodos de condicionamento encontram-se na Tabela 46.

Da mesma forma que o verificado para o hibrido Debora Plus, os periodos de 48 e 72 horas, em ambas as temperaturas, revelaram maior eficiência no sentido de identificar os lotes de qualidade mais baixa (lote 5 , seguido do lote 3 ) e os de melhor desempenho (em geral, lotes 1 e 2), concordando com a classificação obtida pelos testes de germinação e emergência de plântulas em casa de vegetação (Tabela 13). 
Tabela 46. Dados médios obtidos para o teste de envelhecimento acelerado, com solução salina, de sementes de cinco lotes de tomate, híbrido Bruna.

\begin{tabular}{|c|c|c|c|c|c|c|}
\hline \multirow[t]{3}{*}{ Bruna } & \multicolumn{6}{|c|}{ Envelhecimento acelerado (com solução salina) } \\
\hline & \multicolumn{3}{|c|}{$41^{\circ} \mathrm{C}$} & \multicolumn{3}{|c|}{$38^{\circ} \mathrm{C}$} \\
\hline & $48 \mathrm{~h}$ & $72 \mathrm{~h}$ & $96 \mathrm{~h}$ & $48 \mathrm{~h}$ & $72 \mathrm{~h}$ & $96 \mathrm{~h}$ \\
\hline Lotes & ....... & $\cdots$ & 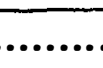 & ........ & ............. & ….... \\
\hline 1 & $97 a^{*}$ & $90 a$ & $85 a$ & $93 a$ & $92 a$ & $95 a$ \\
\hline 2 & $91 \mathrm{ab}$ & $89 a$ & $85 a$ & $87 a$ & $89 a b$ & $86 b$ \\
\hline 3 & $75 d$ & $71 c$ & $69 b$ & $72 b$ & $68 c$ & $71 c$ \\
\hline 4 & $85 \mathrm{bc}$ & $88 \mathrm{ab}$ & $89 a$ & $93 a$ & $86 a b$ & $89 b$ \\
\hline 5 & $81 \mathrm{~cd}$ & $81 b$ & $85 a$ & $76 b$ & $82 b$ & $84 b$ \\
\hline
\end{tabular}

C.V.(\%) 4,25

*Comparação de médias em cada coluna, pelo teste de Tukey a $5 \%$ de probabilidade.

Os dados de grau de umidade, após os períodos de envelhecimento (Tabela 47), foram semelhantes para os cinco lotes estudados. Assim como observado para o hibrido Debora Plus, as sementes expostas à solução saturada do sal apresentaram valores menores e mais uniformes do que os observados para as envelhecidas com o uso do método tradicional (Tabela 39). 
Tabela 47. Dados médios referentes ao grau de umidade obtidos após os periodos de envelhecimento, com solução salina, de sementes de cinco lotes de tomate, híbrido Bruna.

\begin{tabular}{|c|c|c|c|c|c|c|}
\hline \multirow[t]{3}{*}{ Bruna } & \multicolumn{6}{|c|}{ Grau de umidade após EA (com solução salina) } \\
\hline & \multicolumn{3}{|c|}{$41^{\circ} \mathrm{C}$} & \multicolumn{3}{|c|}{$38^{\circ} \mathrm{C}$} \\
\hline & $48 \mathrm{~h}$ & $72 \mathrm{~h}$ & $96 \mathrm{~h}$ & $48 \mathrm{~h}$ & $72 \mathrm{~h}$ & $96 \mathrm{~h}$ \\
\hline Lotes & ..... & $\cdots$ & ............. & ........... & $\ldots . . . .$. & $\ldots . .$. \\
\hline 1 & 9,6 & 9,9 & 10,6 & 9,7 & 10,0 & 10,3 \\
\hline 2 & 9,6 & 9,9 & 10,9 & 9,7 & 10,3 & 10,8 \\
\hline 3 & 10,0 & 10,4 & 10,7 & 10,1 & 10,6 & 10,9 \\
\hline 4 & 9,5 & 9,6 & 10,4 & 9,3 & 9,7 & 10,2 \\
\hline 5 & 9,9 & 10,3 & 10,8 & 9,9 & 10,4 & 10,5 \\
\hline
\end{tabular}

Assim, novos testes foram conduzidos, utilizando-se as combinações temperatura/periodo mais promissoras $\left(41^{\circ} \mathrm{C} / 48\right.$ e 72 horas; $38^{\circ} \mathrm{C} / 48$ e 72 horas), com a finalidade de determinar a metodologia mais adequada. As informações estão apresentadas na Tabela 48.

Com base nos resultados fornecidos pelos testes de germinação, emergência de plântulas em casa de vegetação e método Agroflora (Tabela 13), verificou-se que o periodo de 72 horas de condicionamento, a $41^{\circ} \mathrm{C}$ e $38^{\circ} \mathrm{C}$, foi o mais eficiente quanto à ordenação de lotes em diferentes niveis de vigor.

Em razão do uso mais freqũente da temperatura de $41^{\circ} \mathrm{C}$ para realização do teste de envelhecimento acelerado, foi considerada como mais adequada a combinação $41^{\circ} \mathrm{C} / 72$ horas de condicionamento. 
Tabela 48. Dados médios obtidos para o teste de envelhecimento acelerado, com solução salina, de sementes de cinco lotes de tomate, híbrido Bruna.

\begin{tabular}{|c|c|c|c|c|}
\hline \multirow[t]{3}{*}{ Bruna } & \multicolumn{4}{|c|}{ Envelhecimento acelerado (com solução salina) } \\
\hline & \multicolumn{2}{|c|}{$41^{\circ} \mathrm{C}$} & \multicolumn{2}{|c|}{$38^{\circ} \mathrm{C}$} \\
\hline & $48 \mathrm{~h}$ & $72 \mathrm{~h}$ & $48 \mathrm{~h}$ & $72 \mathrm{~h}$ \\
\hline Lotes & \multicolumn{2}{|c|}{ …...............\%................ } & \multicolumn{2}{|c|}{ …............................ } \\
\hline 1 & $95 a^{*}$ & $93 a$ & $95 a$ & $93 a$ \\
\hline 2 & $90 a b$ & $88 \mathrm{ab}$ & $90 a b$ & 91ab \\
\hline 3 & $73 c$ & 71c & $79 b$ & $78 c$ \\
\hline 4 & $86 b$ & $87 a b$ & $93 a$ & 92ab \\
\hline 5 & $85 b c$ & $83 \mathrm{bc}$ & $80 \mathrm{~b}$ & $84 \mathrm{bc}$ \\
\hline C.V.(\%) & 5,22 & & & \\
\hline
\end{tabular}

*Comparação de médias em cada coluna, pelo teste de Tukey a $5 \%$ de probabilidade.

O grau de umidade das sementes após o períodos de envelhecimento (Tabela 49) foi, em geral, semelhante para todos os lotes, estando de acordo com o obtido anteriormente (Tabela 47). 
Tabela 49. Dados médios referentes ao grau de umidade obtidos após os periodos de envelhecimento, com solução salina, de sementes de cinco lotes de tomate, híbrido Bruna.

\begin{tabular}{|c|c|c|c|c|}
\hline \multirow[t]{3}{*}{$\overline{\text { Bruna }}$} & \multicolumn{4}{|c|}{ Grau de umidade após EA (com solução salina) } \\
\hline & \multicolumn{2}{|c|}{$41^{\circ} \mathrm{C}$} & \multicolumn{2}{|c|}{$38^{\circ} \mathrm{C}$} \\
\hline & $48 \mathrm{~h}$ & $72 \mathrm{~h}$ & $48 \mathrm{~h}$ & $72 \mathrm{~h}$ \\
\hline Lotes & \multicolumn{2}{|c|}{ …..............\%............... } & \multicolumn{2}{|c|}{.................\%.............. } \\
\hline 1 & 9,6 & 10,2 & 9,2 & 9,8 \\
\hline 2 & 9,2 & 9,9 & 9,4 & 10,0 \\
\hline 3 & 10,2 & 10,6 & 10,1 & 10,4 \\
\hline 4 & 9,1 & 10,0 & 9,4 & 9,9 \\
\hline 5 & 9,6 & 10,4 & 9,5 & 10,1 \\
\hline
\end{tabular}

\subsubsection{Deterioração controlada}

\subsubsection{Hibrido Debora Plus}

Os dados obtidos para o teste de deterioração controlada, híbrido Debora Plus, utilizando-se sementes com três graus de umidade diferentes e dois periodos de condicionamento, estão apresentados na Tabela 50.

Examinando os dados, observou-se que as combinações $24 \mathrm{~h} / 24 \%$ e $48 \mathrm{~h} / 21 \%$ mostraram tendência de agrupamento das médias mais compativel com a ordenação dos lotes obtida pelos testes de emergência de plântulas em casa de vegetação e método Agroflora (Tabela 12). Assim, classificaram, de maneira geral, os lotes 1 e 2 como 
superiores; os lotes 4 e 5 como inferiores e, o lote 3, como de qualidade intermediária, porém, tendendo para inferioridade.

As demais combinações mostraram-se menos relacionadas com os testes de avaliação inicial da qualidade (Tabela 12) quanto à identificação de lotes de potencial fisiológico elevado.

Tabela 50. Dados médios obtidos para o teste de deterioração controlada de sementes de cinco lotes de tomate, hibrido Debora Plus.

\begin{tabular}{|c|c|c|c|c|c|c|}
\hline \multirow{3}{*}{$\begin{array}{c}\text { Debora } \\
\text { Plus }\end{array}$} & \multicolumn{6}{|c|}{ Deterioração controlada } \\
\hline & \multicolumn{3}{|c|}{$24 \mathrm{~h}$} & \multicolumn{3}{|c|}{$48 \mathrm{~h}$} \\
\hline & $19 \%$ & $21 \%$ & $24 \%$ & $19 \%$ & $21 \%$ & $24 \%$ \\
\hline Lotes & \multicolumn{3}{|c|}{ 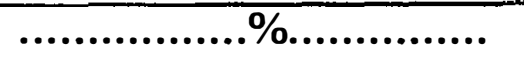 } & \multicolumn{3}{|c|}{ …..............\%................ } \\
\hline 1 & $93 a^{*}$ & $96 a$ & $89 a$ & $96 a$ & $92 a b$ & $86 a$ \\
\hline 2 & $86 b$ & $80 b$ & $91 \mathrm{a}$ & $80 b$ & $86 a$ & $91 \mathrm{a}$ \\
\hline 3 & $83 b c$ & $91 \mathrm{a}$ & $83 b c$ & $95 a$ & $73 b c$ & $88 a$ \\
\hline 4 & $67 d$ & $76 b$ & $70 d$ & $55 \mathrm{c}$ & $67 c$ & $65 b$ \\
\hline 5 & $73 \mathrm{~cd}$ & $81 b$ & $79 \mathrm{~cd}$ & $87 b$ & $73 b c$ & $73 b$ \\
\hline
\end{tabular}

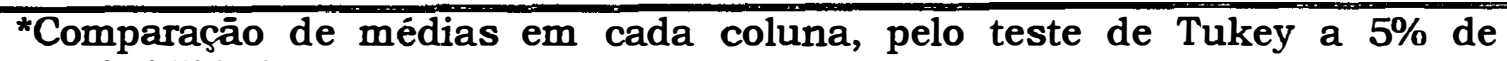
probabilidade.

Na Tabela 51 encontram-se os dados referentes ao grau de umidade das sementes após o periodo em banho-maria, no teste de deterioração controlada. Pode-se observar que as sementes permaneceram, praticamente, com os mesmos graus de umidade em relação ao início do teste, ou seja, $19 \%, 21 \%$ e $24 \%$. Assim, a técnica utilizada para a deterioração controlada mostrou-se eficiente, no 
sentido de manter constante o grau de umidade das sementes durante o decorrer do teste.

Tabela 51. Dados médios referentes ao grau de umidade obtidos após o teste de deterioração controlada de sementes de cinco lotes de tomate, híbrido Debora Plus.

\begin{tabular}{|c|c|c|c|c|c|c|}
\hline \multirow{3}{*}{$\begin{array}{c}\text { Debora } \\
\text { Plus }\end{array}$} & \multicolumn{6}{|c|}{ Grau de umidade após DC } \\
\hline & \multicolumn{3}{|c|}{$24 \mathrm{~h}$} & \multicolumn{3}{|c|}{$48 \mathrm{~h}$} \\
\hline & $19 \%$ & $21 \%$ & $24 \%$ & $19 \%$ & $21 \%$ & $24 \%$ \\
\hline Lotes & \multicolumn{3}{|c|}{ 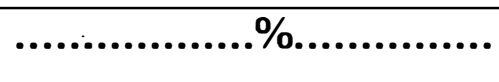 } & \multicolumn{3}{|c|}{ 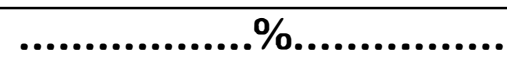 } \\
\hline 1 & 18,9 & 20,8 & 24,2 & 18,7 & 21,0 & 23,7 \\
\hline 2 & 19,4 & 20,7 & 23,8 & 19,0 & 20,7 & 24,1 \\
\hline 3 & 18,6 & 20,7 & 23,7 & 19,2 & 20,9 & 24,1 \\
\hline 4 & 18,7 & 20,8 & 23,7 & 19,4 & 20,6 & 23,8 \\
\hline 5 & 18,7 & 21,1 & 24,2 & 19,5 & 20,7 & 24,4 \\
\hline
\end{tabular}

Dessa forma, novos testes foram conduzidos utilizando-se as melhores combinações período/temperatura obtidas $(24 \mathrm{~h} / 24 \%$ e $48 \mathrm{~h} / 21 \%$ ), visando determinar o procedimento mais promissor.

Analisando a Tabela 52, pode-se verificar que o periodo de 24 horas em banho-maria, a $24 \%$ de água, proporcionou uma separação mais eficiente dos lotes em diferentes níveis de potencial fisiológico, destacando a superioridade dos lotes 1 e 2, a inferioridade dos lotes 4 e 5 , ficando o lote 3 entre os extremos, confirmando o obtido na avaliação anterior (Tabela 50). É importante salientar que essa ordenação foi semelhante, de maneira geral, à observada pelos testes de emergência de plântulas em casa de vegetação e método Agroflora (Tabela 12); além 
disso, o periodo de 24 horas apresentou a vantagem de possibilitar respostas mais rápidas sobre a qualidade dos lotes.

A combinação $48 \mathrm{~h} / 21 \%$ classificou os lotes de maneira semelhante à obtida pelo teste de germinação (Tabela 12), identificando os lotes 3 , 4 e 5 como os potencial fisiológico mais baixo.

Tabela 52. Dados médios obtidos para o teste de deterioração controlada de sementes de cinco lotes de tomate, hibrido Debora Plus.

\begin{tabular}{|c|c|c|}
\hline \multirow[t]{2}{*}{ Debora Plus } & \multicolumn{2}{|c|}{ Deterioração controlada } \\
\hline & $24 \mathrm{~h} / 24 \%$ & $48 \mathrm{~h} / 21 \%$ \\
\hline Lotes & ..........\%......... & ..........\%.......... \\
\hline 1 & $92 a^{*}$ & $94 a$ \\
\hline 2 & $94 a$ & $96 a$ \\
\hline 3 & $88 a b$ & $75 b$ \\
\hline 4 & $68 c$ & $78 b$ \\
\hline 5 & $79 b c$ & $78 \mathrm{~b}$ \\
\hline C.V.(\%) & 5,94 & \\
\hline
\end{tabular}

Os graus de umidade das sementes, após os periodos em banho-maria (Tabela 53), praticamente não se alteraram em comparação aos iniciais, ou seja, $21 \%$ e $24 \%$, confirmando os resultados obtidos preliminarmente (Tabela 51). 
Tabela 52. Dados médios referentes ao grau de umidade obtidos após o teste de deterioração controlada de sementes de cinco lotes de tomate, híbrido Debora Plus.

\begin{tabular}{ccc}
\hline Debora Plus & \multicolumn{2}{c}{ Grau de umidade após DC } \\
\cline { 2 - 3 } & $24 \mathrm{~h} / 24 \%$ & $48 \mathrm{~h} / 21 \%$ \\
\hline Lotes & $\ldots \ldots \ldots \% \ldots \ldots \ldots \ldots \ldots \ldots$ \\
1 & 23,6 & $\ldots \ldots \ldots . . . . \ldots \ldots$ \\
2 & 23,7 & 20,9 \\
3 & 24,0 & 21,0 \\
4 & 23,7 & 21,1 \\
5 & 24,2 & 21,0 \\
\hline
\end{tabular}

\subsubsection{Híbrido Bruna}

Na Tabela 54 encontram-se os dados referentes ao teste de deterioração controlada, utilizando-se três graus de umidade e dois periodos em banho-maria.

Assim como observado para o híbrido Debora Plus, as combinações $24 \mathrm{~h} / 24 \%$ e $48 \mathrm{~h} / 21 \%$ mostraram-se, em geral, concordantes com os resultados obtidos nos testes de germinação e emergência de plãntulas em casa de vegetação (Tabela 13) quanto à separação dos lotes em niveis de vigor e, por esse motivo, foram consideradas como mais promissoras. Nesse sentido, revelaram a superioridade dos lotes 1,2 e 4 e o pior desempenho dos lotes 3 e 5 . 
Tabela 54. Dados médios obtidos para o teste de deterioração controlada de sementes de cinco lotes de tomate, hibrido Bruna.

\begin{tabular}{|c|c|c|c|c|c|c|}
\hline \multirow[t]{3}{*}{ Bruna } & \multicolumn{6}{|c|}{ Deterioração controlada } \\
\hline & \multicolumn{3}{|c|}{$24 \mathrm{~h}$} & \multicolumn{3}{|c|}{$48 \mathrm{~h}$} \\
\hline & $19 \%$ & $21 \%$ & $24 \%$ & $19 \%$ & $21 \%$ & $24 \%$ \\
\hline Lotes & \multicolumn{6}{|c|}{ 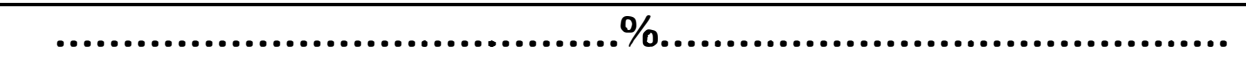 } \\
\hline 1 & $90 a^{*}$ & $90 a$ & $94 a$ & $93 a$ & $91 \mathrm{a}$ & $91 \mathrm{a}$ \\
\hline 2 & $88 \mathrm{a}$ & $89 a$ & $92 \mathrm{ab}$ & $91 \mathrm{ab}$ & $87 a$ & $87 a$ \\
\hline 3 & $71 \mathrm{~b}$ & $67 \mathrm{~b}$ & $78 \mathrm{c}$ & $66 c$ & $75 b$ & $67 b$ \\
\hline 4 & $92 a$ & $89 a$ & $93 a$ & $92 a$ & $89 a$ & $86 a$ \\
\hline 5 & $89 a$ & $87 a$ & $83 \mathrm{bc}$ & $83 b$ & $75 b$ & $87 a$ \\
\hline C.V.(\%) & 4,68 & & & & & \\
\hline
\end{tabular}

Com relação ao grau de umidade das sementes após os periodos em banho-maria (Tabela 55), pode-se observar que a técnica empregada para realização da deterioração controlada foi eficiente, mantendo aproximadamente constantes os graus de umidade das sementes durante o decorrer do teste. 
Tabela 55. Dados médios referentes ao grau de umidade obtidos após o teste de deterioração controlada de sementes de cinco lotes de tomate, hibrido Bruna.

\begin{tabular}{|c|c|c|c|c|c|c|}
\hline \multirow[t]{3}{*}{ Bruna } & \multicolumn{6}{|c|}{ Grau de umidade após DC } \\
\hline & \multicolumn{3}{|c|}{$24 \mathrm{~h}$} & \multicolumn{3}{|c|}{$48 \mathrm{~h}$} \\
\hline & $19 \%$ & $21 \%$ & $24 \%$ & $19 \%$ & $21 \%$ & $24 \%$ \\
\hline Lotes & & & & $\overline{c . . . . . .}$ & ......... & $\ldots \ldots .$. \\
\hline 1 & 19,4 & 20,8 & 23,7 & 19,4 & 21,2 & 23,7 \\
\hline 2 & 18,7 & 21,0 & 23,6 & 18,7 & 20,8 & 23,9 \\
\hline 3 & 19,0 & 21,0 & 23,9 & 19,4 & 21,3 & 24,2 \\
\hline 4 & 18,8 & 21,2 & 23,8 & 19,3 & 21,7 & 23,9 \\
\hline 5 & 19,3 & 20,9 & 23,8 & 18,7 & 20,8 & 24,4 \\
\hline
\end{tabular}

Consequentemente, novos testes foram conduzidos, empregando-se as melhores combinações periodo/grau de umidade ( $24 \mathrm{~h} / 24 \%$ e $48 \mathrm{~h} / 21 \%)$, com a finalidade de escolher o método mais adequado. Na Tabela 56 encontram-se os resultados referentes a essa fase de estudo do teste de deterioração controlada.

Estabelecendo relações com os demais testes (Tabela 13), constatou-se que o periodo de 24 horas em banho-maria e sementes com $24 \%$ de água mostrou ser o indicador de potencial fisiológico mais eficiente, classificando, de modo geral, como de melhor desempenho os lotes 1,2 e 4 e de pior qualidade os lotes 3 e 5 , confirmando o obtido anteriormente. 
Tabela 56. Dados médios obtidos para o teste de deterioraçāo controlada de sementes de cinco lotes de tomate, híbrido Bruna.

\begin{tabular}{|c|c|c|}
\hline \multirow[t]{2}{*}{ Bruna } & \multicolumn{2}{|c|}{ Deterioraçāo controlada } \\
\hline & $24 \mathrm{~h} / 24 \%$ & $48 \mathrm{~h} / 21 \%$ \\
\hline Lotes & ..........\%.......... & ..........\%.......... \\
\hline 1 & $91 a^{*}$ & $97 a$ \\
\hline 2 & 89ab & $90 \mathrm{~b}$ \\
\hline 3 & $68 c$ & 77c \\
\hline 4 & $90 a$ & $95 a$ \\
\hline 5 & $78 \mathrm{bc}$ & $79 c$ \\
\hline C.V.(\%) & 4,74 & \\
\hline
\end{tabular}

*Comparaçāo de médias em cada coluna, pelo teste de Tukey a 5\% de probabilidade.

Na Tabela 57 estāo apresentados os dados de grau de umidade das sementes após os periodos em banho-maria, revelando que as sementes permaneceram, praticamente, com os mesmos graus de umidade em relaçāo ao início do teste, isto é, $21 \%$ e $24 \%$. 
Tabela 57. Dados médios referentes ao grau de umidade obtidos após o teste de deterioração controlada de sementes de cinco lotes de tomate, híbrido Bruna.

\begin{tabular}{ccc}
\hline \multirow{2}{*}{ Bruna } & \multicolumn{2}{c}{ Grau de umidade após DC } \\
\cline { 2 - 3 } & $24 \mathrm{~h} / 24 \%$ & $48 \mathrm{~h} / 21 \%$ \\
\hline Lotes & $\ldots \ldots \ldots \% \ldots \ldots \ldots \ldots \ldots \ldots$ \\
1 & 23,9 & 21,2 \\
2 & 23,6 & 20,7 \\
3 & 24,0 & 21,1 \\
4 & 24,3 & 21,0 \\
5 & 24,1 & 20,8 \\
\hline
\end{tabular}

\subsubsection{Considerações finais (Etapa 1)}

Analisando de uma maneira geral os resultados obtidos na Etapa 1, verificou-se para o hibrido Debora Plus que os testes de emergência de plântulas em casa de vegetação, método Agroflora, lixiviação de potássio, envelhecimento acelerado (com e sem o uso de solução saturada de sal) e deterioração controlada apresentaram tendências semelhantes na separação dos lotes, embora pequenas variações tenham ocorrido. No caso da condutividade elétrica, durante toda essa primeira etapa de estudo, pode-se observar discordância marcante quanto à identificação da qualidade dos lotes 1 e 5 , em relação aos demais testes, o que acabou comprometendo a eficiência da avaliação.

Em contrapartida, para o híbrido Bruna, os testes empregados demonstraram, de modo geral, aptidão para separar os lotes em niveis 
de potencial fisiológico. Vale ressaltar, no entanto, o comportamento diferenciado do lote 5 no teste de lixiviação de potássio, identificado ora como apresentando alto vigor (Tabela 33), ora qualidade inferior (Tabela 13)

Assim, com relação especificamente ao teste de condutividade elétrica houve eficiência variável em termos de separação dos lotes quanto ao vigor, de acordo com o híbrido estudado.

Analisando-se a sensibilidade dos periodos de embebição em detectar diferenças entre os lotes nos estudos de condutividade elétrica, notou-se, de maneira geral, que as avaliações feitas com 1 hora apresentaram tendências nesta direção. Contudo, para o hibrido Bruna, as diferenças entre os lotes tornaram-se mais acentuadas com o decorrer do processo de embebição. Dessa forma, levando-se em consideração que para utilização do referido teste, em análise de rotina, as diferenças nos valores de condutividade devem ser suficientemente nitidas, foram considerados como mais adequados os periodos de embebição superiores a 6 horas.

Por outro lado, pode-se constatar, em geral, que houve discordância entre os testes de condutividade elétrica e o de lixiviação de potássio quanto à classificação dos lotes 1 e 5 (híbrido Debora Plus) e lote 5 (hibrido Bruna), sendo que os demais lotes foram identificados de maneira semelhante.

Apesar de ambos apresentarem principios similares e, ainda, o potássio ser considerado o principal ion em termos de quantidade lixiviada pelas sementes (Lott et al., 1991), a forma de avaliação de cada teste pode, talvez, estar interferindo no resultado, ou seja, pode haver diferenças quanto à eficiência em se avaliar um ion ou o conjunto de ions. 
Assim, foi considerado interessante a determinação da quantidade de outro ion liberada por ocasiāo da embebição das sementes, na próxima fase de estudo (Etapa 2), com a finalidade de revelar as causas das diferenças entre os dois testes. No caso, foi escolhido o sódio, uma vez que sua determinação foi viabilizada pelo Fotômetro de Chama.

Portanto, os resultados obtidos nessa primeira etapa de testes, ou seja, os procedimentos que forneceram indicações consistentes e promissoras a respeito do potencial fisiológico das sementes, foram avaliados em um segundo experimento (Etapa 2), através de estudos comparativos entre os testes, procurando-se verificar sua eficiência quanto à identificação de diferentes niveis de vigor dos lotes de sementes de tomate. 
4.2. Etapa 2 - Comparação entre os testes para avaliação do potencial fisiológico das sementes, utilizando-se os protocolos considerados mais eficientes para a condução de cada um deles, com base nas informações obtidas durante a primeira etapa.

\subsubsection{Híbrido Debora Plus}

\subsubsection{Análise comparativa entre os testes}

Analisando-se os resultados apresentados na Tabela 58, observou-se que, em termos de germinação, os lotes 1 e 2 mostraram-se superiores aos demais, os quais não diferiram entre si.

Tabela 58. Dados médios de grau de umidade, germinação, emergência em casa de vegetação e método Agroflora, de sementes de cinco lotes de tomate, híbrido Debora Plus.

\begin{tabular}{ccccc}
\hline $\begin{array}{c}\text { Debora } \\
\text { Plus }\end{array}$ & $\begin{array}{c}\text { Grau de } \\
\text { umidade }\end{array}$ & Germinação & $\begin{array}{c}\text { Emergência } \\
\text { de Plântulas }\end{array}$ & $\begin{array}{c}\text { Método } \\
\text { Agroflora }\end{array}$ \\
\hline Lotes & $\ldots \ldots \ldots \ldots \ldots \ldots \ldots \ldots \ldots \ldots \ldots \ldots \ldots \ldots \ldots \ldots \ldots \ldots \ldots \ldots \ldots \ldots \ldots \ldots \ldots \ldots \ldots \ldots$ & $9 \ldots \ldots \ldots \ldots$ \\
1 & 8,4 & $91 \mathrm{a} *$ & $92 \mathrm{a}$ & $92 \mathrm{a}$ \\
2 & 8,2 & $90 \mathrm{a}$ & $87 \mathrm{ab}$ & $94 \mathrm{a}$ \\
3 & 8,1 & $84 \mathrm{~b}$ & $81 \mathrm{bc}$ & $81 \mathrm{~b}$ \\
4 & 8,6 & $81 \mathrm{~b}$ & $70 \mathrm{c}$ & $74 \mathrm{~b}$ \\
5 & 8,7 & $81 \mathrm{~b}$ & $79 \mathrm{bc}$ & $77 \mathrm{~b}$ \\
\hline C.V. (\%) & - & 2,71 & 6,71 & 5,32 \\
\hline${ }^{*}$ Comparação de médias em cada coluna, pelo teste de Tukey a $5 \%$ de \\
probabilidade.
\end{tabular}


$O$ teste de emergência de plântulas em casa de vegetação (Tabela 58) identificou o lote 1 como de potencial fisiológico superior, apesar de estatisticamente semelhante ao lote 2 , que não diferiu dos lotes 3 e 5 . Estes, por sua vez, foram significativamente semelhantes ao lote 4 , revelado como o de pior desempenho.

Com relação ao método Agroflora para avaliação do vigor de sementes de tomate (Tabela 58), verificou-se que os lotes 1 e 2 apresentaram qualidade mais alta que os lotes 3,4 e 5 , que não diferiram entre si.

Quanto ao grau de umidade das sementes antes da realização dos testes (Tabela 58), verificou-se que os valores foram semelhantes entre os lotes estudados, fato este importante para padronização das avaliações e obtenção de resultados confiáveis.

Na Tabela 59 encontram-se os dados obtidos para os testes de condutividade elétrica, lixiviação de potássio e lixiviação de sódio.

Com base nos resultados de condutividade elétrica, verificouse que ambos os periodos de embebição (6 e 24 horas) mostraram concordância quanto à ordenação de lotes, indicando os lotes 2,3 e 5 como superiores e o lote 1 como inferior, ficando o lote 4 entre os extremos. Entretanto, da mesma forma como observado na Etapa 1, a condutividade elétrica não forneceu informações semelhantes aos demais testes empregados (Tabela 58).

O teste de lixiviação de potássio, por sua vez, proporcionou uma separação dos lotes de qualidade superior (lotes 1, 2 e 3), inferior (lote 4) e intermediária (lote 5), demonstrando, em geral, sensibilidade semelhante aos demais testes (Tabela 58) no sentido de apontar o lote 5 , seguido do lote 4 , como os de pior desempenho. 
Tabela 59. Dados médios obtidos para os testes de condutividade elétrica (após 6 e 24h de embebição), de lixiviação de potássio e de lixiviação de sódio, de sementes de cinco lotes de tomate, híbrido Debora Plus.

\begin{tabular}{|c|c|c|c|c|}
\hline \multirow{2}{*}{$\begin{array}{c}\text { Debora } \\
\text { Plus }\end{array}$} & \multicolumn{2}{|c|}{$\mathrm{CE}$} & \multirow[t]{2}{*}{$\mathrm{K}^{+}$} & \multirow[t]{2}{*}{$\mathrm{Na}^{+}$} \\
\hline & $6 \mathrm{~h}$ & $24 h$ & & \\
\hline Lotes & \multicolumn{2}{|c|}{$\ldots . . . . \mu \mathrm{mho} / \mathrm{cm} / \mathrm{g} . . . . .}$. & \multicolumn{2}{|c|}{ 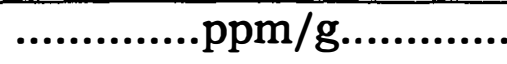 } \\
\hline 1 & $482,4 c^{*}$ & $583,7 \mathrm{c}$ & $20 a$ & $1649 b$ \\
\hline 2 & $40,9 a$ & $47,5 a$ & $12 a$ & $5 a$ \\
\hline 3 & $39,6 a$ & $51,4 a$ & $22 a$ & $7 a$ \\
\hline 4 & $78,5 b$ & $105,9 b$ & $120 c$ & $5 a$ \\
\hline 5 & $43,7 a$ & $52,1 a$ & $34 b$ & $5 a$ \\
\hline C.V.(\%) & 7,95 & 7,95 & 6,0 & 1,38 \\
\hline
\end{tabular}

Analisando de forma comparativa estes resultados com os obtidos pelo teste de condutividade elétrica, constatou-se que houve, novamente, diferenças entre ambos quanto à classificação dos lotes $1 \mathrm{e}$ 5: na condutividade elétrica, foram identificados, respectivamente, como de baixo e alto vigor, ao passo que na lixiviação de potássio, como de baixo e médio vigor, respectivamente.

Complementando estas informações, através da lixiviação de sódio, pode-se verificar que a provável causa da discrepância entre os testes de condutividade elétrica e de lixiviação de potássio, com relação à classificação do lote 1 , baseia-se no fato de que o principal ion liberado durante a embebição dessas sementes foi o sódio, sendo o responsável, portanto, pelas altas leituras de condutividade observadas, para o referido lote, em ambas as etapas. 
Esse fato pode confirmar a hipótese levantada anteriormente, ou seja, da maior eficiência de se avaliar um ion (lixiviação de potássio) ao invés de um conjunto de ions (condutividade elétrica), em sementes de tomate.

Na Tabela 60 estão apresentados os resultados da análise da composição química de sementes dos cinco lotes de tomate, híbrido Debora Plus.

Tabela 60. Resultados da análise da composição química de sementes de cinco lotes de tomate, híbrido Debora Plus.

\begin{tabular}{|c|c|c|c|c|c|c|c|}
\hline $\begin{array}{c}\text { Debora } \\
\text { Plus }\end{array}$ & $\overline{\mathrm{N}}$ & $\mathbf{P}$ & $\overline{\mathrm{K}}$ & $\mathrm{Ca}$ & $\overline{\mathrm{Mg}}$ & $\mathbf{S}$ & $\mathrm{Na}$ \\
\hline Lotes & \multicolumn{7}{|c|}{ 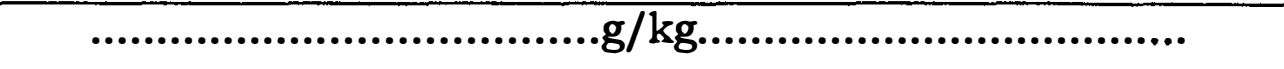 } \\
\hline 1 & 39,90 & 6,54 & 5,34 & 1,06 & 3,74 & 2,06 & 2,30 \\
\hline 2 & 45,50 & 5,08 & 4,59 & 0,51 & 3,17 & 1,92 & 0,04 \\
\hline 3 & 44,38 & 3,74 & 5,34 & 0,88 & 4,11 & 1,81 & 1,02 \\
\hline 4 & 46,76 & 4,36 & 6,89 & 0,65 & 4,07 & 2,09 & 0,05 \\
\hline 5 & 46,06 & 9,34 & 6,89 & 0,50 & 4,14 & 1,92 & 0,04 \\
\hline $\begin{array}{c}\text { Debora } \\
\text { Plus }\end{array}$ & $\mathrm{B}$ & $\mathrm{Cu}$ & \multicolumn{2}{|c|}{ Fe } & $\mathrm{Mn}$ & $\mathrm{Zn}$ & Proteina \\
\hline Lotes & \multicolumn{6}{|c|}{ 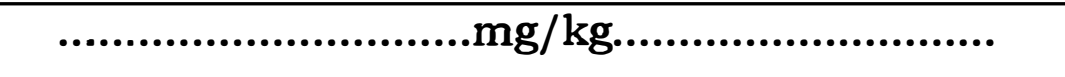 } & $\ldots g / \mathrm{kg} .$. \\
\hline 1 & 2,9 & 19,8 & & & 57,2 & 104,2 & 249,37 \\
\hline 2 & 5,7 & 14,5 & & & 42,9 & 78,8 & 284,37 \\
\hline 3 & 3,5 & 19,1 & & & 50,8 & 103,6 & 277,37 \\
\hline 4 & 11,9 & 16,5 & & & 55,1 & 81,6 & 292,25 \\
\hline 5 & 10,2 & 16,8 & & & 52,1 & 92,4 & 287,87 \\
\hline
\end{tabular}


Esta análise foi realizada com a finalidade de verificar se os resultados da lixiviação de potássio ou da condutividade elétrica poderiam ser influenciados pela concentraçāo de ions presentes nas sementes. Esta observação pode oferecer maior segurança para a interpretaçāo dos resultados obtidos em testes de liberaçāo de exsudatos, pois é desejável que as sementes avaliadas não apresentem variações acentuadas nas concentrações de ions e, mais especificamente no presente trabalho, nas de potássio e de sódio.

Examinando-se os resultados verificou-se que os valores de potássio não variaram acentuadamente entre os lotes, embora tenham sido encontrados valores mais altos para os lotes 4 e 5 , os quais foram apontados pelo teste de lixiviaçāo de potássio (Tabela 59) como de qualidade inferior. A análise de sódio, por sua vez, mostrou diferenças entre os lotes, merecendo ser destacado o lote 1 , identificado no teste de lixiviação de sódio como o de pior desempenho.

Os dados obtidos para análise química do exsudato de sementes dos cinco lotes de tomate, híbrido Debora Plus, estão apresentados na Tabela 61.

Esta determinação foi realizada com o objetivo de se identificar a natureza e a concentração de eletrólitos presentes na soluçāo de embebição das sementes.

Os valores de potássio pouco variaram entre os lotes estudados, com exceção do lote 4, apontado como o de maior valor; este lote foi classificado no teste de lixiviação de potássio (Tabela 59) como o de potencial fisiológico mais baixo. $E$ interessante notar que o lote 5 apresentou concentraçāo de $\mathrm{K}^{+}$semelhante a dos lotes 1 e 3 , porém desempenho inferior (Tabela 59), indicando que embora a concentraçāo inicial seja similar, a liberaçāo do íon pode estar relacionada à condiçāo fisiológica da semente. 
Tabela 61. Resultados da análise quimica do exsudato de sementes de cinco lotes de tomate, híbrido Debora Plus.

\begin{tabular}{ccccccccc}
\hline $\begin{array}{c}\text { Debora } \\
\text { Plus }\end{array}$ & $\mathrm{NH}_{4}{ }^{+}$ & $\mathrm{NO}_{3}{ }^{-}$ & $\mathrm{P}$ & $\mathrm{K}$ & $\mathrm{Ca}$ & $\mathrm{Mg}$ & $\mathrm{S}$ \\
\hline Lotes & $\ldots \ldots \ldots \ldots \ldots \ldots \ldots \ldots \ldots \ldots \ldots . \mathrm{mg} / 1 \ldots \ldots \ldots \ldots \ldots \ldots \ldots \ldots \ldots$ \\
1 & 14,84 & 14,84 & 0 & 0,7 & 0,9 & 0,08 & 2,85 \\
2 & 25,97 & 11,13 & 0 & 0,3 & 0,2 & 0,11 & 2,69 \\
3 & 18,55 & 11,13 & 0 & 0,6 & 0,9 & 0,21 & 3,01 \\
4 & 29,68 & 25,97 & 0,38 & 2,8 & 0,4 & 0,30 & 3,48 \\
5 & 25,97 & 11,13 & 0 & 0,6 & 0,5 & 0,19 & 3,01 \\
& & & & & & & \\
\hline Debora & $\mathrm{Na}$ & $\mathrm{B}$ & $\mathrm{Cu}$ & $\mathrm{Fe}$ & $\mathrm{Mn}$ & $\mathrm{Zn}$ & Proteina \\
Plus & & & & & & & \\
\hline Lotes & $\ldots \ldots \ldots \ldots \ldots \ldots \ldots \ldots \ldots \ldots . . \mathrm{mg} / 1 \ldots \ldots \ldots \ldots \ldots \ldots \ldots \ldots \ldots$ \\
1 & 30,6 & 0,21 & 0,008 & 0,136 & 0,042 & 0,156 & 5,0 \\
2 & 3,1 & 0,33 & 0,074 & 0,180 & 0,008 & 0,162 & 6,25 \\
3 & 4,4 & 0,35 & 0,074 & 0,140 & 0,042 & 0,190 & 5,0 \\
4 & 2,2 & 0,28 & 0,016 & 0,162 & 0,020 & 0,076 & 9,40 \\
5 & 2,6 & 0,34 & 0,012 & 0,126 & 0,018 & 0,094 & 6,25 \\
\hline
\end{tabular}

No caso do sódio, constataram-se variaçōes entre os lotes, especialmente para o lote 1, o qual apresentou valor acentuadamente superior aos demais lotes. Vale ressaltar, ainda, que o referido lote foi identificado, nos testes de lixiviação de sódio e de condutividade elétrica (Tabela 59), como o de menor desempenho. Nesse sentido, pode-se inferir que o teste de lixiviação de potássio mostrou-se mais eficiente quanto à separação dos lotes em níveis de vigor. 
Na Tabela 62 encontram-se os dados obtidos para os testes de envelhecimento acelerado (procedimento tradicional e com o uso de solução saturada de sal) e de deterioração controlada.

Tabela 62. Dados médios obtidos para os testes de envelhecimento acelerado (tradicional e com solução salina) e de deterioração controlada, de sementes de cinco lotes de tomate, híbrido Debora Plus.

\begin{tabular}{|c|c|c|c|}
\hline \multirow{2}{*}{$\begin{array}{c}\text { Debora } \\
\text { Plus }\end{array}$} & EA-tradicional & ução salina & DC \\
\hline & \multicolumn{2}{|c|}{$\left(41^{\circ} \mathrm{C} / 72 \mathrm{~h}\right)$} & $(24 \% / 24 h)$ \\
\hline Lotes & \multicolumn{2}{|c|}{ 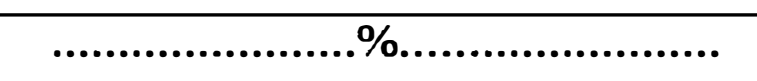 } & ........\%........ \\
\hline 1 & $89 a^{*}$ & $96 a$ & $95 a$ \\
\hline 2 & $84 a b$ & $89 a b$ & $91 \mathrm{ab}$ \\
\hline 3 & $77 \mathrm{bc}$ & $83 \mathrm{bc}$ & $87 \mathrm{bc}$ \\
\hline 4 & $73 c$ & $73 c$ & $74 d$ \\
\hline 5 & $71 c$ & $79 b c$ & $83 \mathrm{~cd}$ \\
\hline C.V.(\%) & 3,91 & 6,09 & 3,43 \\
\hline
\end{tabular}

*Comparação de médias em cada coluna, pelo teste de Tukey a $5 \%$ de probabilidade.

O teste de envelhecimento (tradicional) revelou eficiência no sentido de indicar o lote 1 como o de melhor desempenho e os lotes $4 \mathrm{e}$ 5 como de qualidade inferior. Por sua vez, os lotes 2 e 3 demonstraram desempenho intermediário, com tendência de inferioridade para o lote 3.

Assim, a maior sensibilidade às condições de elevada temperatura e umidade relativa, exibida pelos lotes 4 e 5 , indicou que os mesmos encontravam-se num estádio mais avançado de deterioração em relação aos demais lotes. Pode-se considerar, em geral, que este 
teste exibiu concordância com a germinação, emergência de plântulas em casa de vegetação e método Agroflora (Tabela 58) quanto à ordenação dos lotes.

Por sua vez, o teste de envelhecimento acelerado (com solução salina) mostrou a mesma tendência do procedimento tradicional com relação à separação dos lotes em niveis de potencial fisiológico, com exceção do lote 5, agora classificado como de qualidade intermediária, porém, tendendo para inferioridade.

Com referência aos resultados do teste de deterioração controlada, observou-se comportamento semelhante ao teste de envelhecimento acelerado (tradicional) em termos de identificação dos lotes.

Destacando-se as principais informações obtidas com os testes para avaliação do vigor (envelhecimento acelerado e deterioração controlada) e estabelecendo relaçōes com a emergência das plântulas em casa de vegetação (Tabela 58 ), verificou-se que a correspondência entre os dados fornecidos pelas avaliações de laboratório e os de emergência foi, em geral, positiva, especialmente para o teste de envelhecimento acelerado com o uso de solução saturada de sal.

Com relação aos testes de condutividade elétrica e de lixiviação de potássio (Tabela 59), pode-se considerar que este último mostrou-se mais eficiente para a estimativa do vigor de sementes de tomate, hibrido Debora Plus, uma vez que proporcionou, em geral, separação dos lotes de menor potencial fisiológico compativel com os outros testes.

O grau de umidade das sementes após os periodos de condicionamento, dos testes de envelhecimento acelerado e deterioração controlada, encontram-se na Tabela 63. 
Tabela 63. Dados médios referentes ao grau de umidade das sementes, obtidos após os periodos de condicionamento dos testes de envelhecimento acelerado (tradicional e com solução salina) e de deterioração controlada, híbrido Debora Plus.

\begin{tabular}{|c|c|c|c|}
\hline \multirow{3}{*}{$\begin{array}{c}\text { Debora } \\
\text { Plus }\end{array}$} & \multicolumn{3}{|c|}{ Grau de umidade após condicionamento } \\
\hline & EA-tradicional & EA-solução salina & $\mathrm{DC}$ \\
\hline & \multicolumn{2}{|c|}{$\left(41^{\circ} \mathrm{C} / 72 \mathrm{~h}\right)$} & $(24 \% / 24 h)$ \\
\hline Lotes & \multicolumn{2}{|c|}{ 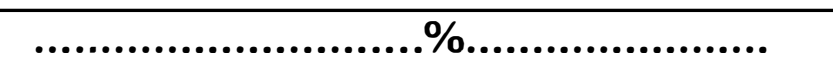 } & ........\%........ \\
\hline 1 & 43,1 & 10,4 & 23,9 \\
\hline 2 & 39,4 & 9,5 & 24,1 \\
\hline 3 & 39,7 & 9,6 & 24,4 \\
\hline 4 & 41,3 & 10,2 & 23,7 \\
\hline 5 & 40,9 & 10,1 & 24,0 \\
\hline
\end{tabular}

Sementes envelhecidas artificialmente, sem o uso de solução salina, mostraram elevação acentuada no grau de umidade, atingindo valores entre 39,4 e $43,1 \%$. Por outro lado, as sementes expostas à solução saturada do sal apresentaram valores menores e mais uniformes do que os observados para as envelhecidas sem o uso do sal, ficando entre 9,5 a $10,4 \%$, revelando a eficiência do método em retardar a absorção de água de sementes pequenas no teste de envelhecimento acelerado.

Com relação aos dados referentes ao grau de umidade após o periodo em banho-maria, no teste de deterioração controlada, pode-se verificar que as sementes permaneceram, praticamente, com o mesmo grau de umidade em comparação ao início do teste, ou seja, 24\%. Dessa forma, a técnica utilizada para deterioração mostrou-se eficiente, 
mantendo-se constante o grau de umidade das sementes durante o decorrer do teste.

\subsubsection{Hîbrido Bruna}

\subsubsection{Análise comparativa entre os testes}

Os valores médios obtidos nos testes de germinação (Tabela 64) indicaram os lotes 3 e 4 como os de pior e melhor desempenho, respectivamente. Por sua vez, os lotes 1,2 e 5 demonstraram desempenho intermediário, com tendência de inferioridade para o lote 5. Portanto, o teste mostrou-se sensivel para detectar diferenças entre os lotes. Em comparação com a avaliação inicial (Tabela 13), os resultados mostraram-se semelhantes.

$O$ teste de emergência de plãntulas em casa de vegetação (Tabela 64) apontou a melhor qualidade dos lotes 1, 2 e 4 e o pior desempenho do lote 3 , sendo que o lote 5 foi identificado como de qualidade intermediária.

Por sua vez, as informações geradas pelo Método Agroflora para avaliação do vigor de sementes de tomate (Tabela 64) revelaram a superioridade dos lotes 1,2 e 4 e a inferioridade dos lotes 3 e 5 .

Os dados obtidos na determinação do grau de umidade das sementes, antes da realização dos testes, foram semelhantes para todos os lotes estudados, apresentando valores entre 8,0 e $8,5 \%$. 
Tabela 64. Dados médios de grau de umidade, germinação, emergência em casa de vegetação e método Agroflora, de sementes de cinco lotes de tomate, híbrido Bruna.

\begin{tabular}{ccccc}
\hline Bruna & $\begin{array}{c}\text { Grau de } \\
\text { umidade }\end{array}$ & Germinação & $\begin{array}{c}\text { Emergência } \\
\text { de plãntulas }\end{array}$ & $\begin{array}{c}\text { Método } \\
\text { Agroflora }\end{array}$ \\
\hline Lotes & $\ldots \ldots \ldots \ldots \ldots \ldots \ldots \ldots \ldots \ldots \ldots \ldots \ldots \ldots \ldots \ldots \ldots \ldots \ldots \ldots \ldots \ldots \ldots \ldots \ldots \ldots \ldots \ldots \ldots \ldots \ldots$ & $9 \ldots \ldots \ldots \ldots$ \\
1 & 8,4 & $93 \mathrm{ab}^{*}$ & $90 \mathrm{a}$ & $95 \mathrm{a}$ \\
2 & 8,1 & $91 \mathrm{ab}$ & $88 \mathrm{a}$ & $88 \mathrm{a}$ \\
3 & 8,4 & $83 \mathrm{c}$ & $68 \mathrm{~b}$ & $71 \mathrm{~b}$ \\
4 & 8,0 & $96 \mathrm{a}$ & $89 \mathrm{a}$ & $89 \mathrm{a}$ \\
5 & 8,5 & $86 \mathrm{bc}$ & $75 \mathrm{ab}$ & $76 \mathrm{~b}$ \\
\hline C.V. (\%) & - & 3,55 & 7,56 & 5,23
\end{tabular}

*Comparação de médias em cada coluna, pelo teste de Tukey a $5 \%$ de probabilidade.

Os valores obtidos para os teste de condutividade elétrica, lixiviação de potássio e lixiviação de sódio estão apresentados na Tabela 65.

No caso do hibrido Bruna, os resultados de condutividade elétrica, tanto no periodo de 6 horas quanto 24 horas de embebição, mostraram tendências semelhantes de separação dos lotes, em comparação aos testes germinação, emergência de plântulas em casa de vegetação e método Agroflora (Tabela 64), apesar da alteração na classificação dos piores lotes, ou seja, pela maioria dos testes o lote 3 foi apontado como o de qualidade mais baixa e o lote 5 como de qualidade intermediária (tendendo para inferioridade), o mesmo não ocorrendo para a condutividade elétrica, em que os lotes 3 e 5 foram considerados como de médio e baixo vigor, respectivamente. 
Tabela 65. Dados médios obtidos para os testes de condutividade elétrica (após 6 e 24h), de lixiviação de potássio e de lixiviação de sódio, de sementes de cinco lotes de tomate, híbrido Bruna.

\begin{tabular}{|c|c|c|c|c|}
\hline \multirow[t]{2}{*}{ Bruna } & \multicolumn{2}{|c|}{$\mathrm{CE}$} & \multirow[t]{2}{*}{$\mathrm{K}^{+}$} & \multirow[t]{2}{*}{$\mathrm{Na}^{+}$} \\
\hline & $6 h$ & $24 h$ & & \\
\hline Lotes & \multicolumn{2}{|c|}{........umho/cm/g....... } & \multicolumn{2}{|c|}{ 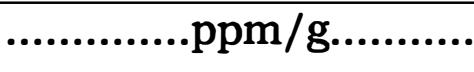 } \\
\hline 1 & $52,1 a^{*}$ & $60,7 a$ & $22 a$ & $20 a$ \\
\hline 2 & $53,4 a$ & $59,5 a$ & $34 a$ & $15 a$ \\
\hline 3 & $60,6 b$ & $67,6 b$ & $91 b$ & $44 b$ \\
\hline 4 & $49,5 a$ & $59,9 a$ & $39 a$ & $12 \mathrm{a}$ \\
\hline 5 & $71,5 c$ & $90,4 c$ & $25 a$ & $128 \mathrm{c}$ \\
\hline C.V.(\%) & 5,36 & 5,36 & 7,09 & 8,58 \\
\hline
\end{tabular}

*Comparaçāo de médias em cada coluna, pelo teste de Tukey a $5 \%$ de probabilidade.

As leituras de lixiviação de potássio mostraram a inferioridade do lote 3 em relação aos demais, não havendo correspondência com a classificação obtida pela condutividade elétrica com relação ao lote 5 .

Por outro lado, analisando os resultados de lixiviação de sódio, verificou-se concordância com o teste de condutividade elétrica quanto à separação dos lotes, revelando o lote 5 como o de pior desempenho e o lote 3 como de desempenho intermediário; os lotes 1, 2 e 4 apresentaram qualidade superior.

É importante ressaltar que a provável causa da discrepância entre os testes de condutividade elétrica e de lixiviação de potássio, na identificação da qualidade do lote 5 , foi o fato de que o principal ion liberado durante a embebição das sementes foi o sódio, sendo o 
responsável, portanto, pelos valores mais altos de condutividade elétrica observados para o referido lote.

Quanto aos resultados da análise da composição química de sementes, hibrido Bruna, o exame da Tabela 66 revelou que os valores de potássio foram constantes entre os lotes, com exceção do lote 5 , que apresentou a maior concentração de potássio lixiviada.

Tabela 66. Resultados da análise da composição química de sementes de cinco lotes de tomate, hibrido Bruna.

\begin{tabular}{|c|c|c|c|c|c|c|c|}
\hline Bruna & $\mathbf{N}$ & $\mathrm{P}$ & $\mathbf{K}$ & $\overline{\mathrm{Ca}}$ & $\mathrm{Mg}$ & $\mathbf{S}$ & $\mathrm{Na}$ \\
\hline Lotes & \multicolumn{7}{|c|}{ 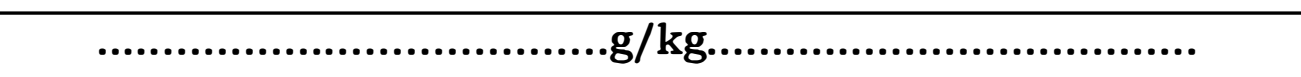 } \\
\hline 1 & 43,82 & 9,96 & 5,36 & 0,78 & 4,32 & 2,11 & 0,12 \\
\hline 2 & 43,40 & 3,74 & 5,36 & 0,59 & 4,04 & 1,77 & 0,06 \\
\hline 3 & 45,08 & 6,74 & 5,36 & 0,85 & 4,25 & 1,73 & 0,77 \\
\hline 4 & 22,26 & 5,40 & 5,36 & 0,78 & 4,27 & 1,91 & 0,77 \\
\hline 5 & 18,48 & 4,46 & 6,12 & 0,88 & 4,14 & 3,28 & 0,50 \\
\hline Bruna & B & \multicolumn{2}{|l|}{$\mathrm{Cu}$} & & Mn & $\mathrm{Zn}$ & Proteina \\
\hline Lotes & \multicolumn{6}{|c|}{ } & $\ldots g / k g . .$. \\
\hline 1 & 10,9 & \multicolumn{3}{|c|}{13,4} & 40,1 & 74,7 & 273,87 \\
\hline 2 & 10,0 & \multicolumn{2}{|l|}{12,5} & 196,6 & 40,0 & 70,9 & 271,25 \\
\hline 3 & 3,5 & \multicolumn{2}{|l|}{11,2} & 249,0 & 38,0 & 79,7 & 281,75 \\
\hline 4 & 3,7 & \multicolumn{2}{|l|}{12,5} & 225,4 & 42,8 & 75,1 & 139,12 \\
\hline 5 & 4,7 & \multicolumn{2}{|l|}{105,7} & 46,4 & 47,0 & 75,0 & 115,50 \\
\hline
\end{tabular}

É interessante notar que o lote 5 apresentou a maior concentração deste elemento na análise quimica e uma das menores leituras no teste de lixiviação de potássio (Tabela 65), indicando que a 
lixiviação de potássio não dependeu diretamente da concentração desse elemento na semente, de modo que os resultados obtidos permitiram atribuir, a maior ou menor liberação desse íon, à condição fisiológica da semente, refletindo a integridade das membranas, conforme observado também por Custódio \& Marcos Filho (1997), com sementes de soja.

Os valores de sódio variaram entre os lotes, sendo verificados resultados mais elevados para os lotes 3 e 4, não revelando correspondência com o obtido na lixiviação de sódio, que identificou o lote 5 como o de menor qualidade.

Diante do exposto, os resultados parecem indicar que, para o híbrido Bruna, as respostas das sementes aos testes de condutividade elétrica, lixiviação de potássio e de sódio não podem ser atribuídas a diferenças na concentração de íons dos diferentes lotes.

Os dados obtidos para análise química do exsudato de sementes, hibrido Bruna, encontram-se na Tabela 67.

Para o potássio foram verificadas variações entre os lotes, especialmente para o lote 3 , identificado no teste de lixiviação de potássio como o de menor potencial fisiológico.

No caso do sódio, houve maior variação entre os lotes, encontrando valores mais altos para os lotes 3 e 5, o que está de acordo com o observado no teste de lixiviação de sódio (Tabela 65), que identificou o lote 3 , seguido do lote 5 , como os de pior qualidade. 
Tabela 67. Resultados da análise química do exsudato de sementes de cinco lotes de tomate, híbrido Bruna.

\begin{tabular}{|c|c|c|c|c|c|c|c|}
\hline Bruna & $\overline{\mathrm{NH}_{4}+}$ & $\overline{\mathrm{NO}_{3}}$ & $\overline{\mathrm{P}}$ & $\overline{\mathrm{K}}$ & $\overline{\mathrm{Ca}}$ & $\mathrm{Mg}$ & $\bar{S}$ \\
\hline Lotes & \multicolumn{7}{|c|}{ 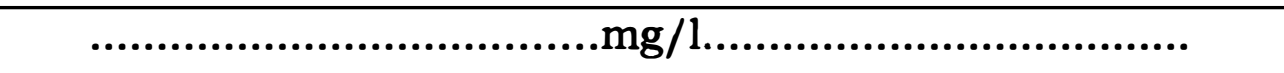 } \\
\hline 1 & 22,26 & 11,13 & 0 & 0,6 & 0,2 & 0,20 & 3,01 \\
\hline 2 & 25,97 & 18,55 & 0 & 1,1 & 0,5 & 0,19 & 2,69 \\
\hline 3 & 18,55 & $11,13^{\circ}$ & 0 & 1,8 & 0,7 & 0,24 & 3,32 \\
\hline 4 & 18,55 & 11,13 & 0 & 1,1 & 0,4 & 0,22 & 3,32 \\
\hline 5 & 18,55 & 11,13 & 0,57 & 0,9 & 1,3 & 0,31 & 6,30 \\
\hline Bruna & $\mathrm{Na}$ & $\mathrm{B}$ & $\mathrm{Cu}$ & $\mathrm{Fe}$ & $\mathrm{Mn}$ & Zn & Proteina \\
\hline Lotes & \multicolumn{7}{|c|}{ 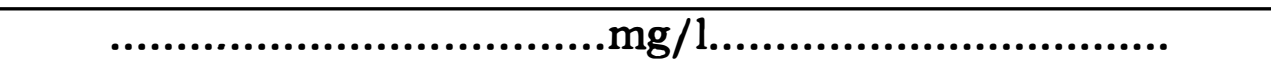 } \\
\hline 1 & 2,9 & 0,29 & 0,098 & 0,086 & 0,028 & 0,060 & 5,62 \\
\hline 2 & 2,5 & 0,34 & 0,040 & 0,100 & 0,016 & 0,104 & 7,50 \\
\hline 3 & 3,4 & 0,25 & 0,050 & 0,126 & 0,036 & 0,106 & 5,0 \\
\hline 4 & 1,3 & 0,52 & 0,090 & 0,154 & 0,012 & 0,060 & 5,0 \\
\hline 5 & 4,4 & 0,38 & 0,140 & 0,122 & 0,024 & 0,090 & 5,0 \\
\hline
\end{tabular}

Na Tabela 68 estão apresentados os resultados dos testes de envelhecimento acelerado (procedimento tradicional e com o uso de soluçāo saturada de sal) e de deterioração controlada.

$O$ teste de envelhecimento acelerado (tradicional) proporcionou a separação dos lotes em niveis de vigor, destacando a superioridade do lote 4 e a inferioridade do lote 3 . Os lotes 1,2 e 5 apresentaram desempenho intermediário, com tendência de inferioridade para o lote 5 .

Os valores médios obtidos no teste de envelhecimento acelerado (com solução salina) revelaram um agrupamento de médias 
caracterizando os lotes 1, 2 e 4 como de potencial fisiológico superior, o lote 3 como inferior, ficando o lote 5 entre os extremos. Por outro lado, o teste de deterioração apontou o pior desempenho dos lotes 3 e 5 em relação aos demais.

Tabela 68. Dados médios obtidos para os testes de envelhecimento acelerado (tradicional e com solução salina) e de deterioração controlada, de sementes de cinco lotes de tomate, híbrido Bruna.

\begin{tabular}{|c|c|c|c|}
\hline \multirow[t]{2}{*}{ Bruna } & EA-tradicional & uçāo salina & \multirow{2}{*}{$\begin{array}{c}\mathrm{DC} \\
(24 \% / 24 \mathrm{~h})\end{array}$} \\
\hline & \multicolumn{2}{|c|}{$\left(41^{\circ} \mathrm{C} / 72 \mathrm{~h}\right)$} & \\
\hline Lotes & \multicolumn{2}{|c|}{ …................\%.................. } & ........\%........ \\
\hline 1 & $92 \mathrm{ab}^{*}$ & $93 a$ & $96 a$ \\
\hline 2 & $92 a b$ & $94 a$ & $94 a$ \\
\hline 3 & $77 \mathrm{c}$ & $79 b$ & $79 b$ \\
\hline 4 & $94 a$ & $92 a$ & $92 a$ \\
\hline 5 & $86 b c$ & $84 a b$ & $83 b$ \\
\hline C.V.(\%) & 3,83 & 5,0 & 2,67 \\
\hline
\end{tabular}

${ }^{\star}$ Comparação de médias em cada coluna, pelo teste de Tukey a $5 \%$ de probabilidade.

Examinando de forma comparativa os dados, verificou-se que, de maneira geral, os testes de envelhecimento acelerado (tradicional e com solução saturada de sal) e deterioração controlada mostraram tendências semelhantes na ordenação dos lotes, em relação aos testes de germinação, emergência de plāntulas em casa de vegetação e método Agroflora (Tabela 64). No entanto, é importante observar que o envelhecimento com solução salina revelou a mesma sensibilidade para 
separação dos lotes que a apresentada pelo teste de emergência em casa de vegetação.

$\mathrm{O}$ teste de condutividade elétrica (Tabela 65) mostrou, em geral, tendências semelhantes de separação dos lotes em comparação aos testes envelhecimento acelerado e deterioração controlada, apesar da alteração na classificação dos piores lotes.

O teste de lixiviação de potássio (Tabela 65), por sua vez, apresentou sensibilidade semelhante a da maioria dos testes para identificar, principalmente, o lote de menor desempenho (lote 3).

O grau de umidade obtido após os periodos de condicionamento, dos testes de envelhecimento acelerado e deterioração controlada, encontra-se na Tabela 69.

Tabela 69. Dados médios referentes ao grau de umidade das sementes, obtidos após os periodos de condicionamento dos testes de envelhecimento acelerado (tradicional e com sal) e de deterioração controlada, híbrido Bruna.

\begin{tabular}{cccc}
\hline \multirow{2}{*}{ Bruna } & \multicolumn{2}{c}{ Grau de umidade após condicionamento } \\
\cline { 2 - 3 } & EA-tradicional & EA-solução salina & após DC \\
\cline { 2 - 3 }$\left(41^{\circ} \mathrm{C} / 72 \mathrm{~h}\right)$ & & $(24 \% / 24 \mathrm{~h})$ \\
\hline Lotes & $\ldots \ldots \ldots \ldots \ldots \ldots \ldots \ldots \ldots \ldots \ldots \ldots \ldots \ldots \ldots \ldots \ldots \ldots \ldots \ldots \ldots \ldots \ldots \ldots \ldots$ & 24,2 \\
1 & 36,1 & 9,9 & 23,8 \\
2 & 37,3 & 9,6 & 23,6 \\
3 & 38,8 & 10,3 & 24,1 \\
4 & 36,9 & 9,8 & 24,4 \\
5 & 38,6 & 10,1 & \\
\hline
\end{tabular}


No caso do envelhecimento acelerado, pode-se observar que os valores foram semelhantes para ambos os métodos, sendo que as sementes expostas à solução saturada do sal apresentaram valores menores e mais uniformes do que os observados para as envelhecidas sem o uso do sal, ficando entre 9,6 e 10,3\%.

Com relação aos dados referentes ao grau de umidade após o periodo em banho-maria, no teste de deterioração controlada, pode-se verificar que as sementes permaneceram, praticamente, com o mesmo grau de umidade em comparação ao início do teste, ou seja, $24 \%$.

\subsubsection{Considerações finais (Etapa 2)}

Considerando o teste de condutividade elétrica, verificou-se, para os dois híbridos, que a combinação empregada (50 sementes $/ 25^{\circ} \mathrm{C} / 25 \mathrm{ml}$ ) foi capaz de detectar diferenças de vigor entre os lotes, diferenciando lotes com potencial fisiológico elevado, intermediário e inferior.

É importante notar que as avaliações feitas com 6 e 24 horas de embebição mostraram concordância quanto à ordenação dos lotes, revelando a possibilidade de redução no periodo de condicionamento das sementes de tomate no teste de condutividade elétrica, sem que haja prejuizo na confiabilidade dos resultados. Sá (1999) verificou que as sementes de tomate apresentaram valores elevados de condutividade já nas primeira 6 horas, ao redor de $75 \%$ do total lixiviado, viabilizando a redução do periodo de embebição de 24 para 6 horas.

No entanto, as informaçōes fornecidas pelo teste, em ambas as etapas, híbrido Debora Plus, mostraram-se pouco relacionadas não 
só com a emergência de plântulas em casa de vegetação, mas também com os demais testes empregados.

No caso do híbrido Bruna, os resultados de condutividade elétrica, tanto no periodo de 6 horas quanto 24 horas de embebição, mostraram tendências semelhantes de separação dos lotes em comparação aos testes germinação, emergência de plântulas em casa de vegetação e método Agroflora (Tabela 64), apesar da alteração na classificação dos piores lotes, ou seja, pela maioria dos testes o lote 3 foi apontado como o de qualidade mais baixa e o lote 5 como de qualidade intermediária (tendendo para inferioridade), o mesmo não ocorrendo para a condutividade elétrica, em que os lotes 3 e 5 foram considerados como de médio e baixo vigor, respectivamente.

Por outro lado, observaram-se diferenças acentuadas entre os lotes do hibrido Debora Plus, em termos de condutividade. Resultados semelhantes foram obtidos por Sá (1999), que também constatou um comportamento diferenciado entre lotes do mesmo cultivar, em sementes de tomate.

Uma hipótese para justificar as diferenças marcantes entre lotes do híbrido Debora Plus (especialmente do lote 1 em relação aos demais) baseia-se em caracteristicas do embrião, conforme demonstrado através da microscopia eletrônica de varredura (Figura 2). Pode-se notar comparando-se, por exemplo, os lotes 1 e 2, híbrido Debora Plus, a nitida diferença entre ambos quanto ao tamanho do embrião. É interessante observar que esses lotes foram classificados como de alto potencial fisiológico pela maioria dos testes, ao passo que na condutividade elétrica foram identificados como de qualidade inferior e superior (lotes 1 e 2 , respectivamente). 


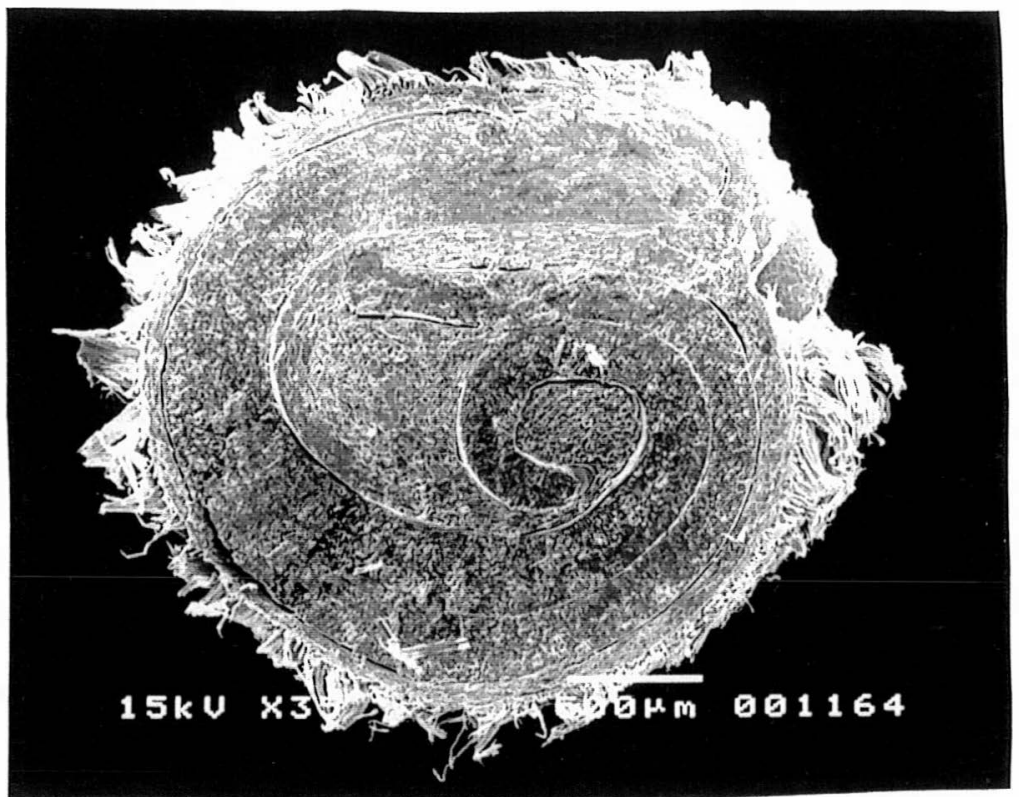

Lote 1

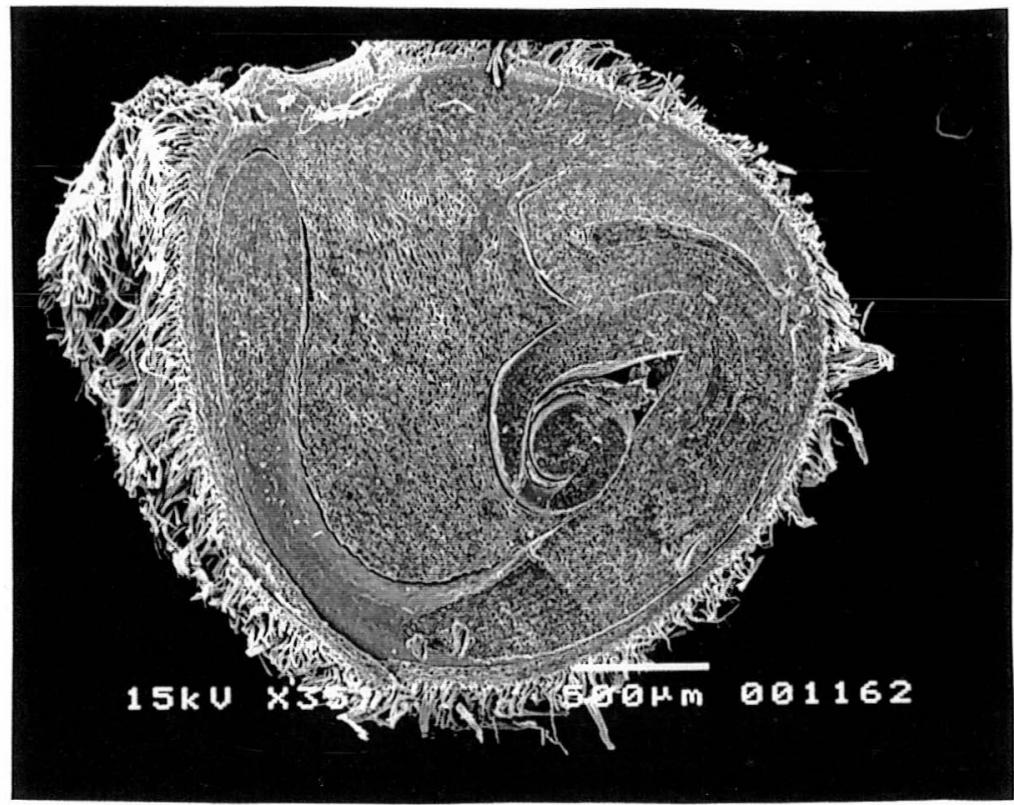

Lote 2

Figura 2. Microscopia eletrônica de varredura em sementes de tomate. Lotes 1 e 2, híbrido Debora Plus. 
O teste de lixiviação de potássio, empregando-se a combinação 100 sementes $/ 25 \mathrm{ml} / 30^{\circ} \mathrm{C} / 3 \mathrm{~h}$, mostrou, de modo geral, sensibilidade semelhante aos demais testes no sentido de separar, principalmente, os lotes de pior desempenho, ou seja, lotes 4 e 5 (híbrido Debora Plus) e lote 3 (híbrido Bruna).

Analisando de forma comparativa os testes de condutividade elétrica e de lixiviação de potássio, verificaram-se diferenças entre os mesmos quanto à classificação dos lotes, provavelmente associadas ao fato de que o sódio foi o principal íon liberado durante a embebição de sementes de alguns lotes, causando consequentemente variação entre os resultados. Esse fato pode indicar a maior eficiência de se avaliar um ion (lixiviação de potássio) ao invés de um conjunto de ions (condutividade elétrica), em sementes de tomate.

Com relação aos testes de envelhecimento acelerado (com e sem solução salina) e deterioração controlada, as metodologias empregadas $\left(41^{\circ} \mathrm{C} / 72 \mathrm{~h}\right.$ e $24 \% / 45^{\circ} \mathrm{C} / 24 \mathrm{~h}$, respectivamente) proporcionaram, de maneira geral, informações semelhantes aos testes de germinação, emergência de plântulas em casa de vegetação e método Agroflora. Entretanto, o envelhecimento com solução saturada de $\mathrm{NaCl}$ forneceu, para os dois híbridos estudados, separação de lotes mais próxima à obtida na emergência em casa de vegetação.

Assim, com base nos dados desta pesquisa, pode-se afirmar que dentre os testes avaliados, o de envelhecimento acelerado e o de deterioração controlada possibilitaram a melhor identificação de lotes com diferentes niveis de potencial fisiológico, revelando resultados compativeis com os testes de germinação, emergência de plântulas em casa de vegetação e método Agroflora, o que demonstra, dessa forma, eficiência para avaliação do vigor de sementes de tomate. 
Complementando, o teste de envelhecimento acelerado com solução salina pode ser considerado uma alternativa promissora para utilização em programas de controle de qualidade, visto que requer metodologia e equipamento semelhantes ao procedimento tradicional, sem o uso de solução salina. Com relação ao teste de deterioração controlada, deve-se considerar a sua relativa simplicidade, não exigindo equipamentos específicos, com possibilidade considerável de padronização; contudo, apresenta a desvantagem, em comparação ao envelhecimento acelerado, de ser mais trabalhoso, exigindo a uniformização do grau de umidade das sementes no início do teste.

O teste de lixiviação de potássio, por sua vez, revelou resultados semelhantes aos obtidos pela maioria dos testes quanto à identificação dos lotes de menor potencial fisiológico, em periodo de tempo consideravelmente reduzido (três horas). Apesar da menor precisão das informações geradas, o referido teste pode se constituir em uma opção promissora, em razão da sua simplicidade de execução e rapidez, permitindo a tomada de prontas decisões, principalmente em programas de controle de qualidade pós-colheita.

Em contrapartida, o teste de condutividade pode ser considerado como menos adequado para estimativa do vigor das sementes de tomate, uma vez que os seus resultados sofreram influência marcante tanto da forma de avaliação do teste (conjunto de ions) quanto de características do próprio embrião (como o tamanho), revelando valores contraditórios aos obtidos nos outros testes, em maior ou menor intensidade, dependendo do híbrido avaliado. 


\section{CONCLUSŌES}

A análise dos dados e interpretação dos resultados permitiram concluir que:

a) Dentre os testes estudados, o de envelhecimento acelerado $\left(41^{\circ} \mathrm{C} / 72 \mathrm{~h}\right)$ e o de deterioração controlada $\left(24 \% / 45^{\circ} \mathrm{C} / 24 \mathrm{~h}\right)$ são eficientes para avaliação do vigor de sementes de tomate, possibilitando a identificação de lotes com diferentes niveis de potencial fisiológico.

b) $\mathrm{O}$ teste de lixiviação de potássio (100sementes/ $25 \mathrm{ml} / 30^{\circ} \mathrm{C} / 3 \mathrm{~h}$ ) constitui opção promissora para avaliação da qualidade de sementes de tomate, identificando principalmente os lotes de menor desempenho, em periodo de tempo consideravelmente reduzido.

c) A avaliação do vigor de sementes de tomate através do teste de condutividade elétrica é considerada menos adequada, uma vez que seus resultados sofrem interferência tanto do parâmetro avaliado (conjunto de íons) quanto de características do embrião, apresentando eficiência variável de acordo com o híbrido estudado. 


\section{REFERÊNCIAS BIBLIOGRÁFICAS}

ABDEL SAMAD, L.M.; PEARCE, R.S. Leaching of ions, organic molecules, and enzymes from seeds of peanut (Arachis hypogaea L.) imbibing without testas or with intact testas. Journal of Experimental Botany, v.29, n.112, p.1471-1478, 1978.

ABDUL-BAKI, A.A. Biochemical aspects of seed vigour. HortScience, v.15, p.765-771, 1980.

ANDRADE, R.N.; FORMOSO, A. Análise de sementes de hortaliças. In: ENCONTRO SOBRE PRODUÇÃO DE SEMENTES DE HORTALIÇAS. Anais... Brasilia, 1991. 151p. (EMBRAPA/CNPH - Documentos, 8).

ANDRADE, R.N.; YWASAKY, K.; ANDRADE, A.P.; SANTOS, D.S.B.; SANTOS FILHO, B.G.; COLVARA, V.D. Qualidade fisica e fisiológica de sementes de cenoura cv. Tiatc-original obtidas através do método com poda e sem poda. Revista Brasileira de Sementes, v.15, n.1, p.43-48, 1993.

ANDRADE, R.N.; SANTOS, D.S.B.; SANTOS FILHO, B.G.; MELLO, V.D.C. Correlação entre testes de vigor em sementes de cenoura armazenadas por diferentes periodos. Pesquisa Agropecuária Gaúcha, v.1, n.2, p.153-162, 1995. 
ARGERICH, C.A.; BRADFORD, K.J. The effects of priming and ageing on seed vigour in tomato. Journal of Experimental Botany, v.40, n.214, p.599-607, 1989.

ASSOCIATION OF OFFICIAL SEED ANALYSTS - AOSA. Seed vigor testing handbook. East Lasing: AOSA, 1983. 93p. (Contribution, 32).

BENNETT, M.A.; BARR, A.J.; GRASSBAUGH, E.M.; EVANS, A.F. Seed vigor evaluation of su, se and sh2 sweet corn genotypes using the saturated salt accelerated aging (SSAA) test. In: CONGRESS OF ISTA, 25., Pretoria, 1998. Abstracts. Pretoria, 1998. p.92-93.

BEWLEY, J.D.; BLACK, M. Seeds. Physiology of development and germination. New York: Plenum Press, 1994. 444p.

BRASIL. Ministério da Agricultura. Regras para anâlise de sementes. Brasilia: SNDA/DNDV/CLAV. 1992. 365p.

BUSTAMANTE, L.; SEDDON, M.G.; DON, R.; RENNIE, W.J. Pea seed quality and seedling emergence in the field. Seed Science and Technology, v.12, p.551-558, 1984.

CALIARI, M.F.; MARCOS FILHO, J. Comparação entre métodos para avaliação da qualidade fisiológica de sementes de ervilha (Pisum sativum L.). Revista Brasileira de Sementes, v.12, n.3, p.52-75, 1990. 
CARVALHO, M.V. Determinação do fator de correção para condutividade elétrica em função do teor de água de sementes de soja [Glycine max (L.) Merrill]. Jaboticabal, 1994. 36p. Monografia (Graduação) - Faculdade de Ciências Agrárias e Veterinárias, Universidade Estadual Paulista "Julio de Mesquita Filho".

CAVARIANI, C.; PIANA, Z.; TILLMANN, M.A.A.; MINAMI, K. Métodos de remoção da mucilagem e qualidade fisiológica de sementes de tomate (Lycopersicon esculentum, Mill.). Scientia Agricola, v.50, n.3, p.4346, 1994.

CORTES, P.M.; SPAETH, S.C. Potassium leakage from artificially aged pea (Pisum sativum L.) embryos during imbibition. Journal of Seed Technology, v.8, n.1, p.30-42, 1994.

CUSTODIO, C.C.; MARCOS FILHO, J. Potassium leachate test for the evaluation of soybean seed physiological quality. Seed Science and Technology, v.25, n.3, p.549-564, 1997.

DELOUCHE, J.C. Standardization of vigor tests. Journal of Seed Technology, v.1, n.2, p.75-85, 1976.

DELOUCHE, J.C.; BASKIN, C.C. Accelerated aging techniques for predicting the relative storability of seed lots. Seed Science and Technology, v.1, n.2, p.427-452, 1973.

DEMIR, I.; ELLIS, R.H. Development of pepper (Capsicum annuum) seed quality. Annals of Applied Biology, v.121, p.385-399, 1992. 
DESWAL, D.P.; SHEORAN, I.S. A simple method for seed leakage measurement: applicable to single seeds of any size. Seed Science and Technology, v.21, n.1, p.179-185, 1993.

DIAS, D.C.F.S.; MARCOS FILHO, J. Testes de vigor baseados na permeabilidade das membranas celulares: I. Condutividade elétrica. Informativo Abrates, v.5, n.1, p.26-36, 1995.

DIAS, D.C.F.S.; MARCOS FILHO, J.; CARMELLO, Q.A.C. Potassium leakage test for the evaluation of vigour in soybean seeds. Seed Science and Technology, v.25, n.1, p.7-18, 1996.

DIAS, D.C.F.S.; VIEIRA, A.N.; BHÉRING, M.C. Estudo dos testes de condutividade elétrica e lixiviação de potássio para avaliação do vigor de sementes de hortaliças: I. Couve-flor, cebola e cenoura. In: SEMINÁRIO PANAMERICANO DE SEMILLAS, 15., Gramado. Anais. 1996. p.28.

DIAS, D.C.F.S.; VIEIRA, A.N.; BHÉRING, M.C. Condutividade elétrica e lixiviação de potássio para avaliação do vigor de sementes de hortaliças: feijão de vagem e quiabo. Revista Brasileira de Sementes, v.20, n.2, p.408-413, 1998.

DOIJODE, S.D. Solute leakage in relation to loss of seed viability in chilli cultivars. Indian Journal of Plant Physiology, v.31, n.3, p.285-287, 1988. 
DUKE, S.H.; KAKEFUDA, G. Role of the testa in preventing cellular rupture during imbibition of legume seeds. Plant Physiology, v.67, n.2, p.449-456, 1981.

FERGUSON, J.M. AOSA perspective of seed vigor testing. Journal of Seed Technology, v.17, n.2, p.101-104, 1993.

GIVELBERG, A.; HOROWITZ, M.; POLJAKOFF-MAYBER, A. Solute leakage from Solanum nigrum L. seeds exposed to high temperatures during imbibition. Journal of Experimental Botany, v.35, n.161, p.1754-1763, 1984.

GLOBIRSON, D. The quality of lettuce seed harvested at different times after anthesis. Seed Science and Technology, v.9, p.861-866, 1981.

GRANQVIST, G.A. Leakage of cations from a carrot seed lot. Acta Horticulturae, v.215, p.219-224, 1987.

GRAY, D. The effect of time to emergence on head weight and variation in head weight at maturity in lettuce (Lactuca sativa). Annals of Applied Biology, v.82, p.569-575, 1976.

GUIMARĀES, J.R.M.; MALAVASI, M.M.; LOPES, H.M. Definição do protocolo do teste de condutividade elétrica para avaliação do vigor de sementes de alface (Lactuca sativa L.). Informativo ABRATES, v.3, n.3, p.138, 1993. 
HALLOIN, J.M. Solute loss deteriorated cottonseed: relationship between deterioration, seed moisture, and solute loss. Crop Science, v.15, n.1, p.11-15, 1975.

HAMPTON, J.G. Conductivity test. In: VAN DER VENTER, H.A. (Ed.). Seed Vigour Testing Seminar. Zurich, International Seed Testing Association. p.10-28, 1995.

HAMPTON, J.G. Vigour testing within laboratories of the International Seed Testing Association: a survey. Seed Science and Technology, v.20, suppl. 1, p.199-203, 1992.

HAMPTON, J.G.; COOLBEAR, P. Potential versus actual seed performance can vigour testing provide an answer? Seed Science and Technology, v.18, p.215-228, 1990.

HAMPTON, J.G.; JOHNSTONE, K.A.; EUA-UMPON, V. Bulk conductivity test variables for mungbean, soybean and French bean seed lots. Seed Science and Technology, v.20, n.3, p.677-686, 1992.

HAMPTON, J.G.; LUNGWANGWA, A.L.; HILL, K.A. The bulk conductivity test for Lotus seed lots. Seed Science and Technology, v.22, n.1, p.177-180, 1994.

HEPBURN, H.A.; POWELL, A.A.; MATTHEWS, S. Problems associated with the routine application of electrical conductivity measurements of individual seeds in the germination testing of peas and soybeans. Seed Science and Technology, v.12, n.2, p.403-413, 1984. 
HILL, H.J.; TAYLOR, A.G.; HUANG, X.L. Seed viability determinations in cabbage utilizing sinapine leakage and electrical conductivity measurements. Journal of Experimental Botany, v.39, n.207, p.1439-1447, 1988.

IDIARTE, H.G. Relação do envelhecimento acelerado na qualidade fisiológica de semente de cebola. Piracicaba, 1995. 84p. Dissertação (M.S.) - Escola Superior de Agricultura "Luiz de Queiroz”, Universidade de São Paulo.

INTERNATIONAL SEED TESTING ASSOCIATION. Handbook of vigour test methods. 3ed. ISTA, 1995. 117p.

JIANHUA, Z.; McDONALD, M.B. The saturated salt accelerated aging test for small-seeded crops. Seed Science and Technology, v.25, p.123-131, 1996.

KRISHNASAMY, V.; RAMARAJPALANIAPPAN, M.S.M.G. Electrical conductivity of seed leachate in tomato and brinjal. South Indian Horticulture, v.37, n.5, p.303-304, 1989.

KRZYZANOWSKI, F.C.; FRANÇA NETO, J.B. Situação atual do uso de testes de vigor como rotina em programas de sementes no Brasil. Informativo ABRATES, v.1, n.3, p.42-53, 1991.

LEOPOLD, A.C. Temperature effects on soybean imbibition and leakage. Plant Physiology, v.65, n.4, p.1096-1098, 1980. 
LIMA, D. Avaliação da viabilidade e vigor de sementes de cebola (Alltum cepa L.). Pelotas, 1993. 61p. Dissertação (M.S.) Universidade Federal de Pelotas.

LOEFFLER, T.M. The bulk conductivity test as an indicator of soybean seed quality. Lexington, 1981. 181p. Dissertação (M.S.) University of Kentucky.

LOEFFLER, T.M.; TEKRONY, D.M.; EGLI, D.B. The bulk conductivity test as an indicator of soybean seed quality. Journal of Seed Technology, v.12, n.1, p.37-53, 1988.

LOOMIS, E.L.; SMITH, O.E. The effect of artificial aging on the concentration of $\mathrm{Ca}, \mathrm{Mg}, \mathrm{Mn}, \mathrm{K}$ and $\mathrm{Cl}$ in imbibing cabbage seed. Journal of American Society of Horticultural Science, v.105, n.5, p.647-650, 1980.

LOTT, J.N.A.; CAVDEK, V.; CARSON, J. Leakage of $\mathrm{K}, \mathrm{Mg}, \mathrm{Cl}, \mathrm{Ca}$ and Mn from imbibing seeds, grains and isolated seed parts. Seed Science Research, v.1, n.4, p.229-233, 1991.

MARCOS FILHO, J. Testes de Vigor: Importância e utilização. In: KRZYZANOWSKI, F.C., VIEIRA, R.D., FRANÇA NETO, J.B. (Ed.). Vigor de sementes: Conceitos e Testes. Londrina: ABRATES, 1999a. cap.1, p.1-21.

MARCOS FILHO, J. Teste de envelhecimento acelerado. In: KRZYZANOWSKI, F.C., VIEIRA, R.D., FRANÇA NETO, J.B. (Ed.). 
Vigor de sementes: Conceitos e Testes. Londrina: ABRATES, 1999b. cap.3, p.1-24.

MARCOS FILHO, J.M.; AMORIM, H.V.; SILVAROLA, M.B.; PESCARIN, H.M.C. Relação entre germinação, vigor e permeabilidade das membranas celulares durante a maturação de sementes de soja. In: SEMINÁRIO NACIONAL DE PESQUISA DE SOJA, 2, Brasilia, 1981. Anais. Londrina: EMBRAPA/CNPSo, 1982. p.676-683.

MARCOS FILHO, J.M.; CICERO, S.M.; SILVA, W.R. Avaliação da qualidade das sementes. Piracicaba: FEALQ, 1987. 230p.

MARTINS, L.; SPINOLA, M.C.M.; CALIARI, M.F.; TESSARIOLI NETO, J. Comparação entre métodos para avaliação do vigor de sementes de cenoura (Daucus carota L.). In: SEMINÁRIO PANAMERICANO DE SEMILLAS, 15. Anais. Gramado, 1996. p.11.

MATTHEWS, S. Controlled deterioration: a new vigour test for crop seeds. In: HEBBLETHWAITE, P.D. (ed.) Seed Production. London, 1980. p.647-660.

McDONALD, M.B.; WILSON, D.O. An assesment of the standardization and ability of the ASA-610 to rapidly predict potential soybean germination. Journal of Seed Technology, v.4, n.2, p.1-11, 1979.

MCKERSIE, B.D.; STINSON, R.H. Effect of dehydration on leakage and membrane structure in Lotus corniculatus L. seeds. Plant Physiology, v.66, n.2, p.316-320, 1980. 
MENÊZES, J.E.; NASCIMENTO, W.M. Teste de envelhecimento precoce em sementes de ervilha (Pisum sativum L.). Horticultura Brasileira, v.6, n.1, p.63, 1988.

MIRANDA, Z.F.S. Avaliação da qualidade de sementes de berinjela (Solanum melongena L.). Pelotas, 1987. 46p. Dissertação (M.S.) Universidade Federal de Pelotas.

MOORE, F.D.; JOLLIFFE, P.A.; STANWOOD, P.C.; ROOS, E.E. Use of the Richards function to interpret single seed conductivity data. HortScience, v.23, n.2, p.396-398, 1988.

MOSS, G.I.; MULLET, J.H. Potassium release and seed vigour in germination bean (Phaseolus vulgaris L.) seed as influenced by temperature over the previous five generations. Journal of Experimental Botany, v.33, n,137, p.1147-1160, 1982.

MULLETT, J.H.; CONSIDINE, J.A. Potassium release and uptake in germination legume seeds in relation to seed condition and germination environment. Journal of Experimental Botany, v.31, p.151-162, 1980.

MULLETT, J.H.; WILKINSON, R.I. The relationship between amounts of electrolyte lost on leaching seeds of Pisum sativum and some parameters of plant growth. Seed Science and Technology, v.7, n.3, p.393-398, 1979. 
MURPHY, J.B.; NOLAND, T.L. Temperature effects on seed imbibition and leakage mediated by viscosity and membranes. Plant Physiology, v.69, n.2, p.428-431, 1982.

NASCIMENTO, W.M.; ANDREOLI, C. Teste de envelhecimento precoce em sementes de cenoura. In: CONGRESSO BRASILEIRO DE SEMENTES, 5. Gramado, 1987. Resumos... Brasilia: ABRATES, 1987, p.86.

NASCIMENTO, W.M.; BARROS, B.C.G.; PESSOA, H.B.S.V. Teste de envelhecimento acelerado em sementes de tomate. Revista Brasileira de Sementes, v.15, n.2, p.251-253, 1993.

NASCIMENTO, W.M.; GUEDES, A.C. Efeito do tempo de frigorificação das raizes na produção e qualidade de sementes de cenoura, cv. 'Brasília'. Horticultura Brasileira, v.6, n.2, p.7-9, 1988.

NOVEMBRE, A.D.L.C.; DIAS, D.C.F.S.; CHAMMA, H.M.C.P.; MARCOS FILHO, J. Estudo da metodologia dos testes de envelhecimento acelerado e de condutividade elétrica para sementes de tomate. Informativo ABRATES, v.3, n.3, p.140, 1995.

OLIVEIRA, J.A. Correlação entre a evolução de hexanal e de aldeidos totais, a lixiviação de ions e o potencial de germinação de sementes de soja (Glycine max (L.) Merrill). Viçosa, 1990. 79p. Dissertação (M.S.) - Universidade Federal de Viçosa.

OLUOCH, M.O.; WEBAUM, G.E. Effect of postharvest washing and post-storage priming on viability and vigour of six-year-old 
muskmelon (Cucumis melo L.) seeds from eight stages of development. Seed Science and Technology, v.24, p.195-209, 1996.

PANOBIANCO, M.; MARCOS FILHO, J. Comparação entre métodos para avaliação da qualidade fisiológica de sementes de pimentão. Revista Brasileira de Sementes, v.20, n.2, p.306-310,1998.

PANOBIANCO, M.; VIEIRA, R.D. Electrical conductivity of soybean soaked seeds: I - Effect of genotype. Pesquisa Agropecuária Brasileira, v.31, n.9, p.621-627, 1996.

PANOBIANCO, M.; VIEIRA, R.D.; KRZYZANOWSKI, F.C.; FRANÇANETO, J.B. Electrical conductivity of soybean seed and correlation with seed coat lignin content. Seed Science and Technology, v.27, n.3, p.945-949, 1999.

PENARIOL, A.L. Efeito do teor de água de sementes de soja sobre os resultados do teste de condutividade elétrica. Jaboticabal, 1997. 73p. Dissertação (M.S.) - Faculdade de Ciências Agrárias e Veterinárias, Universidade Estadual Paulista "Julio de Mesquita Filho".

PERRY, D.A. Report of the vigour test committee 1977-1980. Seed Science and Technology, v.9, n.1, p.115-126, 1981.

PIANA, Z.; TILLMANN, M.A.A.; MINAMI, K. Avaliação da qualidade físiológica de sementes de cebola e sua relação com a produção de 
mudas vigorosas. Revista Brasileira de Sementes, v.17, n.2, p.149153, 1995.

POWELL, A.A. Cell membranes and seed leachate conductivity in relation to the quality of seed for sowing. Journal of Seed Technology, v.10, n.2, p.81-100, 1986.

POWELL, A.A. Seed vigour and field establishment. Advances in Research and Technology of Seeds, v.11, p.29-61, 1988.

POWELL, A.A. The controlled deterioration test. In: van de VENTER, H.A. (Ed.). Seed Vigour Testing Seminar. Copenhagen. The International Seed Testing Association. 1995. p.73-87.

POWELL, A.A.; FERGUSON, A.J.; MATTHEWS, S. Identification of vigour differences among combining pea (Pisum sativum) seed lots. Seed Science and Technology, v.25, n.3, p.443-464, 1997.

POWELL, A.A.; MATTHEWS, S. The influence of testa condition on the imbibition and vigour of pea seeds. Journal of Experimental Botany, v.30, n.114, p.193-197, 1979.

POWELL, A.A.; MATTHEWS, S. Evaluation of controlled deterioration, a new vigour test for small seeds vegetables. Seed Science and Technology, v.9, p.633-640, 1981.

POWELL, A.A.; MATTHEWS, S. Prediction of the storage potential of onion seed under commercial storage conditions. Seed Science and Technology, v.12, n.2, p.641-647, 1984a. 
POWELL, A.A.; MATTEWS, S. Application of the controlled deterioration vigour test to detect seed lots of Brussels sprouts with low potential for storage under commercial conditions. Seed science and Technology, v.12, p.649-657, 1984b.

POWELL, A.A.; MATTHEWS, S. The role of seed size and the controlled deterioration test in determining seed quality in brassicas. Acta Horticulturae, v.362, p. 263-272, 1994.

POWELL, A.A.; DON, R.; HAIGH, P.; PHILLIPS, G.; TONKIN, J.H.B.; WHEATON, O.E. Assessment of the repeatability of the controlled deterioration vigour test both within and between laboratories. Seed Science and Technology, v.12, p.42 1-427, 1984.

POWELL, A.A.; OLIVEIRA, M.A.; MATTHEWS, S. The role of imbibition damage in determining the vigour of white and colored seed lots of dwarf French beans (Phaseolus vulgaris). Journal of Experimental Botany, v.37, n.178, p.716-722, 1986.

RAM, C.; KUMARI, P.; SINGH, O.; SARDANA, R.K. Relationship between seed vigour tests and field emergence in chickpea. Seed Science and Technology, v.17, p.169-173, 1989.

RODO, A.B.; TILLMANN, M.A.A.; VILLELA, F.A.; SAMPAIO, N.V. Teste de condutividade elétrica em sementes de tomate. Revista Brasileira de Sementes, v.20, n.1, p.29-38, 1998a. 
RODO, A.B.; TILLMANN, M.A.A.; VILLELA, F.A. Testes de vigor na avaliação da qualidade fisiológica de sementes de tomate. Revista Brasileira de Sementes, v.20, n.1, p.23-28, 1998b.

RODO, A.B.; PANOBIANCO, M.; MARCOS FILHO, J. Metodologia alternativa do teste de envelhecimento acelerado para sementes de cenoura. Scientia Agricola, v.57, n.2, p.289-292, 2000.

ROSSETTO, C.A.V.; FERNANDEZ, E.M.; MARCOS FILHO, J. Metodologias de ajuste do grau de umidade e comportamento das sementes de soja no teste de germinação. Revista Brasileira de Sementes, v.17, n.2, p.171-178, 1995.

SÁ, M.E. Condutividade elétrica em sementes de tomate (Lycopersicon lycopersicum L.). Scientia Agricola, v.56, n.1, p.13-19, 1999.

SAMAD, I.M.A.; PEARCE, R.S. Leaching of ions, organic molecules, and enzymes from seeds of peanut (Arachis hypogea L.) imbibing without testas or with intact testas. Journal of Experimental Botany, v.29, n.113, p.1471-1478. 1978.

SANTOS, J.M. Microscopia eletrônica de varredura aplicada às ciências biológicas. Jaboticabal: FUNEP, 1996. 55p.

SARRUGE, J.R.; HAAG, H.P. Análises quimicas em plantas. Piracicaba, ESALQ, 1974. 55p. 
SCHMIDT, D.H.; TRACY, W.F. Duration of imbibition affects seed leachate conductivity in sweet corn. HortScience, v.24, n.2, p.346$347,1989$.

SHORT, G.E.; LACY, M.L. Carbohydrate exudation from pea seeds: effect of cultivar, seed age, seed color, and temperature. Phytopathology, v.66, n.2, p.182-187, 1976.

SIDDIQUE, M.A.; GOODWIN, P.B. Conductivity measurements on single seeds to predict the germinability of French beans. Seed Science and Technology, v.13, n.3, p.643-652, 1985.

SILVA, M.A.S.; TORRES, S.B.; CARVALHO, I.M.S. Teste de envelhecimento acelerado em sementes de maxixe (Cucumis anguria L.). Revista Brasileira de Sementes, v.20, n.1, p.212-214, 1998.

SIMON, E.W.; MATHAVAN, S. The time-course of leakage from imbibing seeds of different species. Seed Science and Technology, v.14, n.1, p.9-13, 1986.

SIMON, E.W.; RAJA HARUN, R.M. Leakage during seed imbibition. Journal of Experimental Botany, v.23, n.77, p.1076-1085. 1972.

SPINOLA, M.C.M.; CALIARI, M.F.; MARTINS, L.; TESSARIOLI NETO, J. Comparação entre métodos para avaliação do vigor de sementes de cenoura. Revista Brasileira de Sementes, v.20, n.1, p.301-305, 1998. 
STYER, R.C.; CANTLIFFE, D.J. Changes in seed structure and composition during development and their effects on leakage in two endosperm mutants of sweet corn. Journal of the American Society Horticultural Science, v.108, n.5, p.721-728, 1983.

STRYDOM, A.; van de VENTER, H.A. Comparison of seed vigour tests for cabbage (rassica oleracea L. var. capitata L.). Seed Science and Technology, v.26, n.3, p.579-585, 1998.

TAO, J.K. Factors causing variations in the conductivity test for soybean seeds. Journal of Seed Technology, v.3, n.1, p.10-18, 1978.

TAYLOR, A.G.; LEE, S.S.; BERESNIEWICZ, M.M.; PAINE, D.H. Amino acid leakage from aged vegetable seeds. Seed Science Technology, v.23, p.113-122, 1995.

TEBALDI, N.D.; SADER, R.; BIRUEL, R.P.; SCALON, N.J.O.; BALLARIS, A.L.; GAVIOLI, E. Determinação do tempo e da temperatura para o teste de envelhecimento acelerado de sementes de brócolos (Brassica oleracea L.) var. italica Plenk. In: CONGRESSO BRASILEIRO DE SEMENTES, 11. Foz do Iguaçu, 1999. Resumos. Curitiba: ABRATES, 1999, p.120.

TEDESCO, M.J.; GIANELlO, C.; BISSANI, C.A.; BOHNEN, H.; VOLKWEISS, S.J. Análise de solo, plantas e outros matexiais. Porto Alegre. Depto. de Solos, UFRGS. Boletim Técnico de Solos, n.5, 1995. 
TEKRONY, D.M. Seed vigor testing - 1982. Journal of Seed Technology, v.8, n.1, p.55-60, 1983.

TEKRONY, D.M. Accelerated ageing. In: van de VENTER, H.A. (Ed.). Seed Vigour Testing Seminar. Copenhagen. The International Seed Testing Association. 1995. p.53-72.

THORNTON, J.M.; POWELL, A.A.; MATTHEWS, S. Investigation of the relationship between seed leachate conductivity and the germination of Brassica seed. Annals of Applied Biology, v.117, n.1, p. 129-135, 1990.

TOMES, L.T.; TEKRONY, D.M.; EGLI, D.B. Factors influencing the tray accelerated aging test for soybean seed. Journal of Seed Technology, v.12, n.1, p.24-36, 1988.

TORRES, S.B. Qualidade fisiológica de sementes de pimentāo (Capsicum annuum L.) através do teste de estresse hídrico. Revista Brasileira de Sementes, v.18, n.2, p.246-250, 1996.

TORRES, S.B. Comparaçāo entre diferentes testes de vigor e a correlaçāo com a emergência no campo de sementes de cebola. Revista Brasileira de Sementes, v.20, n.1, p.65-69, 1998.

TORRES, S.B.; CARVALHO, I.M.S. Teste de envelhecimento acelerado em sementes de quiabo (Abelmoschus esculentus (L.) Moench). Revista Brasileira de Sementes, v.20, n.1, p.209-211, 1998. 
TORRES, S.B.; CASEIRO, R.F.; RODO, A.B.; MARCOS FILHO, J. Testes de vigor em sementes de maxixe (Cucumis anguria L.) com ênfase ao teste de condutividade elétrica. Revista Brasileira de Sementes, v.20, n.2, p.480-483, 1998.

TRAWATHA, S.E.; STEINER, J.J.; BRADFORD, K.J. Laboratory vigor tests used to predict pepper seedling field emergence performance. Crop Science, v.30, p.713-717, 1990.

TRIGO, M.F.O.O.; TRIGO, L.F.N. Avaliação do vigor em sementes de pepino (Cucumis sativus L.). Informativo ABRATES, v.5, n.2, p.131, 1995a.

TRIGO, M.F.O.O.; TRIGO, L.F.N. Determinação da qualidade fisiológica de sementes de cenoura. Informativo ABRATES, v.5, n.2, p.134, $1995 b$.

TRIGO, L.F.N.; TRIGO, M.F.O.O. Avaliação da qualidade fisiológica de melancia, Citrulus lanatus (Thunb) Mtsum et Nakai. Informativo ABRATES, v.5, n.2, p.129, 1995c.

VIEIRA, R.D.; KRZYZANOWSKI, F.C. Teste de condutividade elétrica. In: KRZYZANOWSKI, F.C., VIEIRA, R.D., FRANÇA NETO, J.B. (Ed.). Vigor de sementes: Conceitos e Testes. Londrina: ABRATES, 1999. cap.4, p.1-26.

VIEIRA, R.D.; MINOHARA, L.; PANOBIANCO, M.; BERGAMASCHI, M.C.M.; MAURO, A.O. Comportamento de cultivares de soja quanto 
a qualidade fisiológica de sementes. Pesquisa Agropecuária Brasileira, v.33, n.2, p.123-130, 1998.

VIEIRA, R.D.; PANOBIANCO, M.; LEMOS, L.B.; FORNASIERI FILHO, D. Efeito de genótipos de feijão e de soja sobre os resultados da condutividade elétrica de sementes. Revista Brasileira de Sementes, v.18, n.2, p.220-224, 1996.

WANG, Y.R.; HAMPTON, J.G.; HILL, M.J. Red clover vigour testing Effects of three test variables. Seed Science and Technology, v.22, n.1, p.99-105, 1994.

WOLK, W.D.; DILLON, P.F.; COPELAND, L.F.; DILLEY, D.R. Dynamics of imbibition in Phaseolus vulgaris L. in relation to initial seed moisture content. Plant Physiology, v.89, n.3, p.805-810, 1989.

WOODSTOCK, L.W. Seed imbibition: a critical period for successful germination. Journal of Seed Technology, v.12, n.1, p.1-15, 1988.

WOODSTOCK, L.W.; FURMAN, K.; LEFFLER, H.R. Relationship between weathering deterioration and germination, respiratory metabolism, and mineral leaching from cottonseeds. Crop Science, v.25, n.3, p.459-466, 1985.

WURR, D.C.E.; FELLOUS, J.R. The effect of time of seedling emergence of crisp lettuce on the time of maturity. Journal of Horticultural Science, v.58, n.4, p.561-566, 1983. 
ZONTA, E.P.; MACHADO, A.A. Sistema de análise estatistica para microcomputadores - SANEST. Pelotas, UFPel, 1984. 